\title{
Testing Techniques and Fatigue of Additively Manufactured Inconel 718 - A Review
}

\author{
Shyam-Sundar Balasubramanian, Chris Philpott, James Hyder, Mike Corliss, Bruce Tai and \\ Wayne Nguyen Hung
}

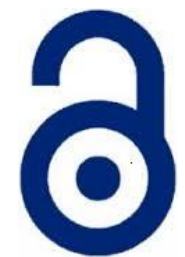

Received: 30 August 2020

Accepted: 10 October 2020

Published: 20 October 2020

Publisher: Deer Hill Publications

(c) 2020 The Author(s)

Creative Commons: CC BY 4.0

\begin{abstract}
Additive Manufacturing (AM) of metallic components shows unfavourable properties in their as-built state; surface roughness, anisotropy, residual stresses, and internal /surface defects are common issues that affect dynamic properties of AM metals. This paper reviews traditional fatigue testing techniques, summarizes published fatigue data for wrought and additively manufactured metals with focus on Inconel 718. Surface and volume defects of AM metals were presented and how post processing techniques could improve fatigue performance were shown. Different methods for normalizing fatigue data were explored due to varying results of different fatigue testing techniques.
\end{abstract}

Keywords. Fatigue, Testing standards, Additive Manufacturing, Selective Laser Melting, Inconel 718.

\section{INTRODUCTION}

There are several additive manufacturing techniques for metals: powder bed fusion (PBF), direct energy deposition, binder jetting, and wire arc additive manufacturing. Since PBF provides better dimensional precision and surface finish, it has been utilized for fabrication of super alloy components in demanding applications such as in nuclear, energy, aerospace, and turbomachinery applications. Even though a wide variety of metallic powders are available commercially, majority of the published literature covers research studies for popular alloys: Ti-6Al-4V, Inconel 718 (IN718), austenitic and martensitic stainless steels, and Al-10Si-Mg. The super alloy IN718 is widely used for manufacture of components subjected to high stress and elevated temperature due to its high strength and stiffness to weight ratios, excellent high temperature performance including creep, fatigue, oxidation /corrosion resistance.

Selective Laser Melting (SLM), one of the PBF techniques, uses a high-power density laser to selectively melt metal powder particles and systematically join layers to form a complex shape component. As seen with all additive manufacturing (AM) processes for metals, the SLM'ed IN718 components would contain one or more defects such as rough surface, porosity, shrinkage cavity, lack of bonding between layers, microcracks, thermal-induced deformation, balling effect, residual stresses, anisotropy, and partially melted metal powder on the outer surface of the components. Brittle particles in the ductile matrix of a microstructure also shorten fatigue and creep lives of AM metallic components.

To be accepted for replacing components fabricated by traditional techniques - such as machining or casting the SLM'ed component must show favourable static and dynamic properties compared to those from traditional approaches. The objectives of this paper are to:

1. Review fatigue testing techniques and how data from different tests can be cross referenced,

2. Compare fatigue performance of IN718 fabricated by traditional or additive routes, and

3. Identify factors that affects the fatigue performance of additive manufactured IN718.

\section{LITERATURE REVIEW}

\subsection{Fatigue Testing Techniques}

Traditional fatigue tests include axial, rotating bending, flexure (four-point bending) tests. Recently vibratory test at ultrasonic frequencies has been used for fast fatigue testing.

In rotating bending fatigue testing (Table $1 \mathrm{~A})$, the specimen is rotating while the dual loads $\mathrm{P}$ are applied at two ends of the specimen. The load generates a uniform bending moment with the highest stress along the gage length of

\author{
S. Balasubramanian', C. Philpott², J. Hyder², M. Corliss², B. Tai and W. Hung ${ }^{1}$ 府 \\ 'Texas A\&M University, College Station, Texas, USA \\ ${ }^{2} \mathrm{KCSBO}$, Katy, Texas, USA \\ E-mail: hung@tamu.edu
}

Reference: Balasubramanian, S., Philpott, C., Hyder, J., Corliss, M., Tai, B. and Hung, W. (2020). Testing Techniques and Fatigue of Additively Manufactured Inconel 718 - A Review. International Journal of Engineering Materials and Manufacture, 5(4), 156194. 
the specimen occurring on the outer surfaces of the specimen. In a four-point bending test (Table 1B), also known as the reversed bending test, a uniform bending stress is generated on the outer surfaces of the gage length of the specimen due to the cyclic loads P. In rotating bending and four-point bending tests, the stress magnitude varies along the cross section of the specimen and zero towards the neutral axis of the specimen (Figure 1a). The stress is maximum along the outer surfaces of specimen; subjecting the upper outer regions to compressive stresses and the lower outer regions to tensile stresses as the specimen rotates (Figure 1a). Similarly, a cantilever beam fatigue testing uses either a static load on rotating beam, or static beam with alternating load (Table 1C).

Table 1. Schematics of different fatigue testing setups [1].

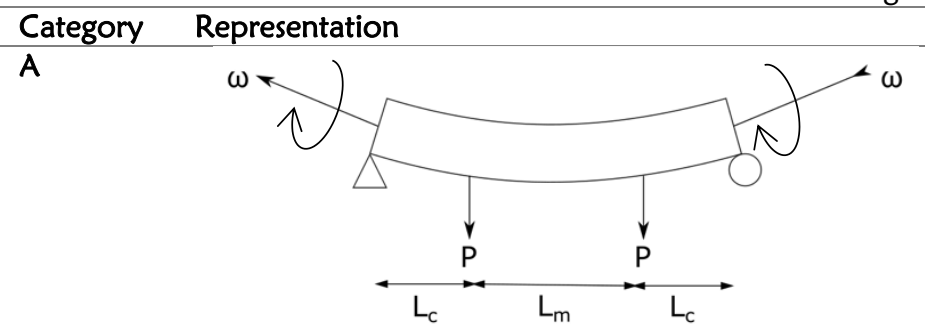

Nomenclature

Rotating

bending/Alternating

bending

\section{Dimensions}

$L_{m}$ : Gage length.

$L_{c}$ : Length between the point of support to point of application of load.

P: magnitude of alternating load applied. $\omega$ : Speed of rotation

\section{B}

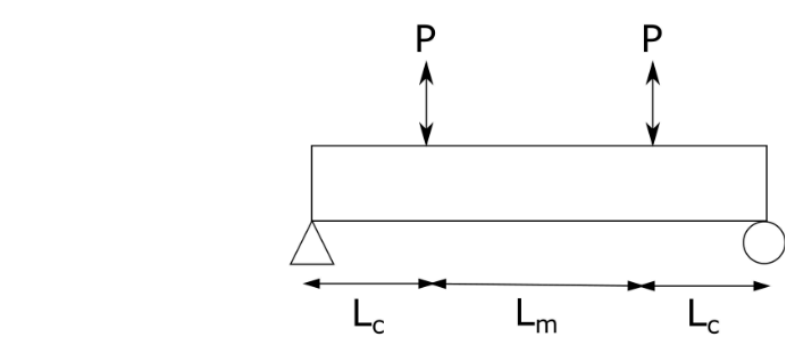

Four-point bending $\mathrm{L}_{\mathrm{m}}$ : Gage length. $L_{c}$ : Length between the point of support to point of application of load.

P: magnitude of alternating load applied.

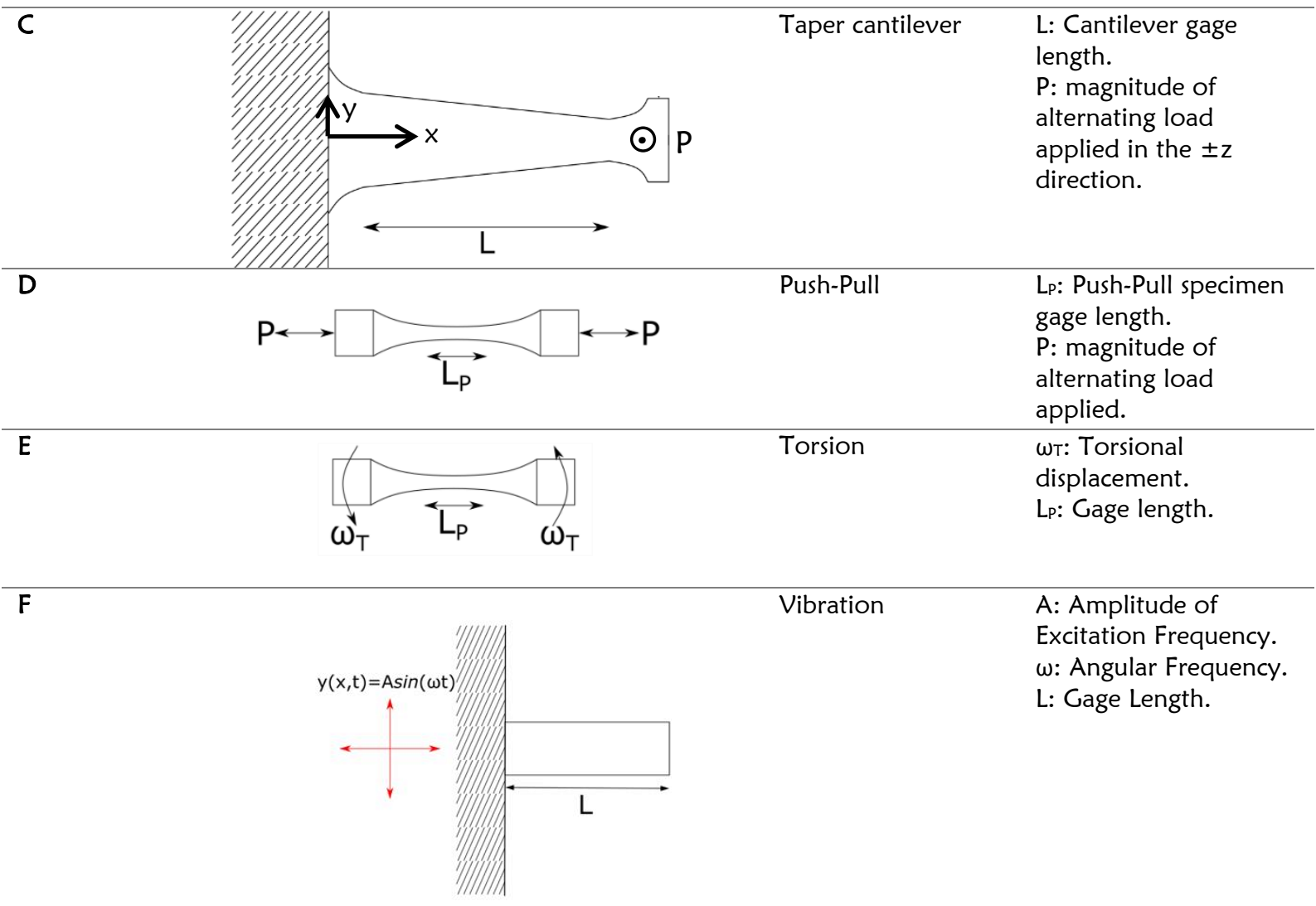




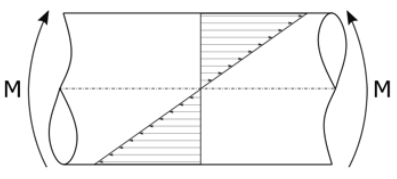

(a)

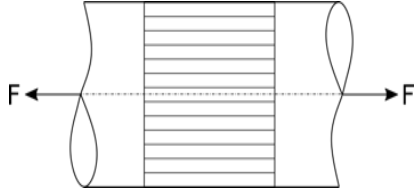

(b)

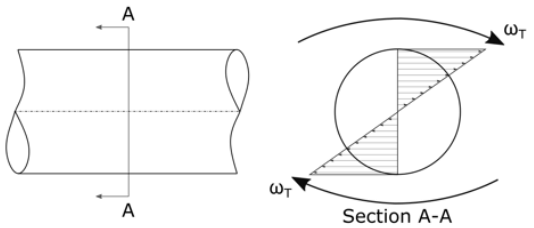

(c)

Figure 1: Stress gradient in (a) axial loading, (b) rotating bending and (c) torsional fatigue tests.

The stress distribution in the cross section of a cantilever beam due to alternating bending fatigue loading is similar to the cross-sectional stress distribution in alternating bending (Figure 1a). In the axial push-pull type tests, a uniform cross-sectional stress (Figure $1 \mathrm{~b}$ ) is generated in the gage section ( $\mathrm{LP}$ ) of the specimen by inducing uniform displacement at the ends of the specimen. In torsional fatigue tests, a torque is applied to the ends of the test specimen to generate a radially varying stress state (Figure 1c). Vibration tests are used to conduct accelerated fatigue tests under non uniform loading conditions by using an electrodynamic shaker to excite the specimen at its resonant frequency (Table $1 F)$. In vibratory tests, the resonant frequency induced in the specimen generate either a uniaxial or biaxial stress depending on the material and the geometry of the specimen.

The configuration of the fatigue test and stress types affect the fatigue life of the component. Tensile stress is detrimental to fatigue life than compressive stress since tensile stress would open/propagate a crack while compressive stress would close a crack. Component subjected to axial loading has a shorter fatigue life because the entire cross section of a sample is subjected to uniform stress of constant and high magnitude (Figure 1a). In rotating bending or alternating bending tests the stress distribution is varying with the stress being zero at the neutral axis, a tensile stress increasing to a maximum magnitude towards the outer fibre above the neutral axis and a compressive stress increasing to a maximum magnitude towards the outer fibre below the neutral axis (Figure 1b). Risk volume is the volume of specimen subjected above $90 \%$ of the maximum stress due to applied loading, specimen with larger risk volume will have higher probability to fracture and lead to short fatigue lives. The risk volume of axial test specimen is greater than rotary bending specimen due to a larger specimen volume subjected to tensile stress.

In fatigue life testing, an uniform cyclic stress is applied --due to either load, strain, or displacement-- and the corresponding number of cycles to failure are measured. The stress life approach is used to study high cycle fatigue, and the strain life approach is used to study low cycle fatigue. The threshold between high and low cycle fatigues is commonly accepted as $10^{3}$ cycles [2].

Load histories of repetitive loading of components for engineering applications may be simple, but in a majority of cases is random. For example, the loading history of an aircraft wing is random since it varies based on the air resistance, environment factor such as snow or rain, aircraft load etc. Constant amplitude loading is used to obtain material fatigue properties in laboratory tests for engineering design purpose, and load histories of some engineering components can be simplified into constant amplitude loading. Engineering components can be subjected to constant amplitude stress, strain, deflection or moment. Two main types of constant amplitude loading are Stress Life and Strain Life approaches.

\subsection{A Stress Life approach}

This method of fatigue analysis is conducted when the material is loaded below its elastic limit, also known as infinite life analysis or Constant Amplitude Stress-Life analysis. This method is commonly used to study the high cycle fatigue properties of material. A plot of stress " $S$ " against the number of cycles " $N$ " under which fatigue load is applied, is typically named the "S-N Curve" (Figure 2a). Fatigue tests can be conducted using 4-point bending technique with the Moore Fatigue Testing machine, or axial push-pull type method using servo hydraulic machines. A cyclic load is applied till catastrophic specimen failure at which the number of cycles $\left(N_{f}\right)$ to failure is recorded. Some authors prefer to use the number of reversals $\left(2 \mathrm{~N}_{\mathrm{f}}\right)$, since there are two load reversals in one cycle. An $\mathrm{S}-\mathrm{N}$ curve is drawn by fitting the median life of components and hence, represents $50 \%$ expected failure. The parameters $S_{f}$ (the $Y$ axis intercept at one single loading cycle in Figure 2a) which is the ultimate tensile strength of the material, Su, and the endurance limit $S_{\mathrm{FL}}$ at one million cycles are used to define a S-N curve. The fatigue limit or endurance limit $\mathrm{S}_{\mathrm{FL}}$, defined in the ASTM E1823 standard, is the limiting value of median cyclic load below which the material has infinite life when subjected to cyclic loading. Although most materials exhibit clear fatigue limits, some materials do not have fatigue limits and can be fractured after subjecting to very large number of fatigue cycles. Fatigue curves are affected by:

- The primary manufacturing processes (e.g., machining, casting, AM...),

- The post processing of the specimens (e.g., machining, polishing, heat treatment, case hardening, plating...),

- The testing environments (e.g., testing in sea water, or aggressive chemical gas), and

- Testing types (e.g., push pull, bending...)

Fatigue data can be grouped into a band rather a single curve since typical fatigue data can be scattered due to varying of load, specimen dimension, and/or material properties. In Figure $2 \mathrm{~b}$, different $\mathrm{S}-\mathrm{N}$ bands showing varying fatigue life of aluminium specimen processed under different manufacturing processes. The $\mathrm{S}-\mathrm{N}$ curve (band) gives the 
total life of the specimen, but there is no differentiation between various stages of fatigue such as crack nucleation or crack growth.

\subsection{B Strain Life Approach}

Strain life method, also known as the Constant Amplitude Strain-Life analysis, uses true stress and true strain at regions of high localized to analyse the influence of plastic strain and stress concentrations on fatigue life of components. Fatigue cracks nucleate in regions of stress concentrations due to plastic strain, hence strain life methods can be used to study fatigue properties of material in low cycle region $\left(<10^{3}\right.$ cycles). Typical tests are conducted by subjecting a specimen with uniform gage section to axial straining in a servo hydraulic machine; the deflections are controlled and used to calculate strain range $(\Delta \varepsilon)$, number of cycles to failure and resulting forces are recorded to compute applied stress $(\Delta \sigma)$. The number of cycles can be recorded as number of reversals $\left(2 \mathrm{~N}_{\mathrm{f}}\right)$. Materials subjected to cyclic strain exhibit transient behaviour called strain hardening or strain softening, after which exhibit steady behaviour as shown that can be quantified in a hysteresis loop (Figure 3a). The total strain range controlled in the test is divided into the elastic range and the plastic range and plotted in the strain-life or $\varepsilon-\mathrm{N}$ diagram (Figure $3 \mathrm{~b}$ ).

The total strain is obtained by adding the elastic and plastic portion of strain. The life at which the intersection of the plastic strain line and the elastic strain line is called the 'transition fatigue life', denoted by $2 \mathrm{~N}_{\mathrm{t}}$. Below the transition fatigue life, the material is subjected to plastic deformation under cyclic loading, and the material is subjected to elastic deformation at lives greater than $2 \mathrm{~N}_{\mathrm{t}}$. A relationship can be obtained between applied strain and the fatigue life using the material constants obtained by fitting the test data to a simple power function.

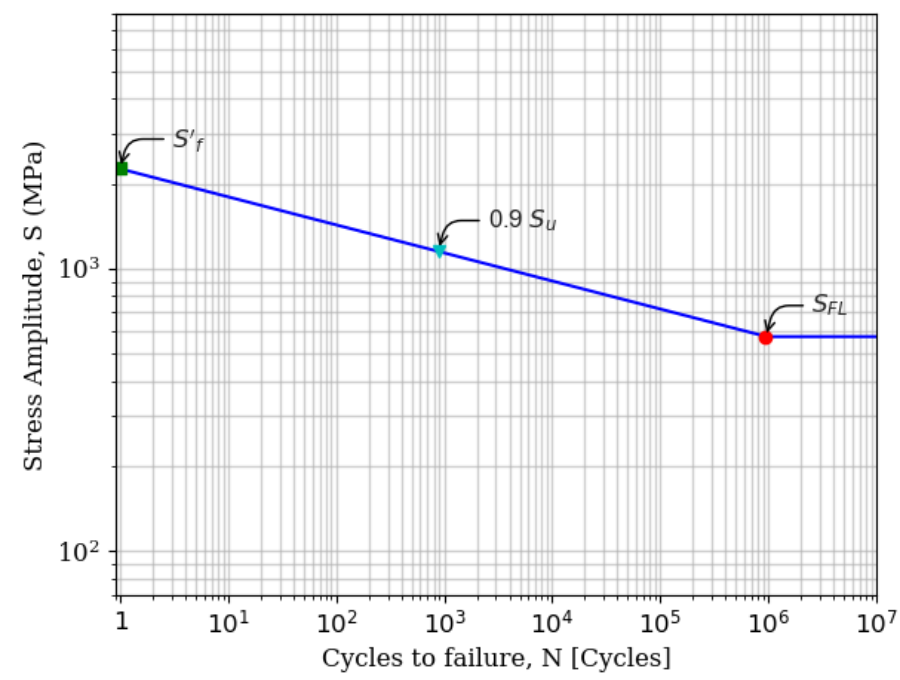

Figure 2a: A hypothetical S-N curve for steels, the endurance limit has a 'knee' at $S_{\mathrm{FL}}$. The stress amplitude and cycles are in log-log scales [2].

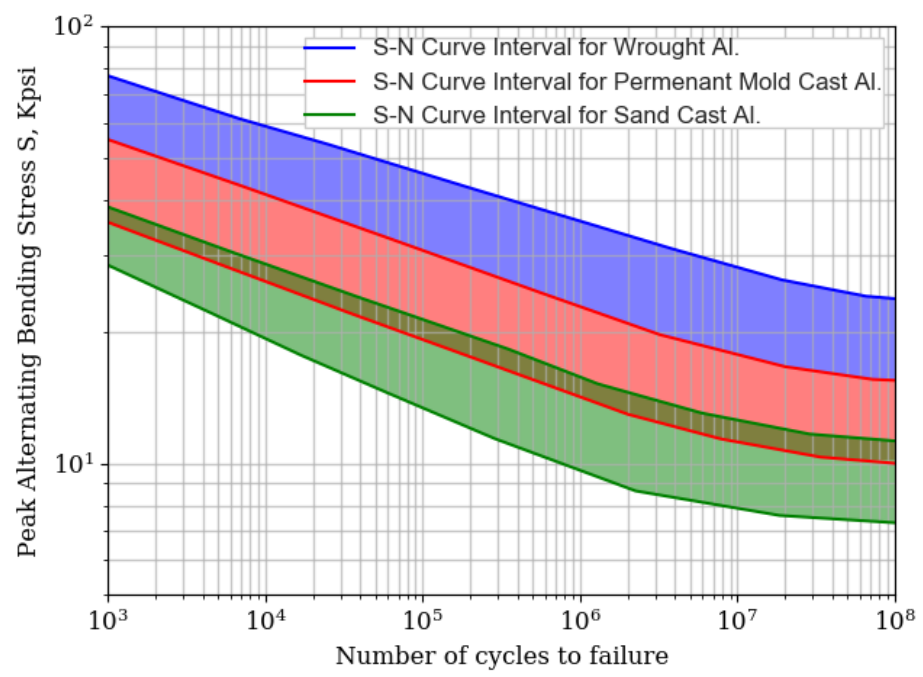

Figure 2b: Variation in $\mathrm{S}-\mathrm{N}$ bands for aluminium alloy components subjected to different processing conditions [3]. 
Where,

$$
\frac{\Delta \varepsilon}{2}=\frac{\sigma_{f}^{\prime}}{E}\left(2 N_{f}\right)^{b}+\varepsilon_{f}^{\prime}\left(2 N_{f}\right)^{C}
$$
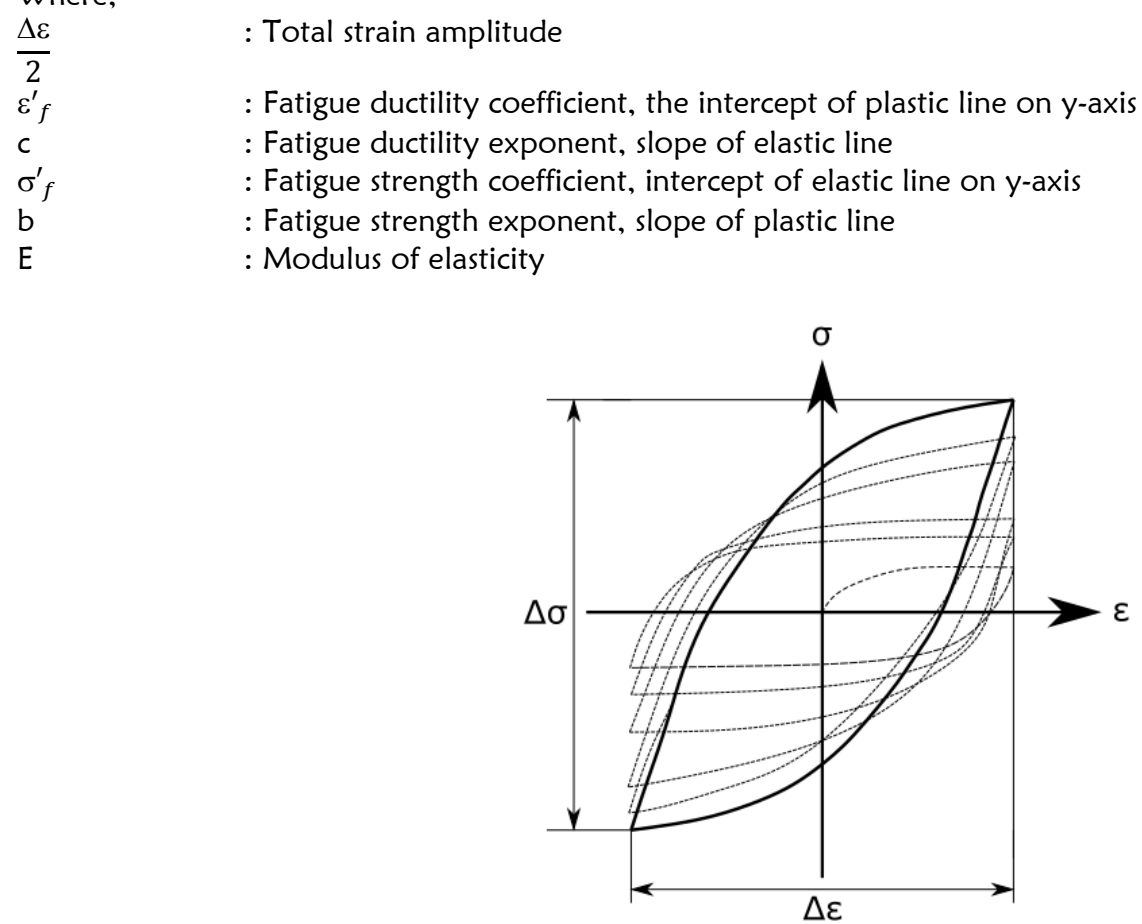

Figure 3a: A stabilized hysteresis loop exhibiting cyclic behaviour of specimen cyclically loaded.

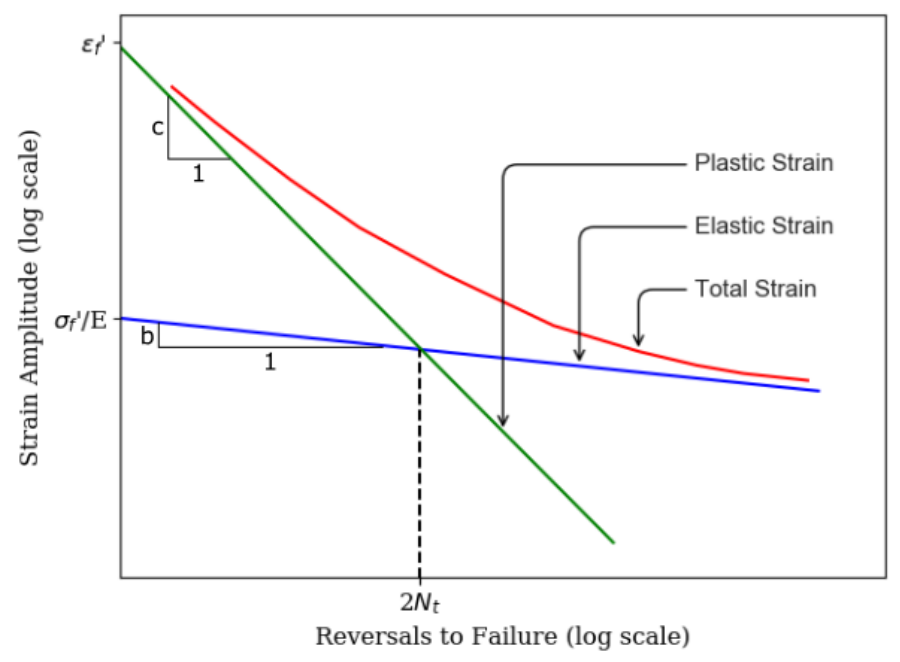

Figure 3b: A typical strain life curve approximation.

\subsection{Fatigue Testing Standards and Equipment}

The testing standards from American Society for Testing and Materials (ASTM) provide a uniform framework for conducting and reporting results of fatigue tests (Table 2). These globally accepted standards provide common template for understanding different stages of the complicated fatigue phenomenon, in terms of stress life and strain life stages, to study component response to cyclic loading, cracking, and crack propagation. Common fatigue testing standards, equipment and tests are described below.

\subsection{A ASTM E466 - Constant Stress Axially Loaded Fatigue Test}

The ASTM E466 standard describes constant amplitude force and temperature controlled axially loaded fatigue tests, typically for specimen with rectangular and circular cross-sections.

Specimen with circular cross-sections are of two types:

- $\quad$ specimens with tangentially blending fillets between the test section and the ends (Figure 4a)

- specimens with continuous radius between ends. 
Specimen with rectangular cross sections are of two types:

- $\quad$ specimens with continuous radius between ends (Figure 4b)

- specimens with tangentially blending fillets between the uniform test section and the ends.

The recommended dimensions of the commonly used specimens to conduct tests according to ASTM E466 standard are shown in Figure 4. The tests are usually carried out at a loading frequency of $30 \mathrm{~Hz}$; at a stress ratio of $R=0.1$ (ratio of minimum and maximum stresses) and runout (test stop without specimen failure) is defined at $10^{7} \mathrm{cycles}$. In these tests, when an axial load is applied, a uniform stress is developed across the cross section of the specimen for the entire gage volume for specimen with tangentially blended fillets (Figure 4a); and a maximum stress is developed in the centre of the gage length of the specimen with continuous radius between ends (Figure 4b). The loading is usually tension-tension to avoid buckling. The recommended fillet radius --eight times the gauge diameter to minimize the theoretical stress concentration factor of $\mathrm{K}_{\mathrm{t}}$ and the gauge length-- is to be maintained at 1.5D to prevent buckling of the specimen under loading. The ASTM E466 fatigue tests are routinely conducted on servo hydraulic testing machines that can be used to perform displacement, stress or strain-controlled tests as required by the testing standard.

Table 2. Summary of ASTM standard practices for various aspects of fatigue testing, reporting and result analysis.

E466 Standard practice for conducting force controlled constant amplitude axial fatigue tests of metals [4].

E467 Standard practice for verification of constant amplitude dynamic forces in axial fatigue testing system [5].

E468 Standard practice for presentation of constant amplitude fatigue test results for metallic materials.

E606 Standard practice for strain-controlled fatigue testing [6].

E647 Standard practice for measurement of fatigue crack growth rates [7].

E739 Standard practice for statistical analysis of linearized stress-life and strain-life fatigue data [8].

E1012 Standard Practice for Verification of Testing Frame and Specimen Alignment Under Tensile and Compressive Axial Force Application [9].

E1049 Standard practice for cycle counting in fatigue analysis [10].

E1823 Standard terminology relating to fatigue and fracture testing [11].

E2207 Standard Practice for Strain-Controlled Axial-Torsional Fatigue Testing with Thin-Walled Tubular Specimens [12].
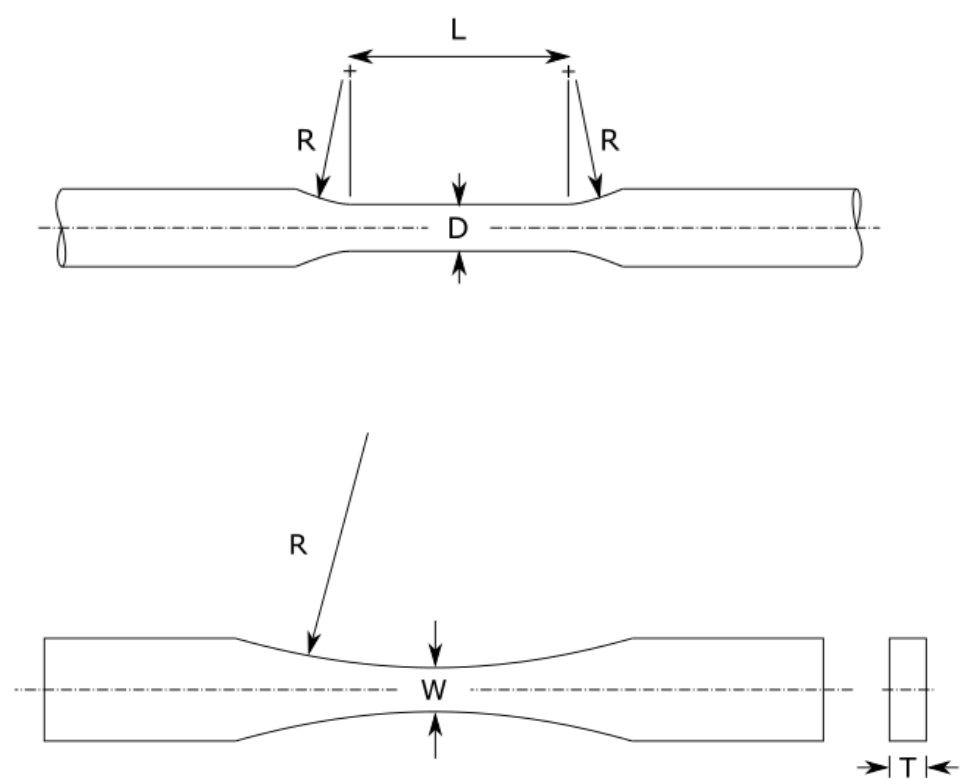

\begin{tabular}{lcc} 
Legend & Definition & Range \\
\hline$L$ & Cylindrical specimen gage length & $\mathrm{L}>1.5 \mathrm{D}$ \\
$\mathrm{R}$ & Fillet Radius & $\mathrm{R}>8 \mathrm{D}$ \\
$\mathrm{D}$ & Cylindrical specimen gage diameter & $<\mathrm{D}<1.0$ \\
$\mathrm{~W}$ & Flat specimen gage width & $2 \mathrm{~T}<\mathrm{W}<6 \mathrm{~T}$ \\
$\mathrm{~T}$ & Flat specimen gage thickness & $2 \mathrm{~T}<\mathrm{W}<6 \mathrm{~T}$
\end{tabular}

Figure 4: Common test specimen used in ASTM E466 standard (a) Specimens with tangentially blending fillets between the test section and the ends (b) Specimens with continuous radius between ends. 


\subsection{B ASTM E606 - Constant Strain Axially Loaded Fatigue Test}

The ASTM E606-12 standard describes strain and temperature controlled axially loaded fatigue tests. The recommended specimen, a flat specimen with rectangular cross section, is designed to prevent buckling (Figure 5). Traditionally, the ASTM E606 specimens are tested in a tension-compression configuration. However, for AM metals the testing is conducted in a tension-tension configuration to prevent stress concentrations at the fillets at the specimen grip-to-gauge transition, which can invalidate the results. The radius of the fillet at the grip-to-gauge transition cannot be increased as it could increase the probability of buckling.

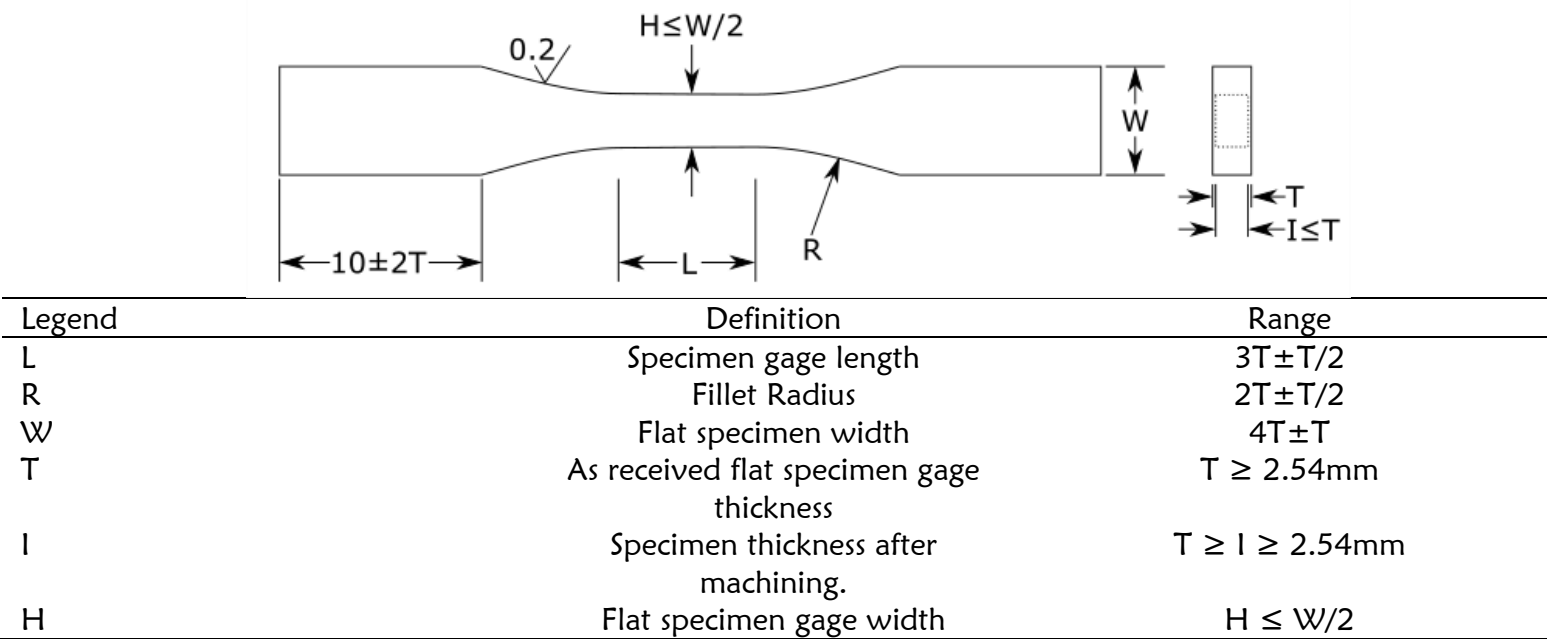

Figure 5: The ASTM E606 specimen with rectangular cross section. Specimen is designed with tangentially blended fillets between the clamping section and the gauge length.

Strain controlled fatigue tests are conducted in a closed loop servo hydraulic machines to satisfy the requirements of ASTM E606 requirements, as these specimens can only be loaded axially. An extensometer can be attached to the uniform gage section (the distance $L$ in Figure 5) to measure and control strain applied to the specimen. Usually, the failure criterion is a $50 \%$ drop in tensile load carrying capacity. A standard test subjects the specimen to completely reversed straining at a constant strain rate.

\subsection{ASTM E2207 - Constant Strain Torsion Fatigue Test}

The ASTM E2207-08 standard is used to conduct strain controlled axial-torsional fatigue testing with thin walled specimen. The specimen (Figure 6) has such large dimensions because the ratio between the specimen diameter and the wall thickness is to be maintained at 10:1 for thin wall assumption and prevent buckling of the specimen while loading. These specimens can be used to perform multi axial fatigue tests by combining in-phase or out-of-phase axialtorsion loads. These tests are usually carried out using axial-torsional electrodynamic testing machine.

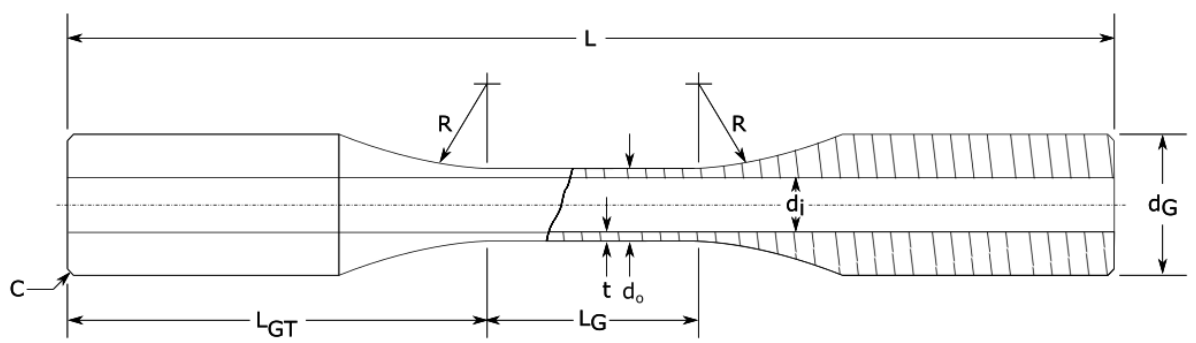

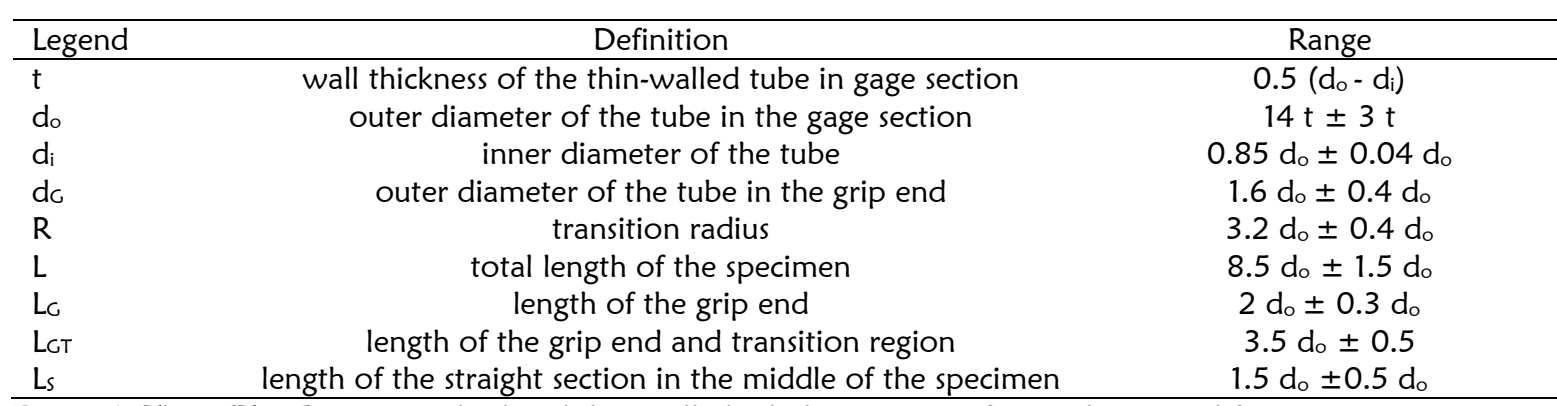

Figure 6: The ASTM E2207 standard and thin-walled tubular specimen for axial-torsional fatigue testing [13]. 


\subsection{ASTM E647 - Fatigue Crack Growth Rate Test}

Fatigue life tests are carried out on smooth and polished specimen till failure, and no distinction between crack initiation and crack propagation due to defects is made. Fatigue crack growth tests are conducted to study fatigue crack growth behaviour. The ASTM E647 standard test for measurement of Fatigue Crack Growth Rates (FCGR) using specimens shown in Figure 7. This standard prescribes procedures to generate $\Delta K_{\text {th }}$ (fatigue crack growth threshold) and da/dN (fatigue crack growth rate) according to Paris' law. These tests usually characterize the rate at which a preexisting crack will grow under time varying crack tip driving forces. Crack growth is periodically inspected and measured or can be estimated by calculating the part compliance (i.e., the deflection) with sensitive strain gauges. Automated crack growth technique also involves measuring the potential drop across the specimen as the crack propagates. Commonly FCCR tests are conducted on a servo hydraulic machine at $5 \mathrm{~Hz}$, with a cyclic stress ratio of $\mathrm{R}=0.1[14]$.

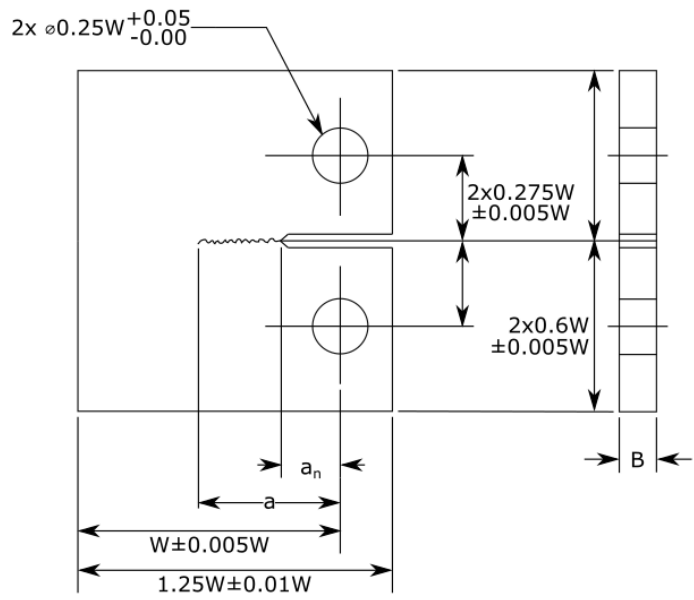

\begin{tabular}{lcc}
\hline Legend & Definition & Range \\
\hline $\mathrm{B}$ & Recommended Thickness & $\mathrm{W} / 20 \leq \mathrm{B} \leq \mathrm{W} / 4$ \\
$\mathrm{~W}$ & Suggested minimum dimensions & $25 \mathrm{~mm}$ \\
$\mathrm{a}_{\mathrm{n}}$ & Grip distance to crack length & $0.20 \mathrm{~W}$ \\
\hline
\end{tabular}

Figure 7: Test specimen used in ASTM E647 standard used to study fatigue crack growth behaviour [15].

\subsection{E Moore Fatigue Test}

Another common rotary bending fatigue test is performed on the Moore fatigue tester that utilizes the 4-point rotary bending principle (Figure 8). The resulted uniform bending moment is applied on the specimen and subjects the specimen surface to the highest alternate tensile /compressive stress. A test is conducted at a constant rotation speed up to 10,000 RPM; and a load is hung symmetrically at the ends of gage sections.

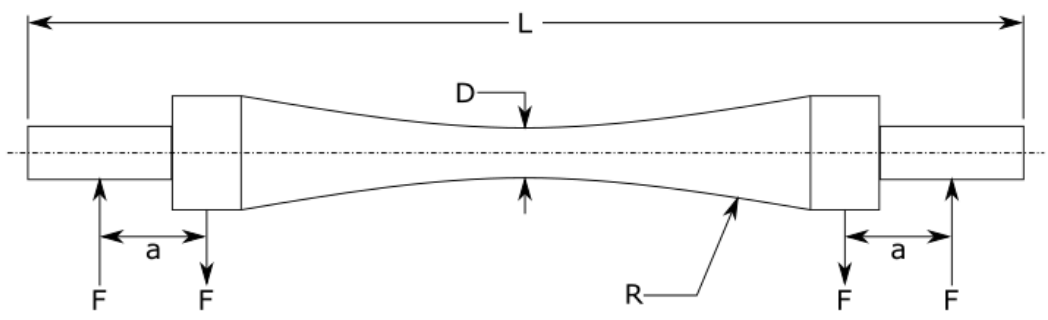

\begin{tabular}{lcc}
\hline Legend & Definition & Range \\
\hline $\mathrm{F}$ & Load applied in Moore's rotating bending test & Material dependent \\
$\mathrm{a}$ & Length between load application and specimen grip & Machine dependent \\
$\mathrm{D}$ & Minimum diameter in gage section & 0.3 in \\
$\mathrm{R}$ & Fillet Radius & 9.8750 in \\
$\mathrm{L}$ & Total length of specimen & 3.4375 in \\
\hline
\end{tabular}

Figure 8: Specimen used for Moore rotating beam fatigue testing machine [3].

\subsection{F Ultrasonic Fatigue Test}

A test at $5 \mathrm{~Hz}$ will takes 555 hours (about 23 days) to reach $10^{7}$ cycles. Such time-consuming task drives the development of high frequency fatigue testing equipment. Ultrasonic frequency testers are commercially available for studying stress life of materials or rapid fatigue crack growth at $20 \mathrm{kHz}$ [16]. Ultrasonic fatigue tests accelerate fatigue tests by applying vibratory stress and displacement field on the test specimen, vibrations are applied using a 
piezoelectric or a magneto-strictive transducer which converts ultrasonic waves to mechanical vibrations of the same frequency. The ultrasonic waves cause the specimen to vibrate at mechanical resonance, and the strain imposed by the vibrations can be monitored and controlled by adjusting the amplitude of ultrasonic waves. For purposes of comparison, data for traditional fatigue testing at $10^{7}$ can be obtained in 10 minutes using standard ultrasonic testing machines. Ultrasonic fatigue testing can be used to study the very high cycle, low stress loading effects on materials which are usually not studied in traditional fatigue testing. With the exception of strain life fatigue approach and single cycle hysteresis fatigue testing, ultrasonic fatigue tests can be applied to conduct traditional fatigue tests [17]. The components of the ultrasonic fatigue testing machine and the fatigue specimen are designed based on the fatigue specimen material properties: resonant frequency, density, modulus of elasticity and half the wavelength of speed of sound in the material at the desired testing frequency. The fatigue specimen is fixed on one end with the transducer and the amplifying horn, the other end is free. Most common types of fatigue specimen used in ultrasonic testing (Figures $9 \mathrm{a}$ and $9 \mathrm{~b}$ ) are the smooth specimen and the notch specimen, the specimen contour equations are obtained using analytical solutions to resonant length equations at different boundary conditions [18]. While conducting ultrasonic fatigue tests a specimen temperature will raise rapidly and possibly damage its microstructure, a cooling technique is usually applied to solve this problem.
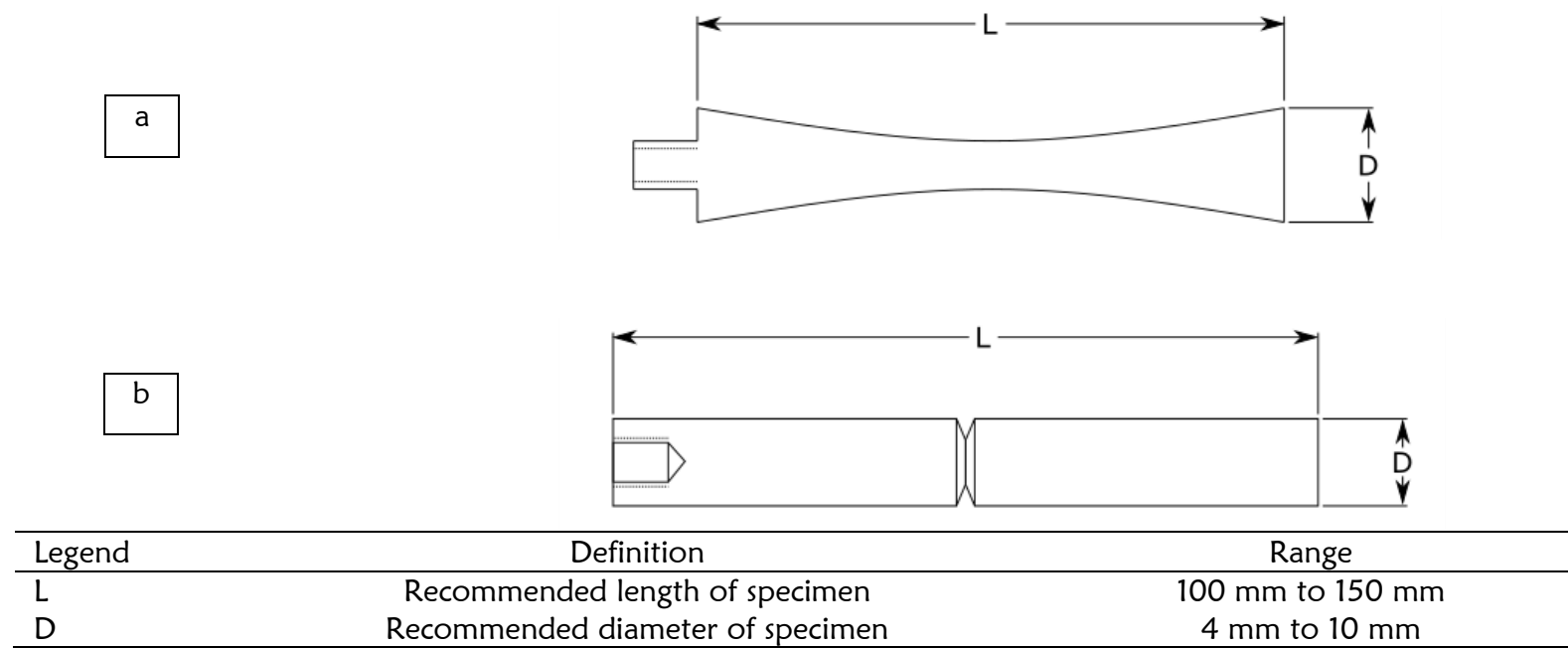

Figure 9: Geometries used for ultrasonic fatigue testing, (a) smooth specimen and (b) notched specimen [17].

\subsection{G Vibration Fatigue Test}

A novel test to study fatigue life of structural materials in a short time, is achieved by exciting a specimen and subjecting it to high frequency resonant mode loading [19]. The endurance limit of the material or the fatigue properties the material corresponding to a large number of loading cycles ( $10^{6}$ or $10^{7}$ cycles) can be established by vibration fatigue tests. The vibration-based testing method applies uniaxial and biaxial stress on the specimen at high frequency reversed bending and specimen can be subject to a multitude of stress ratios, whereas ultrasonic machines are constrained to uniaxial tensile loading. This method is used to test for fatigue failure due to crack initiation, which is detected by a change in resonant frequency and can be used to study crack initiation and crack growth. The specimen must be uniquely designed for each material (Figure 10), based on identifying the natural frequency of mode of the material within the operating range of the electrodynamic shaker.

\subsection{A Correlation of Stress Ratio}

The stress ratio $\mathrm{R}$ is used to normalize the mean stress and the effect of tensile/compressive loading. To provide a straightforward comparison of fatigue life, this stress ratio must be normalized. Depending on the type of fatigue test performed and variation of maximum and minimum applied loads, the numerical value for $R$ varies (Table 3 ) and affects the $\mathrm{S}-\mathrm{N}$ curves. The stress ratios $\mathrm{R}$ indicate the king of load acting on the specimen; when $\mathrm{R}$ value is positive the maximum and minimum value of the alternating load are both positive or both negative and the specimen is subjected to either tension or compression. Similarly, when the R value is negative, the specimen is subjected to a combination of positive and negative stresses. In Table 3, the simplest type of loading for a majority of fatigue tests is the constant amplitude sinusoidal loading, and more complicated forms of non-sinusoidal loading are used to replicate more accurate forms of fatigue loading. The effects of different loading conditions and stress ratios are shown in Figure 11. In general, the maximum stress $\sigma_{\max }$ at a particular fatigue life decreases with decreasing stress ratio [20]. In this study, the maximum stress $\sigma_{\max }$ to failure is similar for samples in either axially loaded testing or rotating bending at $R=-1$. Since the stress ratio $R$ influences the fatigue life of specimen, it is customarily normalized using different equations to calculate the average stress $\sigma_{\mathrm{ar}}$. The $\sigma_{\mathrm{ar}}$ is used for comparison of fatigue results obtained from different fatigue testing methods and stress ratios. 


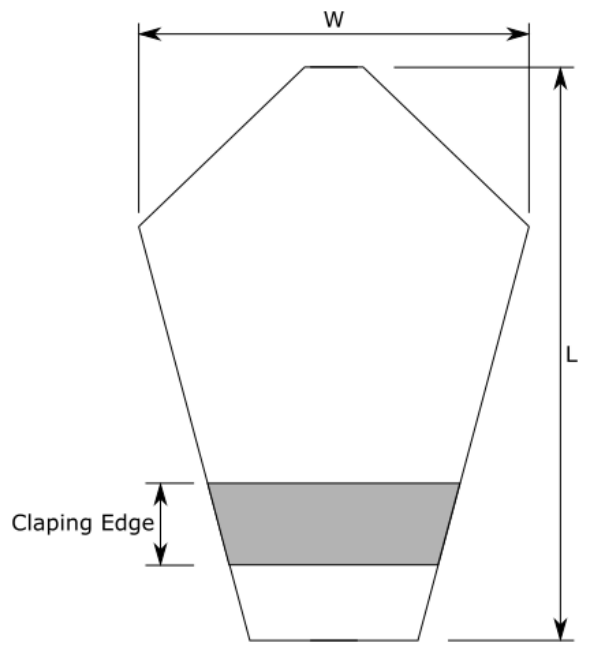

\begin{tabular}{lcc}
\hline Legend & Definition & Suggested Dimensions \\
\hline $\mathrm{L}$ & Length & $301.9 \mathrm{~mm}$ \\
$\mathrm{~W}$ & Width & $142.3 \mathrm{~mm}$ \\
\hline
\end{tabular}

Figure 10: Vibration fatigue specimen of cantilever type subject to biaxial stress [19].

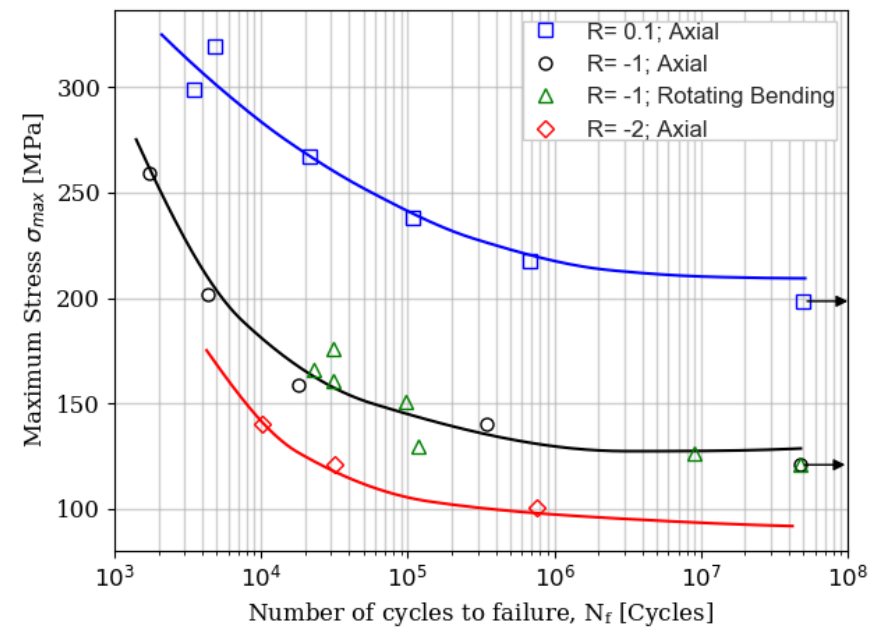

Figure 11: The S-N curves of extruded magnesium alloy AZ31 at different stress ratios $0.1,-1$ and -2 , and loaded both axially and in rotating bending conditions [20].

\subsection{Correlation of Data from Different Test Results}

Different fatigue results on the same material are obtained depending on different testing techniques. For example, a sample fails after $10^{6}$ cycles in a rotate bending test at a particular stress level, but another sample made from the same material might not reach $10^{6} \mathrm{cycles}$ in tensile-tensile fatigue testing. Several studies have proposed to compare the fatigue life obtained through different testing techniques.

There are several techniques of varying complexity that can be used to calculate mean stress, however, the SmithWatson-Topper (SWT) mean stress equation is found to give accurate results [21]. SWT equation is primarily used to fit data in Low Cycle Fatigue (LCF) data but in High Cycle Fatigue (HCF) range elastic behaviour is assumed, the stress range and strain range data can be used interchangeably. The SWT correction assumes that maximum compressive stress leads to no fatigue damage. The SWT factor also does not account for the effect of loading frequency on the effect of fatigue life, which can also affect fatigue life [22]. The $\sigma_{a r}$ is equivalent to the stress amplitude for fully reversed conditions, i.e. R ratio of -1 . In this paper, all stress ratios will be normalized with the SWT correction factor:

$$
\begin{gathered}
R=\frac{\sigma_{\min }}{\sigma_{\max }} \\
\sigma_{\text {mean }}=\frac{\sigma_{\text {max }}+\sigma_{\text {min }}}{2}
\end{gathered}
$$




$$
\begin{gathered}
\sigma_{\text {amplitude }}=\frac{\sigma_{\max }-\sigma_{\min }}{2} \\
\sigma_{a r}=\sigma_{\max } \sqrt{\frac{1-R}{2}}
\end{gathered}
$$

Where,

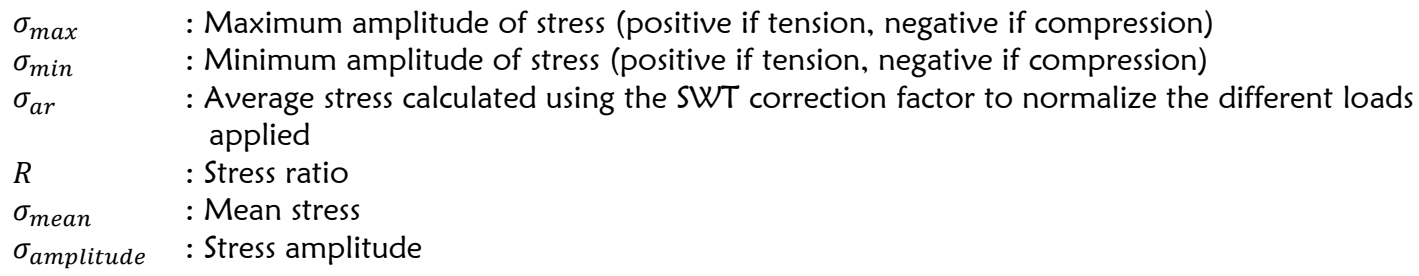

Table 3. Representations of types of fatigue loadings, corresponding stress ratios and descriptions [3].
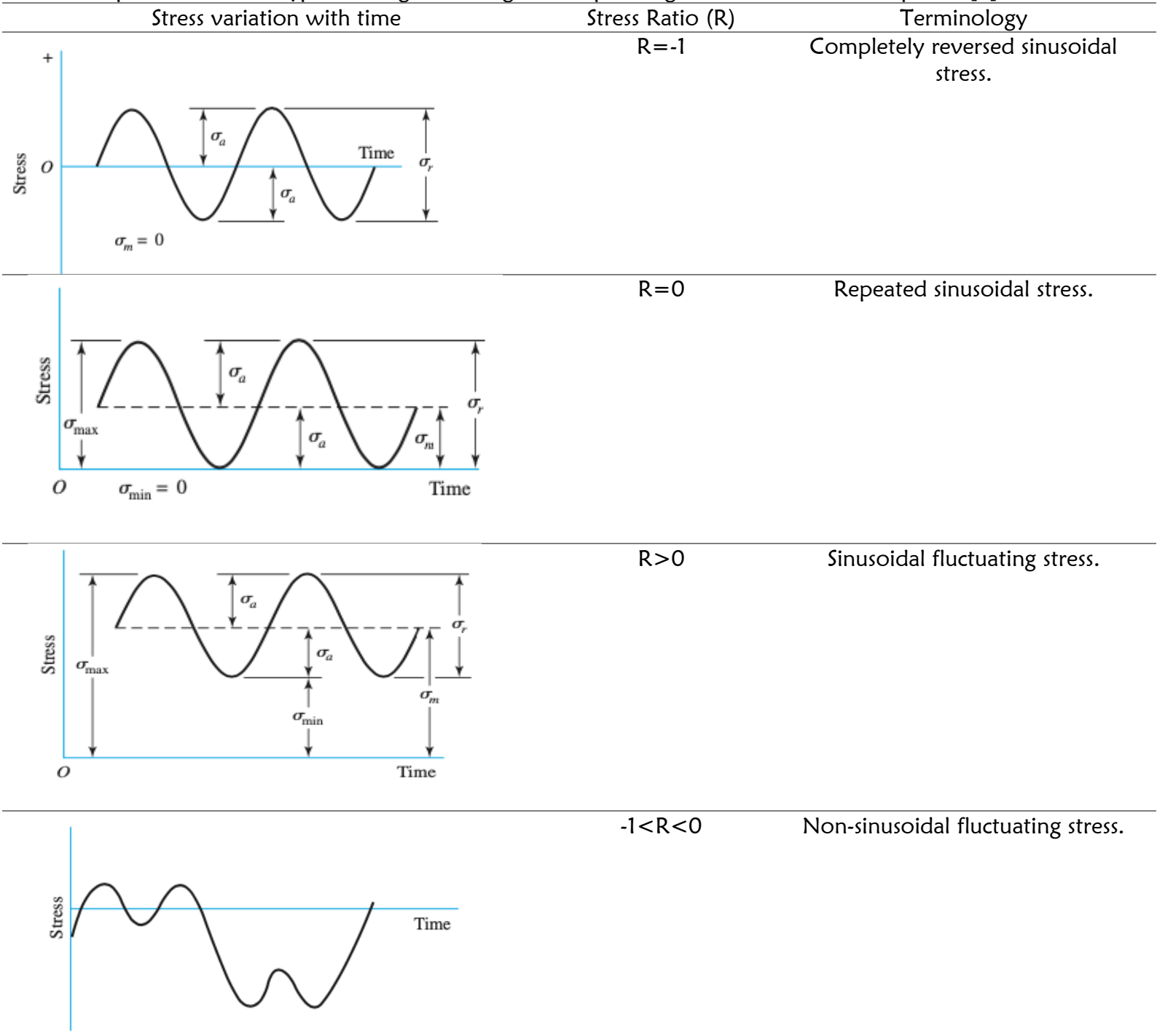


\subsection{B Correlation of Axial and Bending Fatigue Tests}

While the SWT factor is a generalized correlation used to normalize any stress ratio and maximum stress, different solid mechanics-based approaches can be used to equate axial push-pull type loading and rotating bending tests. Correlating fatigue life from different types of testing is necessary because the $\mathrm{S}-\mathrm{N}$ curves obtained from different fatigue tests for the same stress ratio is different. The push-pull type loading leads to conservative (shorter) estimates of fatigue life compared to other types of fatigue testing. Most common types of industrial fatigue tests are either push-pull, alternating bending, or rotating bending types. The fatigue tests performed by different loading methods on the same material and equivalent loading conditions yield different $\mathrm{S}-\mathrm{N}$ curves. Figure 12 shows different S-N curves for the same material after rotate bending and alternating bending tests. In the rotating bending fatigue tests, the stress due to the bending moment on the outermost fibre is calculated in the elastic condition as $\sigma_{\text {max }}$, however this stress causes plastic deformation and the resulting fatigue life is longer [23].

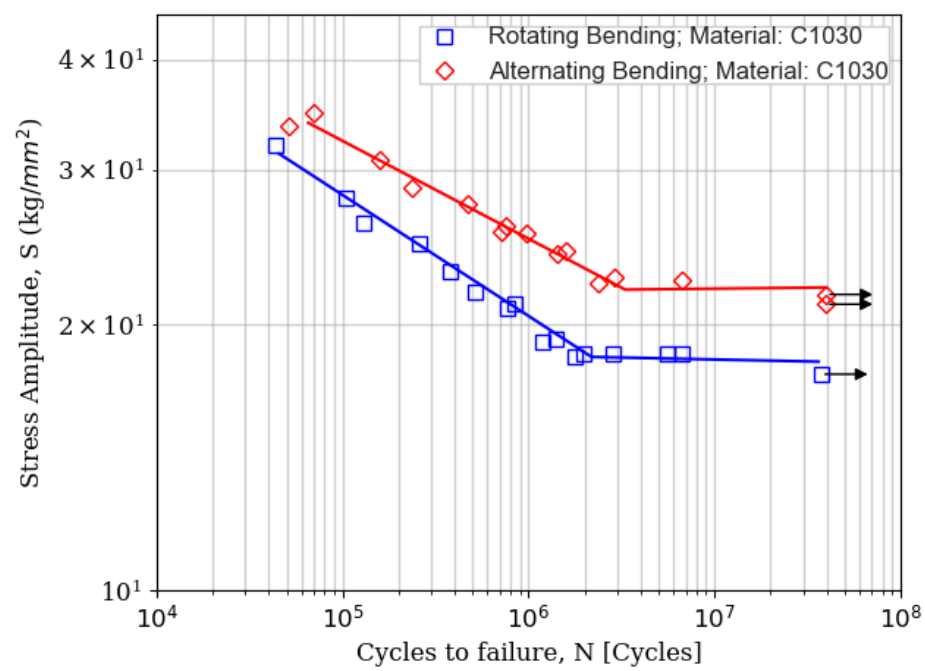

Figure 12: Comparison of rotating and alternating bending fatigue tests for the same loading; the difference has been attributed to (a) difference in presentation of the results or (b) difference in the fatigue process itself [23].

Philipp [24] first observed that fatigue life after rotate bending was longer than that from axial loading. The authors proposed the ratio between axial stress and bending stress $\left(\sigma_{\text {axial }} / \sigma_{\text {bending }}\right)$ to be 0.59 as the correction factor. Another model was also proposed [23] based on study of microplasticity, however this model was not accurate due to conflicting experimental and theoretical results. The different results were also reported when testing at different modes and shown in Figure 13. The presence of a stress gradient in bending fatigue, cyclic strain hardening and softening, difference in crack propagation effects and difference in nominal stress in bending differed considerably from true valued due to plastic flow. The authors proposed a model to determine the $\mathrm{S}-\mathrm{N}$ curve for bending fatigue from axial fatigue data; this model (Eq. 7) can be used to derive rotating bending $\mathrm{S}-\mathrm{N}$ curves for both circular and rectangular specimen [25].

Where;

$S_{\text {axial }}$ and $S_{\text {bending }}$ $f_{1}$ and $f_{2}$ $\mathrm{N}_{S}$ and $\mathrm{N}_{\mathrm{T}}$ $c$ b $\mathrm{E}$ $\varepsilon_{\mathrm{T}}$

$$
\begin{gathered}
S_{\text {axial }}=E \varepsilon_{T} \frac{N_{s}{ }^{b}}{N_{T}} \\
S_{\text {bending }}=\frac{1+\mathrm{f}_{1}{\frac{N_{s}}{N_{T}}}^{c-b}+f_{2}{\frac{N_{s}}{N_{T}}}^{2(c-b)}}{1+2{\frac{N}{N_{T}}}^{c-b}+\frac{N}{S}^{2(c-b)}} * S_{\text {axial }}{ }^{2}
\end{gathered}
$$

: Axial fatigue stress and nominal bending stress

: Functions depending geometry of the cross section and strain hardening exponents

: Surface life and transition life

: Plastic exponent

: Elastic exponent

: Modulus of elasticity

: Transition strain 


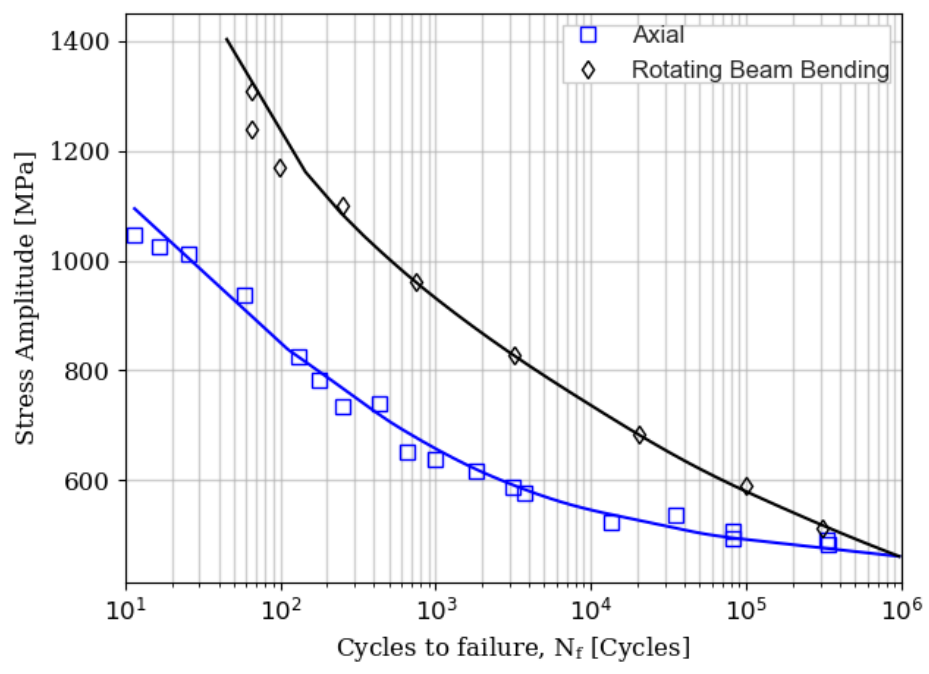

Figure 13: Fatigue performance of 4130 Steel under axial loading and rotating bending [25].

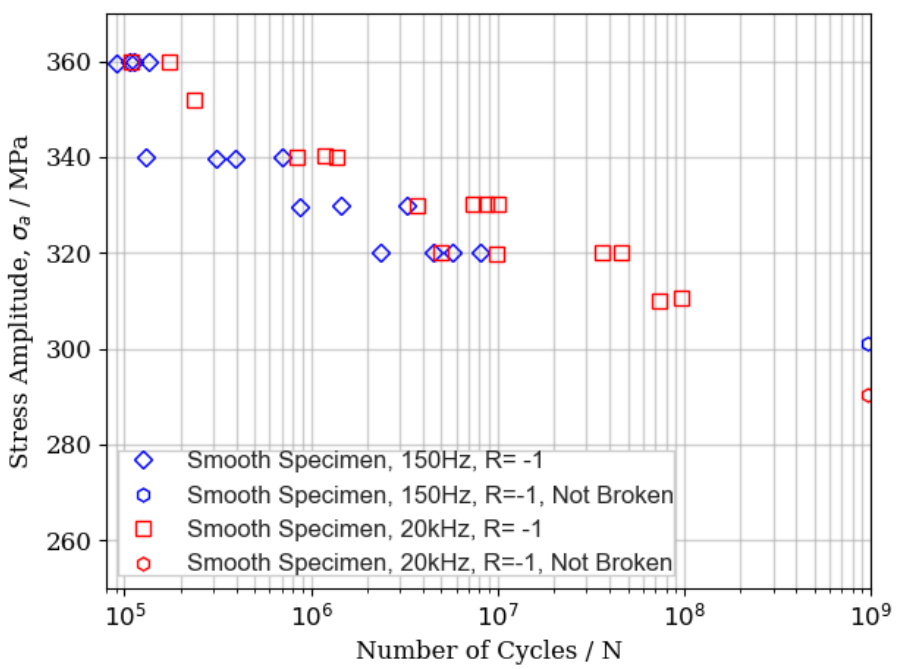

Figure 14: Test results for high strength steels at different loading frequencies [18], where the $150 \mathrm{~Hz}$ test is conducted using traditional fatigue testing technique and the $20 \mathrm{kHz}$ test is conducted using ultrasonic testing technique.

\subsection{Correlation of Ultrasonic Fatigue and Traditional Fatigue Tests}

Fatigue testing at ultrasonic frequency (at $\mathrm{kHz}$ ranges) significantly reduces the testing cycle, but studies have shown that the results are different from those obtaining from traditional fatigue testing techniques. This phenomenon is termed as the frequency effect in ultrasonic fatigue testing.

Ultrasonic fatigue testing reveals a longer fatigue life than conventional fatigue testing techniques (Figure 14). Frequency effect has been attributed to inversion of S-N curves for different metals; the super alloy IN718 under ultrasonic testing has a higher endurance limit and longer fatigue life than those from rotary bending tests (Figure 15) [26]. The risk volume is greater in ultrasonic tests than in rotary bending tests, but the endurance limit of specimen subjected to ultrasonic loading is higher than rotary bending, this inversion of S-N curves can be attributed to frequency effects. The frequency effect is attributed to the strain rate effects and the crystal structure of the metallic material. A damage accumulation life prediction model has been developed to quantitatively describe the Very High Cycle Frequency (VHCF) properties of IN718. It is generalized that the frequency effects are noticeable in body centered cubic metals, negligible in face centered cubic metals and alloys of metallic elements. For example, comparison study conducted with traditional completely reversed fatigue testing and ultrasonic fatigue testing on aluminum alloy revealed no influence of frequency effects on the endurance limit (Figure 16). 


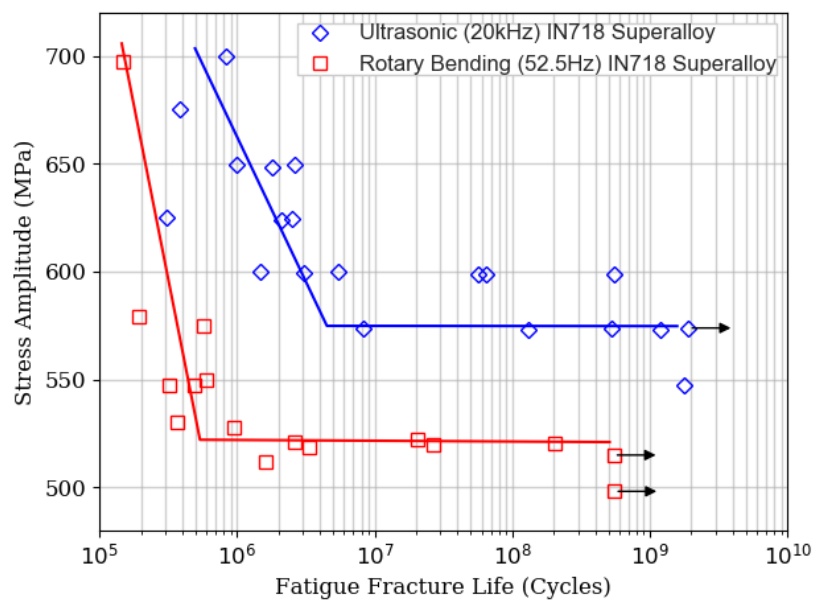

Figure 15: Fatigue test results of ultrasonic tests $(20 \mathrm{KHz}, \mathrm{R}=-1)$ and rotary bending tests $(52.5 \mathrm{~Hz}, \mathrm{R}=-1)$ on wrought IN718 [26].

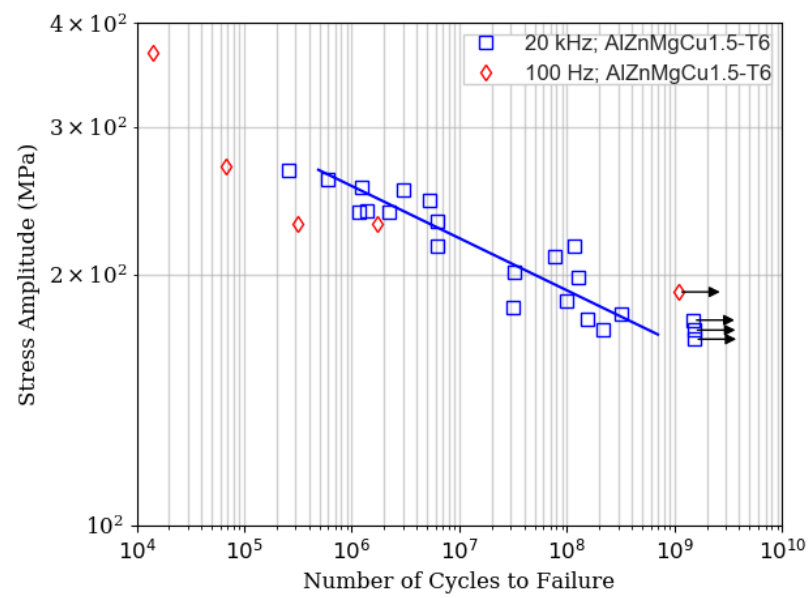

Figure 16: Comparison of fully reversed fatigue testing $(100 \mathrm{~Hz}, \mathrm{R}=-1)$ and Ultrasonic fatigue testing at $(20 \mathrm{kHz}$, $\mathrm{R}=-1$ ) on aluminum alloy [27].

\section{ADDITIVE MANUFACTURING OF METALS}

Additively manufacturing techniques for metals can be classified based on the type of feedstock used and the binding mechanism between layers of deposited materials. A computer-aided software can convert geometry of a solid model into layers and generate an STL file for the AM process. Metallic powder or wire feedstock is fully melted by a laser or an electron beam, and a pool of molten metal is then systematically joined in a line-by-line and layer-by-layer manners to obtain the final geometry. Raw alloying materials for steels, aluminum, titanium, and nickel are commercially available for metal AM processes.

\subsection{Processes}

The popular metal AM processes include Powder Bed Fusion (PBF), Binder Jetting and Direct Energy Deposition (DED). Different PBF techniques involve Selective Laser Sintering (SLS), Selective Laser Melting (SLM), Direct Metal Laser Sintering (DMLS) and Electron Beam Melting (EBM). These techniques convert fine metal powders into near net shape geometries with fine features but with limited build volumes below $0.03 \mathrm{~m}^{3}$ [28].

- In a typical SLM process, a thin layer of metal powder --typically 30-50 $\mu \mathrm{m}$ average diameter-- is spread to form a layer with thickness in the range of 1-5 powder size on a powder bed in an inert atmosphere chamber; a powerful laser (20-1000W) is then used to melt powder corresponding to the CAD geometry of the part. The powder bed is lowered, and metal powder is deposited again for the next laser scan; these steps are repeated until the complete CAD geometry is built. An inert gas environment, typically argon, is used to prevent oxidation and other undesired interactions between the powder bed, melt pool and the component being fabricated [29].

- Selective Laser Sintering (SLS) is similar to SLM process, but the metal powder is heated to a high temperature to allow powders to fuse together at a molecular level without fully melting [30].

- A variation of SLM is Electron Beam Melting (EBM) process. Powder layers are spread in a vacuum chamber in which an electron beam systematically scans to melt selected areas and fuses layers to form the complete part. 
EBM process is conducted in a vacuum to avoid scattering of the electron beam and oxidation of the products [31].

- In binder jetting process, a suitable binder is first sprayed to wet the powders in layers; the subsequent curing step then cures and temporarily fuses selected areas of metal powder. When all layers are completed, the "green part" is either sintered to remove the binding materials and densify the part or filled with other metals in an infiltration process [32].

- In Direct Energy Deposition (DED), the continuous feedstock material at the tool tip is melted by laser before depositing such molten beads onto a building platform. Metal powder or thin wire can be used as feedstock in this DED processes. The DED process can be used to make larger parts at higher build rates of up to $300 \mathrm{~cm}^{3} / \mathrm{hr}$. In a typical setup, the part is stationary and the deposition head, with laser source, is moved with a robotic arm or a 5-axis gantry to form a 3D structure. Electron beam can also be used as the energy source in DED processes, known as Electron Beam Additive Manufacturing (EBAM) [33].

- Wire Arc Additive Manufacturing (WAAM) was successfully developed to overcome the low material depositing rate of the above processes. In this technique, a metallic wire is continuously fed to the tip of an electrode. A high voltage difference creates an electric arc at the electrode tip that melts the wire and deposits the molten pool on a substrate below. The process is similar to metal inert gas welding (MIG) or tungsten inert gas welding (TIG). A typical "welding torch" is fitted to a robot hand that can move in multiple degrees of freedom to deposit molten metal beads and form a very large structure [34].

\subsection{Microstructure of AM Components}

Mechanical properties, including fatigue, are affected by the material microstructure. Microstructure of AM components is a function of thermal cycles that each layer is subjected to. During AM, localized volume is subject to complex thermal cycle involving rapid heating above melting temperature for a high energy source and rapid solidification of molten material after the heat source moves on. As further layers are built on preceding layers, the localized volume is subject to further re-heat and re-cool cycles. AM process result in meta-stable microstructure with non-equilibrium compositions of phases varying between layers [33]. Due to rapid solidification in AM processes and small melt pools, components have fine grained microstructure when compared to wrought components [35]. The solidification rates are influenced by process parameters such as the laser power, layer thickness, scan velocity and pre-heating. Geometry of the component being fabricated influence the microstructure, varying between thin walled sections and bulk regions. Heat conduction in the build direction is higher than the spatial directions due to the presence of solidified material beneath the layer being heated whereas powder is present in spatial direction, leading to anisotropy in microstructure [31]. Epitaxial grain growth resulting in grain sizes greater than layer thickness in the build direction is observed in SLM processes [36]. These are the general trends in microstructure evolution in AM components, however microstructure evolution varies between LBM, EBM and LMD processes.

\subsection{Defects and Mechanical Properties of AM Components}

Dense metallic parts with density greater than $99.5 \%$ can be produced by AM processes for a variety of metals. Pores and voids in AM components cause great concern since they act as sites for crack initiation and crack jumping. Porosity is influenced by scan parameters, scan strategies and laser power; low energy input will result in unmolten material forming irregular shaped voids while high energy input leads to unstable melt pool defects known as balling and spherical pores caused by entrapped gas. Irregular shaped voids (keyholes), caused by low energy input, act as stress risers and cause stress concentrations leading to significant decline in mechanical properties; such keyholes (Figure 17a) are considered to be more deleterious than spherical pores (Figure 17b) [37]. In addition to the shape and size of pores, location of the pores also plays a significant factor in determining the mechanical properties of AM components (Figure 17c).

The static mechanical properties of AM components are a function of the microstructure and the density of the parts. Published literature has shown that the mechanical properties of AM metals are comparable to parts produced by casting. The fine grains produced by the AM process increase the static strength of parts, as the increase in grain boundaries prevent motion of dislocations and increase the yield strength according to the Hall-Petch relation. Due to anisotropy in microstructure of AM components, ultimate tensile strength and elongation to failure are higher in the build directions than directions orthogonal to the build direction. Tensile strength of SLM IN718 varies due to part porosity influenced by processing parameters (scan velocity, hatching distance, layer thickness, and laser power) and quality of powder used in the SLM process. Tensile strength of SLM IN718 is comparable to tensile strength of cast parts but is inferior to that of wrought parts [38].

The fatigue strength and fatigue properties of $A M$ components are dependent on the microstructure, defects (porosity, balling) and surface roughness. The layer-wise manufacturing approach of AM processes results in increased surface roughness (usually, $R_{z}>100 \mu \mathrm{m}$ ) causing increased stress concentrations and early failure of components under cyclic loading. To enhance fatigue life of a component, the rough surface can be alleviated with a suitable post processing step such as finish machining, mechanical/chemical polishing. Although internal defects such as porosity, lack of layer bonding, or residual stress cause variance in experimental results of fatigue tests, their severity can be reduced by thermal post treatment processes (e.g., stress relieving, aging...) or thermal mechanical treatment (e.g., hot isostatic pressing). 

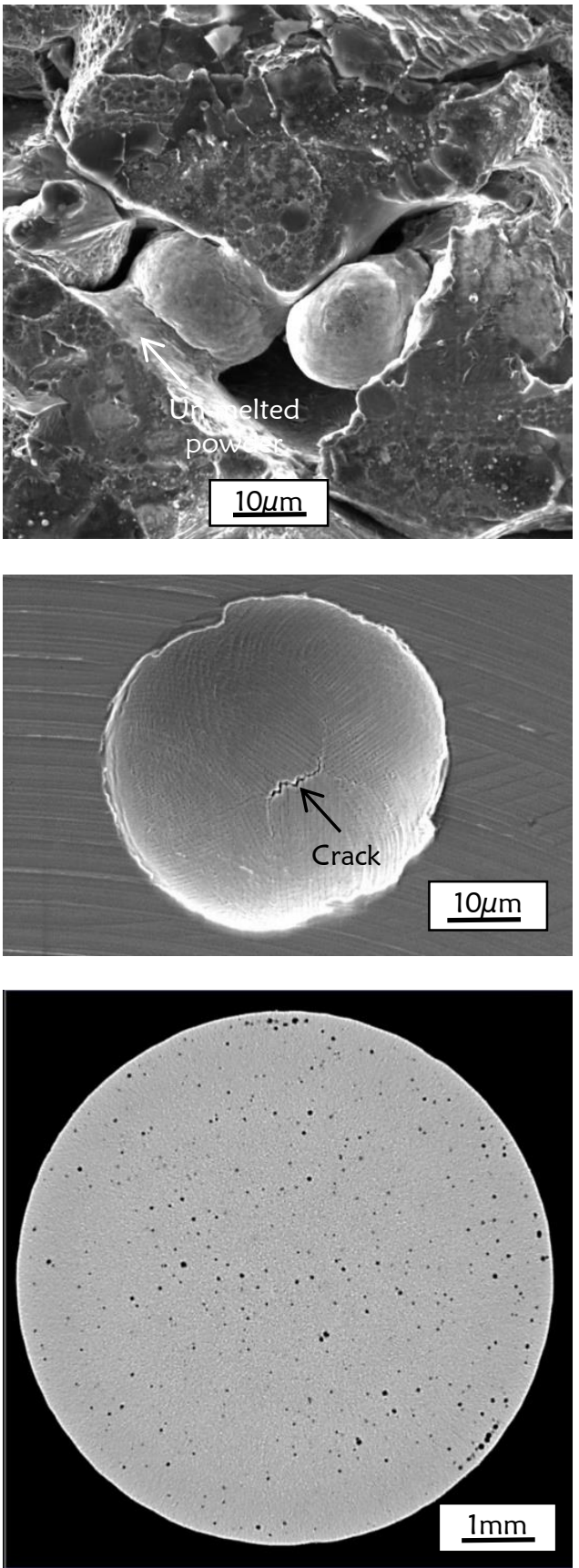

Figure 17: Defects in SLM IN718: (a) unmelted powder particles and adjacent keyhole. (b) a spherical pore sectioned by micromilling [39] and (c) distribution of pores in a cylindrical SLM IN718 bar [40].

\section{INCONEL 718}

Inconel is a registered trademark of Special Metals Corporation for a family of austenitic nickel-chromium based superalloys. These superalloys exhibit high oxidation and corrosion resistance, making them suitable for applications in high pressure/temperature and aggressive environments. When heated, Inconel produces a thick and stable passivating oxide layer which protects its surface. As Inconel retains strength at high temperatures, it is a good alternative to other engineering materials that are susceptible to creep and fatigue at elevated temperatures. The mechanical properties of Inconel can also be altered with strain strengthening and/or precipitation hardening.

The IN718 (ASM wt\% Ni 50-55, Cr 17-21, Fe 17, Nb 4.75-5.5, Mo 2.8-3.3, Ti 0.65-1.15, Al 0.2-0.8, Co <1.0, $\mathrm{C}<0.8$, $\mathrm{Si}<0.35, \mathrm{Mg}<0.35, \mathrm{Cu}<0.3, \mathrm{~S}<0.015, \mathrm{P}<0.015, \mathrm{~B}<0.006)$ is a nickel-chromium-iron based precipitation hardenable alloy with excellent creep properties. Table 4 shows that IN718 can retain its mechanical properties in a broad temperature range, and high corrosion resistance at high temperature. IN718 is so popular that standards for 
heat treatment have been developed for this material; The Society of Automotive Engineers developed Aerospace Materials Specifications (AMS) such as the AMS-5662 and AMS-5383 standards for heat treatment of IN718. The former suggests that the wrought IN718 should be solution heat treated within $927^{\circ} \mathrm{C}$ to $1010^{\circ} \mathrm{C}$, followed by precipitate hardening at $718^{\circ} \mathrm{C}$ for 8 hours, then furnace cooled and held at $621^{\circ} \mathrm{C}$ for 18 hours and then air cooled to room temperature [41]. Another common heat treatment standard is the AMS-5383, in which cast IN718 should be homogenized and solution treated, and then following by a double ageing process [42]. IN718 shows resistance to progressive oxidation up to $1100^{\circ} \mathrm{C}$. It has high weldability with excellent resistance to post weld cracking, in addition to high wear resistance, high magnetic permeability, and high electrical resistance. The AM of IN718 is widely explored because machining IN718 is difficult due to its low thermal conductivity and high hardness, which results in poor surface integrity and high tool wear when processed by traditional material removal processes. The average hardness of as-printed IN718 components is 2.3GPa (17 HRC), and the average hardness after heat treatment is 3.9GPa (41 HRC) [43].

The IN718 is used in the aerospace industry, because of its excellent high temperature mechanical properties and performance. It is also used by the automobile industry to manufacture high performance turbocharger rotors and exhaust system components, aerospace industry for gas turbine blades, combustors and seals, and engine combustion chamber to operate at high pressure (6.9MPa) and high temperatures [44].

Table 4. Mechanical properties of IN718 bar stock subjected to AMS-5662 standard heat treatment [41,45].

\begin{tabular}{lcc}
\hline Property & Room Temperature & $649^{\circ} \mathrm{C}$ \\
\hline Tensile Strength $(\mathrm{MPa})$ & 1240 & 970 \\
\hline Yield Strength $(\mathrm{MPa})$ & 1030 & 860 \\
\hline$\%$ Elongation & 10 & 10 \\
\hline \% Area Reduction & 12 & 12 \\
\hline Hardness & $331 \mathrm{BHN}$ & - \\
\hline
\end{tabular}

\section{POST PROCESSING OF AM IN718}

Like other additively manufactured metals, IN718 can be post-processed in order to relieve internal stresses, close gasfilled pores, and improve mechanical properties. The post processing of AM IN718 and its effect on fatigue life is discussed in this section.

\subsection{Heat treatment and microstructure}

The material strength of IN718 is obtained by precipitation hardening mechanism. In AM process such as SLM, repeated melting and fast cooling of the molten powders formed the dendrite solid solution $\gamma$ phase, NbC niobium carbide, and the Laves phase:

Liquid Inconel $718 \rightarrow \gamma+\mathrm{NbC}+$ Laves

Additional metal carbides were reported as $\mathrm{M}_{23} \mathrm{C}_{6}$ containing $\mathrm{Cr}$, Mo, and $\mathrm{Nb}$. Both the $\mathrm{NbC}$ and $\mathrm{M}_{23} \mathrm{C}_{6}$ carbides were stable; a $\mathrm{NbC}$ phase, with significant $\mathrm{Nb}$ content, depleted $\mathrm{Nb}$ atoms around it and prevented formation of the fine $\gamma$ " precipitates [46]. The Laves phases were the largest phase of all; contained at least $10 \% \mathrm{Nb}$, although a very large percentage of $35 \% \mathrm{Nb}$ in Laves was reported [47]. The large and brittle Laves phase is harmful to mechanical properties and fatigue life of SLM IN718 [38]. The composition of Laves phase is ( $\mathrm{Ni}, \mathrm{Cr}, \mathrm{Fe}, \mathrm{Nb}, \mathrm{Mo}, \mathrm{Ti}$ ) that causes the segregation of $\mathrm{Nb}$ and affects other strengthening phases. Therefore, it is mandatory to dissolving the Laves phases through an appropriate homogenizing or solution heat treating process. The upper limit temperature for dissolving Laves phase is its eutectic temperature $\left(1160-1200^{\circ} \mathrm{C}\right)$. Since the driving mechanism for $\mathrm{Nb}$ and Mo out of Laves phase is diffusion, a trade of between time and exponential of temperature can be expected. Complete dissolving of Laves phase was reported at $1080^{\circ} \mathrm{C}$ after 45 minutes or at $1180^{\circ} \mathrm{C}$ after 15 minutes [48]. Cooling rate of the materials after solution heat treating and subsequent aging processes contribute to the final microstructure and mechanical properties of the material.

The solid solution is not stable, therefore, the $\mathrm{Nb}, \mathrm{Ti}, \mathrm{Al}, \mathrm{Ni} . .$. atoms from the solid will diffuse and form small precipitates that (i) hinder dislocation movement, (ii) effectively increase the yield and tensile strength of the material, but (iii) reduce the material ductility. Aging of IN718's $\gamma$ phase would form the $\delta, \gamma$ ' and $\gamma$ " precipitates (Figure 18). Compositions of the $\delta$ precipitate was reported as $\mathrm{Ni}_{3} \mathrm{Nb}$, and those for the $\gamma$ ' and $\gamma$ " precipitates were $\mathrm{Ni}_{3}(\mathrm{Al}, \mathrm{Ti})$ and $\mathrm{Ni}_{3} \mathrm{Nb}$ respectively $[46,49]$. The $\delta$ precipitates, typically needle shape of few-micron long, were formed primarily at grain boundaries and contained at least $6-8 \% \mathrm{Nb}$. Both the $\gamma$ ' and $\gamma$ " precipitates, in nanometer scale, can be seen with transmission electron microscopy (TEM) and maybe visible with high-resolution scanning electron microscopy (SEM). There is no unique solution heat treating and aging recipe. One can modify the aging temperature and time to grow the precipitates to reach optimal sizes and distributions depending on the requirement. "Peak aging" refers to condition to obtain the maximum strength when the precipitates are optimal. The mechanical strength and hardness would be lower when the materials contain undersized precipitates (under-aging) or oversized precipitates (overaging). Table 5 summarizes the effect of heat treatment on mechanical properties of SLM IN718 [48].

- Solution heat treating at $1080^{\circ} \mathrm{C}, 45 \mathrm{~min}$ and water quench produces the most ductile material with $39.1 \%$ ductility. 
- Double stage aging can be done after solution heat treating. The first aging at $700-720^{\circ} \mathrm{C}$ forms both $\gamma^{\prime}$ and $\gamma^{\prime \prime}$ precipitates, while the second aging at lower temperature of $620^{\circ} \mathrm{C}$ forms additional $\gamma$ ' precipitates. The highest strength of $1500 \mathrm{MPa}$ can be obtained after double aging at $700^{\circ} \mathrm{C}, 12 \mathrm{~h}+620^{\circ} \mathrm{C}, 6 \mathrm{~h}+$ air cool. The presence of fine precipitates enhances the material strengths but at the expense of material ductility.

- The flexible recipes for solution heat treating and aging allow designers to choose post processing steps and balance between material strength and ductility. It is seen that SLM materials can match, if not exceed, the properties of cast, rolled or extruded materials.

Table 5. Effect of solution heat treatment and aging on mechanical properties of SLM IN718 [48].

\begin{tabular}{|c|c|c|c|c|}
\hline Process & Aging & $\begin{array}{l}\text { Yield strength } \\
(\mathrm{MPa})\end{array}$ & $\begin{array}{l}\text { Tensile strength } \\
(\mathrm{MPa})\end{array}$ & $\begin{array}{l}\text { Elongation } \\
(\%)\end{array}$ \\
\hline $\begin{array}{l}\mathrm{SLM}, 1080^{\circ} \mathrm{C}, 45 \mathrm{~min}, \\
\text { furnace cool }\end{array}$ & None & $1037 \pm 19$ & $1329 \pm 3$ & $27.8 \pm 1.0$ \\
\hline $\begin{array}{l}\mathrm{SLM}, 1080^{\circ} \mathrm{C}, 45 \mathrm{~min}, \\
\text { water quench }\end{array}$ & None & $541 \pm 10$ & $976 \pm 5$ & $39.1 \pm 0.3$ \\
\hline $\begin{array}{l}\mathrm{SLM}, 1080^{\circ} \mathrm{C}, 45 \mathrm{~min}, \\
\text { furnace cool }\end{array}$ & $720^{\circ} \mathrm{C}, 8 \mathrm{~h}+620^{\circ} \mathrm{C}, 8 \mathrm{~h}+$ air cool & $1268 \pm 8$ & $1476 \pm 6$ & $17.9 \pm 1.4$ \\
\hline $\begin{array}{l}\text { SLM, } 1080^{\circ} \mathrm{C}, 45 \mathrm{~min} \text {, air } \\
\text { cool }\end{array}$ & $\begin{array}{l}700^{\circ} \mathrm{C}, 12 \mathrm{~h}+620^{\circ} \mathrm{C}, 6 \mathrm{~h}+\text { air } \\
\text { cool }\end{array}$ & $1356 \pm 15$ & $1500 \pm 5$ & $20.8 \pm 1.4$ \\
\hline $\begin{array}{l}\text { SLM, } 1080^{\circ} \mathrm{C}, 45 \mathrm{~min} \text {, air } \\
\text { cool }\end{array}$ & $700^{\circ} \mathrm{C}, 4 \mathrm{~h}+$ air cool & $1172 \pm 5$ & $1414 \pm 3$ & $23.8 \pm 1.0$ \\
\hline Cast [50] & None & 758 & 852 & 5 \\
\hline Wrought [50] & None & 1034 & 1241 & 10 \\
\hline
\end{tabular}

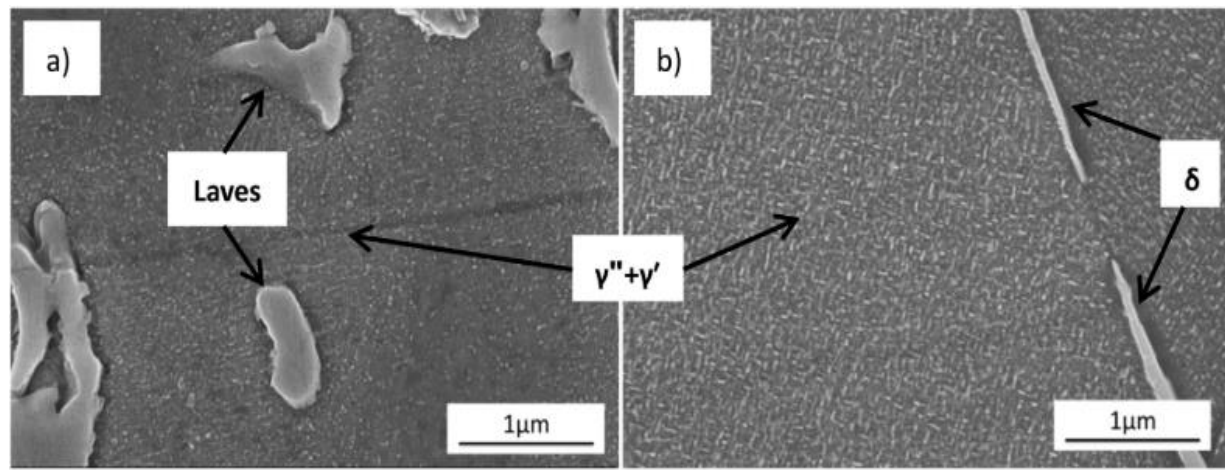

Figure 18: A comparison of constituents of the microstructure of (a) SLM IN718 and (b) wrought IN718. Here, $\gamma$, $\gamma^{\prime \prime}, \delta$ and Laves are different precipitates in the IN718 microstructure [38].

The SLM process instills a large amount of residual stresses in a component due to rapid heating and cooling; such high residual stresses, if not crack a part during SLM, would otherwise decrease the part performance and limit its applications (Figure 19). Tensile residual stresses on a part surface are detrimental to fatigue life whereas compressive residual stresses increase fatigue life since the latter would close a crack and suppress crack initiation/propagation. Elimination of residual stresses are found to improve fatigue performance. This can be done as a post process (Table 6), or in-process improvement by heating the powder-bed base plate to above $570^{\circ} \mathrm{C}$, and carefully controlling the scanning strategy [51]. Stress relief is performed on components while they are still attached to the build plate to prevent warping of the part upon removal from the build plate. Wire-type electrical discharge machining is typically utilized to separate the parts from its built plate without adding additional residual tress to the components. A significant decrease in residual stress is found in SLM IN718 components subjected to heat treatment at $1065^{\circ} \mathrm{C}$, when compared to as-printed components with no heat treatment (Figures 20a, 20b). Thermal treatment like stress relieving should be done before finish machining to avoid unwanted distortion due to residual stress redistribution (Table 6). Notice that the solution heat treating temperature and time are very close to those for stress relieving, therefore, a solution heat treatment following by furnace cooling should effectively remove residual stress in SLM IN718 components. 


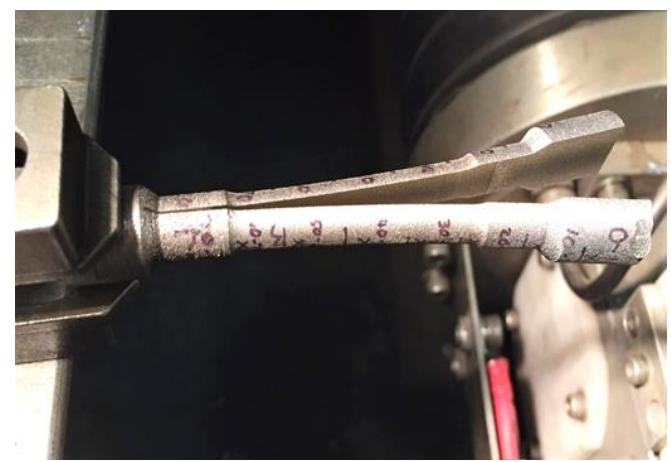

Figure 19: Distortion of a tensile bar due to residual stress. Sectioning of SLM'ed Inconel 718 by wire electrical discharge machining.

Table 6. Other post-processing techniques for SLM IN718.

Treatment

Stress Relief

Hot Isostatic Pressing
Description

$85-105$ minutes at $1065 \pm 15^{\circ} \mathrm{C}[52]$

4 hours at $1120^{\circ} \mathrm{C}, 120 \mathrm{MPa}[53]$

Table 7: Compare mechanical properties of SLM IN718 in as-printed and HIP'ed conditions [59]

\begin{tabular}{ccccccc}
\hline Condition & Porosity (\%) & $\begin{array}{c}\text { Ultimate } \\
\text { Tensile } \\
\text { Strength } \\
(\mathrm{MPa})\end{array}$ & $\begin{array}{c}\text { Elongation } \\
(\%)\end{array}$ & $\begin{array}{c}\text { Yield } \\
\text { Strength } \\
(\mathrm{MPa})\end{array}$ & $\begin{array}{c}\text { Hardness } \\
(\mathrm{HV})\end{array}$ & $\begin{array}{c}\text { Youngs } \\
\text { Modulus } \\
(\mathrm{GPa})\end{array}$ \\
\hline As-Printed & 0.11 & 1011 & 22 & 668 & 320 & 173 \\
\hline HIP & 0.02 & 1025 & 38 & 645 & 310 & 188 \\
\hline
\end{tabular}
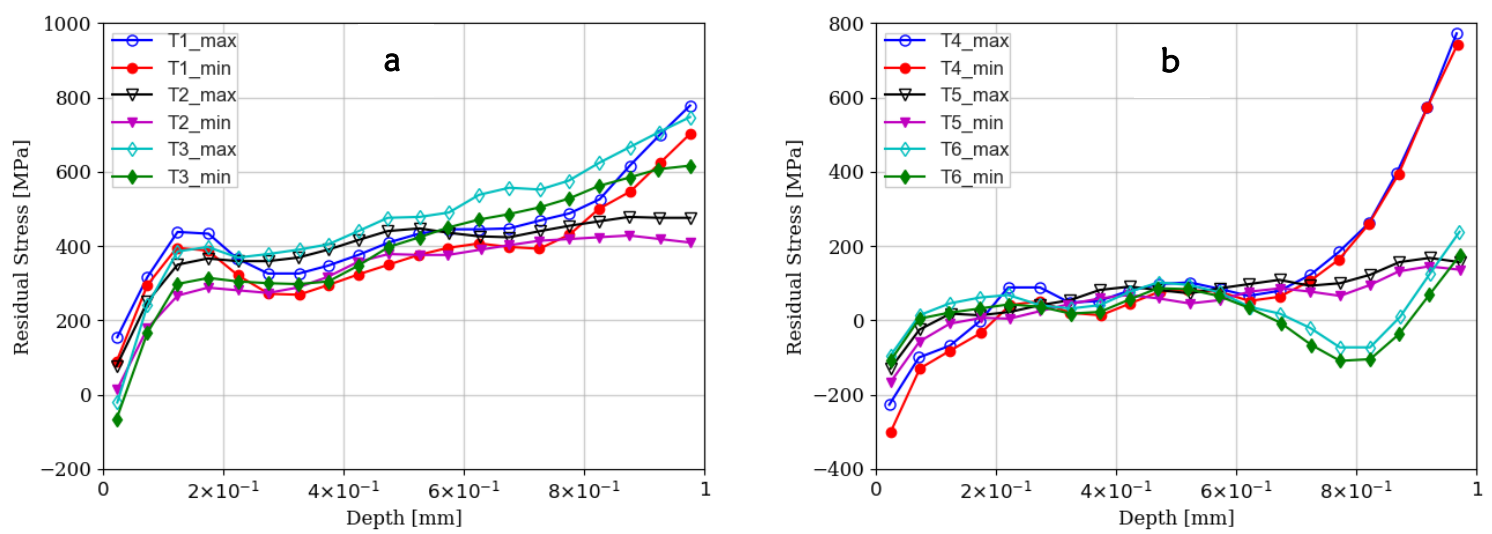

Figure 20: Residual stress profiles in SLM IN718 (a) As printed and (b) after stress relieving. T: location, numbers (1-6): specimen identification [54]. Note different scales for stress in both charts.

Hot Isostatic Pressing is a thermo-mechanical technique for closing pores and minimizing keyhole sizes, therefore, it helps to improve mechanical properties of AM metals (Table 7), therefore prolongs fatigue life. An optimal HIP'ing process for IN718 could be with temperature between $1150^{\circ} \mathrm{C}-1300^{\circ} \mathrm{C}$ and pressure between $100 \mathrm{MPa}$ 150MPA for 3 to 4 hours followed by furnace cooling [55]. The HIP'ing process also improves interlayer bonding, which in turn reduced anisotropy in SLM components [56]. However, the HIP'ing of wrought (i.e., plastically deforming processing such as rolling or extruding) IN718 leads to grain growth which in turn causes a deterioration in mechanical properties [56]. While HIP'ing closes a majority of the pores (e.g., spherical gas-filled pore) in the microstructure of AM component (Figure 21), it does not completely close all the pores because of contaminated inner surfaces of some voids (e.g., the odd shaped keyholes). Even under optimum process parameters, only a near full density of $98.4 \%$ was achieved by HIP'ing of SLM IN718 [57]. Although, HIP'ing reduces the size of these pores in SLM IN718; crack initiation phase of fatigue fracture still starts from the residual microdefects that remain after HIP'ing process [33,58]. Furthermore, HIP'ing does not improve surface roughness resulted from AM stepwise process, therefore HIP'ed components still need additional machining/polishing process for fatigue enhancement. Effect of HIP'ing on fatigue life of IN718 will be discussed in section 6.2. 

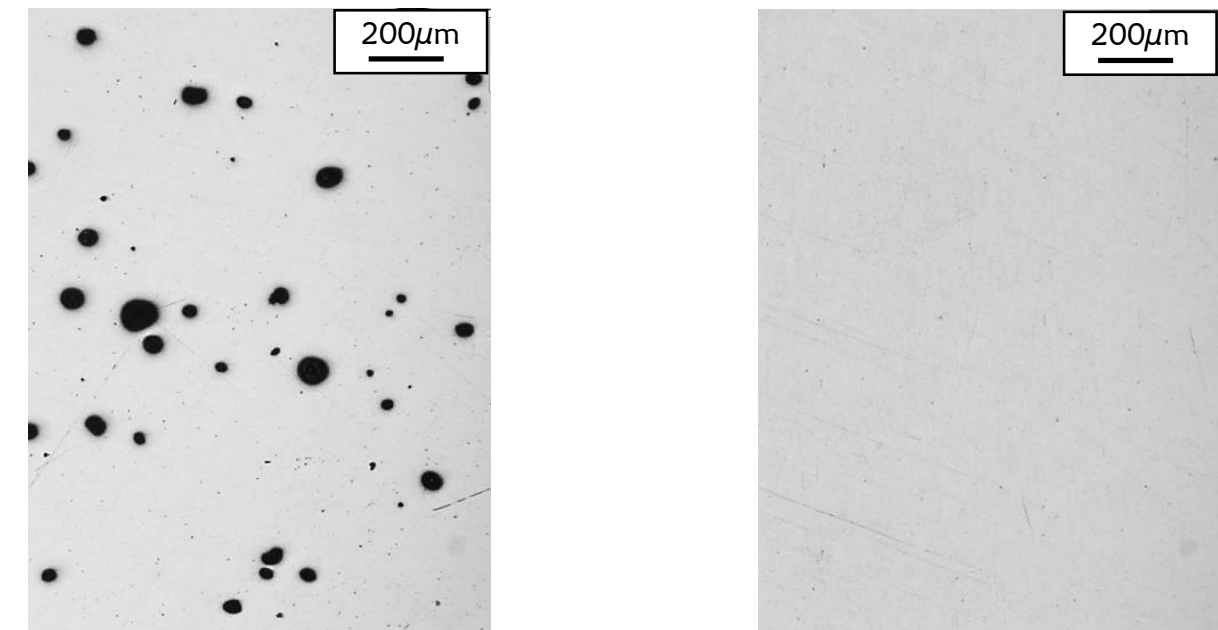

Figure 21: Porosity in SLM IN718 (left) and no visible porosity after HIP'ing (right).

\subsection{Machining and Polishing}
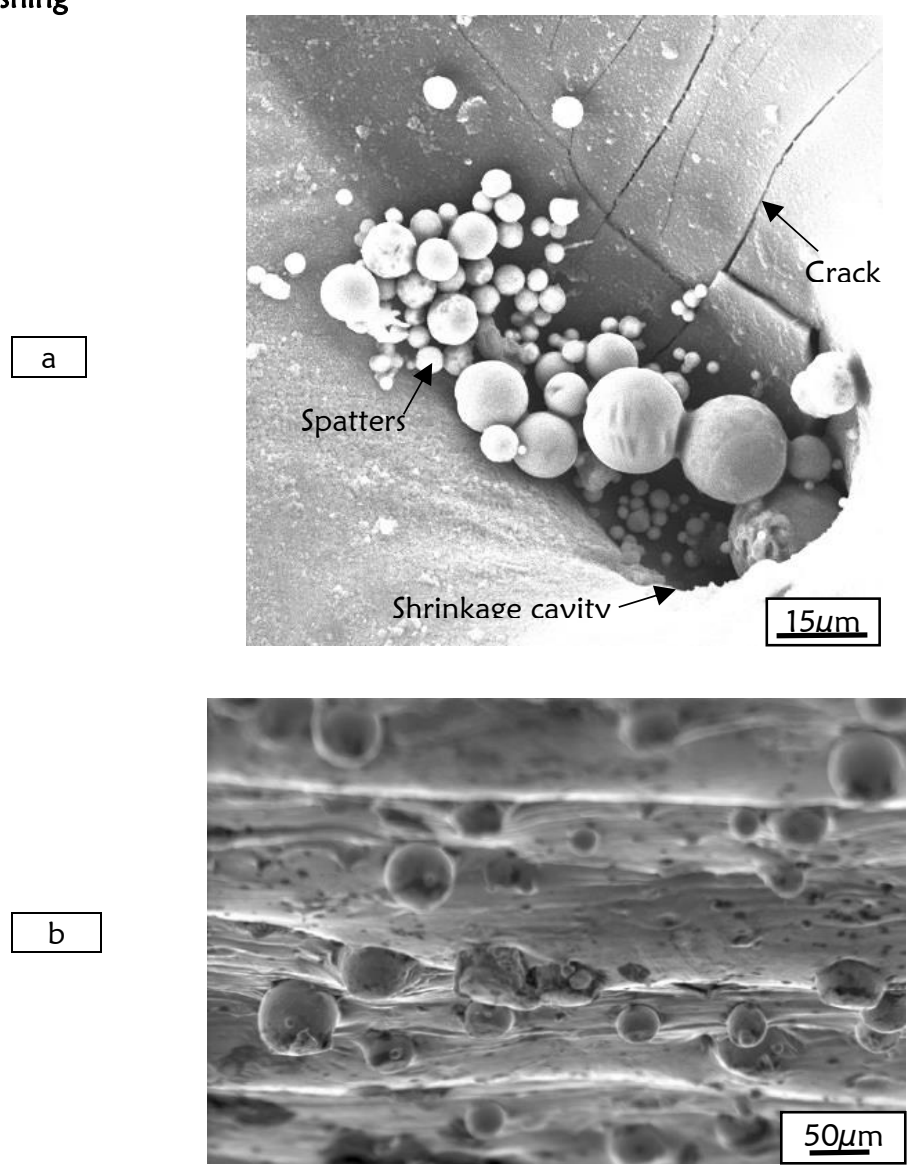

Figure 22. Typical defects found on SLM IN718 surfaces: (a) unmelted particles and spatters, shrinkage cavity, micro microcrack on the $X-Y$ plane (b) rough surface due to partially melted powder and imperfect layer bonding when viewing along the $z$-axis.

As fabricated SLM parts have rough surface finish, slag, spatters, shrinkage cavity, microcracks... on a surface (Figures 22a and 22b), while keyholes, porosity, and Laves particles are embedded just below a surface. Removal of these surface defects would improve mechanical and fatigue properties SLM metals. Although HIP'ing can close the spherical gas-filled pores, it does not "heal" keyholes in the microstructure. Sufficient energy density during processing and optimal scanning strategy can minimize internal defects, but not surface defects. The surface defects, shown partially in Figures 22a and 22b, are sites for fatigue crack initiation and must be removed for reliability of SLM 
components. Material removal processes such as machining and polishing have been explored and presented in literature. Finish machining is a remarkably effective way to improve surface roughness and control dimensional tolerance and precision of AM metals. The arithmetic surface roughness Ra of SLM surface can be decreased $92 \%$ after turning [60]. Micromilling technique was also studied for machining SLM IN718; at optimal speed and feed a surface roughness of as-printed specimen was reduced from 17 to 1-2 $\mu \mathrm{m} \mathrm{R} \mathrm{R}_{\mathrm{a}}$ [39]. Tool wear is high when machining the wrought IN718 due to the material high hardness and low thermal conductivity of IN718. Researchers have found that SLM IN718 was more difficult to machine compared to wrought or cast IN718 due to the presence of hard slags between layers and the brittle and hard Laves particles (Figure 23). The tool coating AITiN-Si ${ }_{3} \mathrm{~N}_{4}$ was found to be effective when micromilling SLM IN718 in minimum quantity lubrication at $14 \mathrm{~m} / \mathrm{min}$ cutting speed and $1.2 \mu \mathrm{m} /$ tooth feed, however, the coating may be damaged when cutting and smearing the hard slags and brittle Laves particles (Figure 24). Although HIP'ing improves fatigue life by closing gas-filled pores it significantly reduces the tool life due to the forming of hard carbide and precipitates during HIP'ing [39]. While eliminating surface defects and improving surface roughness, the finish machining step helps to achieve part features for required dimensional and form accuracy. A metal AM process produces near net-shape parts with large dimensional tolerances and limited accuracy for critical features like holes, gasket seats, mechanical lubrication and lubrication features etc. The deviations of metal AM part from its design could be as high as $20 \%$ depending on SLM process parameters [61].

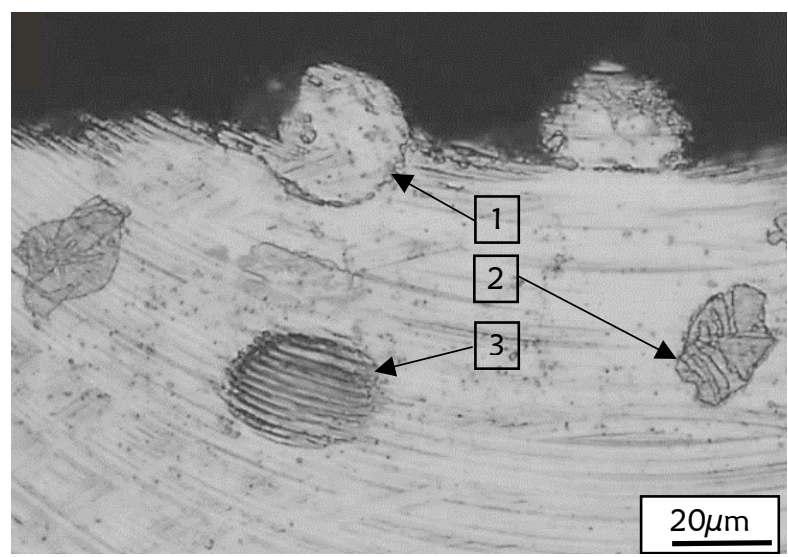

Figure 23. Material defects that affect machining of SLM IN718: (1) unmelted powder at surface, (2) brittle Laves phase, and (3) burr covered pore [39].

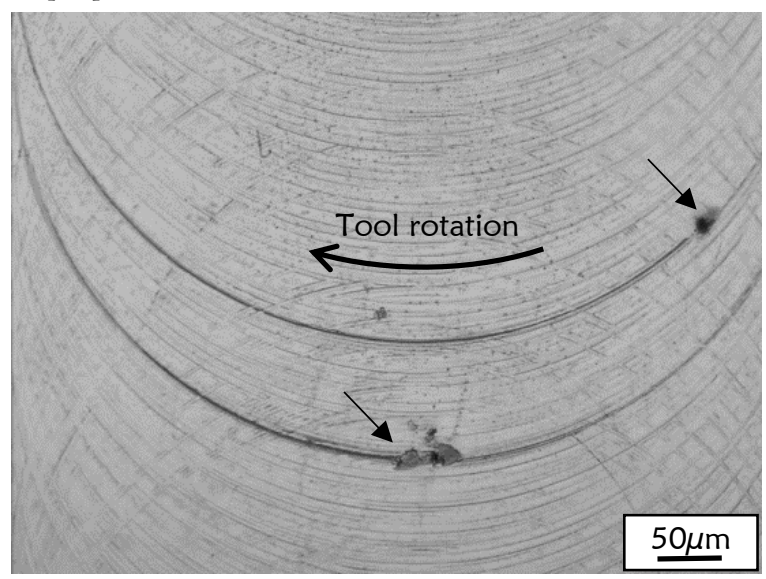

Figure 24. Smearing of sheared brittle Laves particles (at arrows) on a milling surface [39].

Finish machining of SLM IN718 can produce surface finish about 2-4 $\mu \mathrm{m}$ Ra. If a better (smoother) surface finish is required, then a suitable polishing technique can be applied to the machined surface. Buffing, grinding, lapping, abrasive flow polishing, plasma electrolytic polishing, magnetic abrasive polishing, laser polishing, and electrochemical polishing can be used to achieve sub-micron surface finish (Figure 25a and 25b). Under optimal conditions (Figure 25c), surface finish has been improved from $17 \mu \mathrm{m}$ to $0.25 \mu \mathrm{m}$ of as-printed IN718 [62], but the presence of micropores and detrimental phases in microstructure prevented further polishing. The combination of conductive matrix of IN718 and the presence of non-conductive phases such as pores, inclusions, precipitations and slag prevent uniform surface finish by electrochemical polishing (Figures $25 b$ and $25 c$ ). 

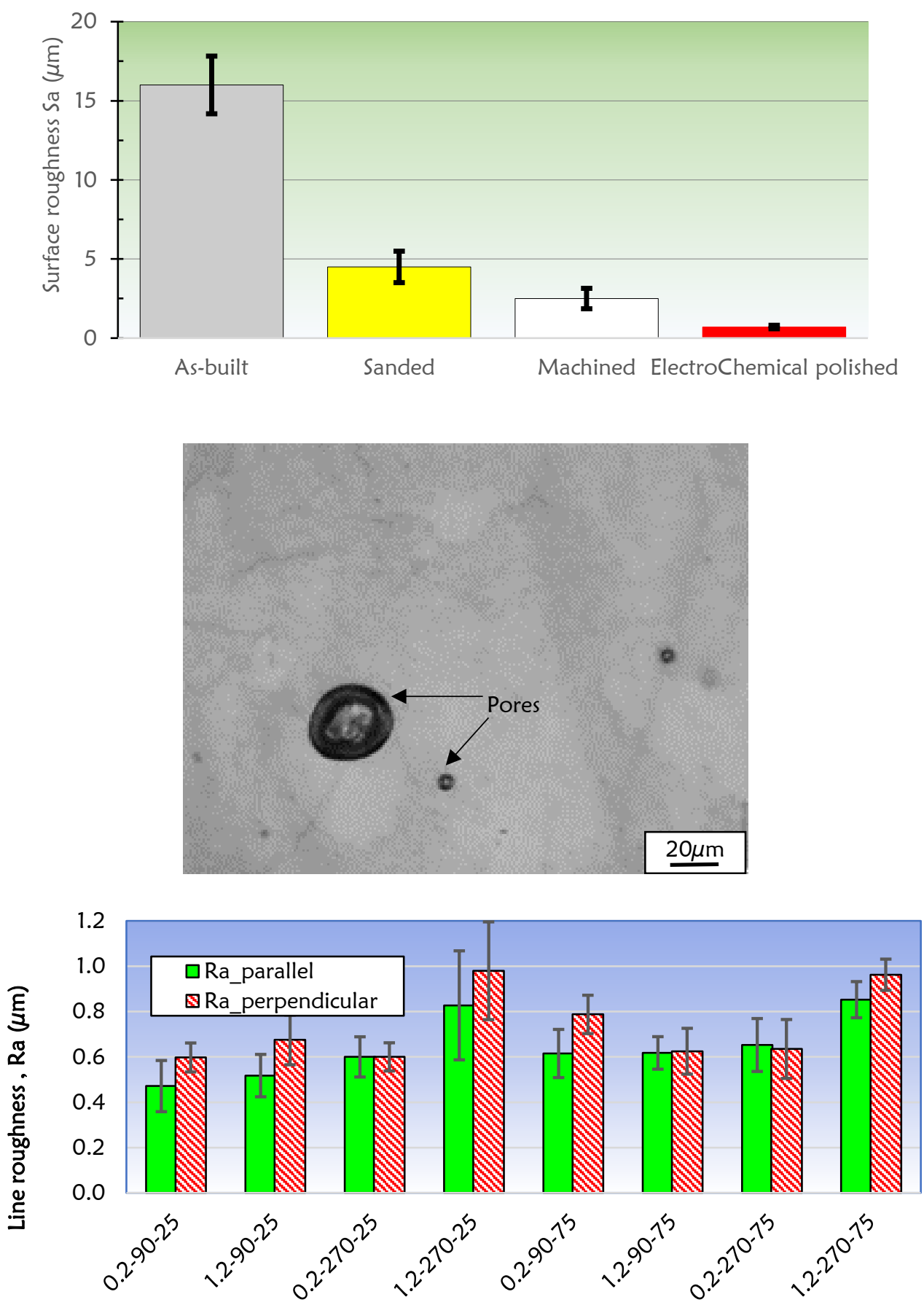

ECP conditions

Figure 25: Surface finish SLM IN718 after electrochemical polishing: (a) Comparison of surface finish after different post processing techniques, (b) Unpolished pores on mirror finished surface, (c) Effect of electrochemical polishing parameters on surface finish. Measurement in two directions on surface; the parameters codes: current density $\left(\mathrm{A} / \mathrm{mm}^{2}\right)$ - time $(\mathrm{s})$ - duty cycle (\%) [62].

\section{FATIGUE OF IN718}

\subsection{Traditionally Manufactured IN718}

The fatigue of traditionally manufactured IN718 is studied to provide a basis of comparison and understanding of the fatigue properties of AM IN718. Published literature on fatigue tests of IN718, failure mechanisms and microstructure affecting fatigue, and the testing methods are presented in following section.

Room temperature fatigue properties of annealed, aged, and annealed then aged wrought IN718 are compared in Table 8. According to AMS-5596 standard for IN718, annealing is conducted at $945^{\circ} \mathrm{C}$ for 1 hour, and ageing is 
conducted at $719^{\circ} \mathrm{C}$ for 8 hours, furnace cooled to $622^{\circ} \mathrm{C}$ and held for 18 hours. If high fatigue strength is desired, the forged IN718 is used in annealed condition, rather than annealed and aged as ageing only raises the fatigue strength marginally (less than $4 \mathrm{ksi}$ or $27 \mathrm{MPa}$ ) [63]. Fatigue of IN718 was conducted with a Moore fatigue testing machine at 10,000RPM using specimens with $7.63 \mathrm{~mm}$ diameter. To achieve a fine grain structure, the researcher utilized low temperature heat treatment procedures (AMS-5596) and successfully enhance the endurance limit of IN718 as shown in Figure 26 [63]. Smaller grain sizes would have more grain boundaries to hinder dislocation movement, therefore increase both yield and tensile strength of the materials and indirectly improve the endurance limit.

Table 8: Room temperature fatigue strength of wrought IN718 subjected to different heat treatments according to AMS-5596 Standard [63].

\begin{tabular}{lcccc}
\hline Heat Treatment & Grain Size in. & \multicolumn{3}{c}{ Fatigue Strength, ksi } \\
\cline { 3 - 5 } & & $10^{6}$ Cycles & $10^{7}$ Cycles & $10^{8}$ Cycles \\
\hline Annealed & 0.0008 & 73 & 70 & 70 \\
\hline Annealed and Aged & 0.0005 & 96 & 88 & 85 \\
\hline Annealed and Aged & 0.0014 & 90 & 81 & 74 \\
\hline Aged & 0.0008 & 95 & 84 & 80 \\
\hline
\end{tabular}

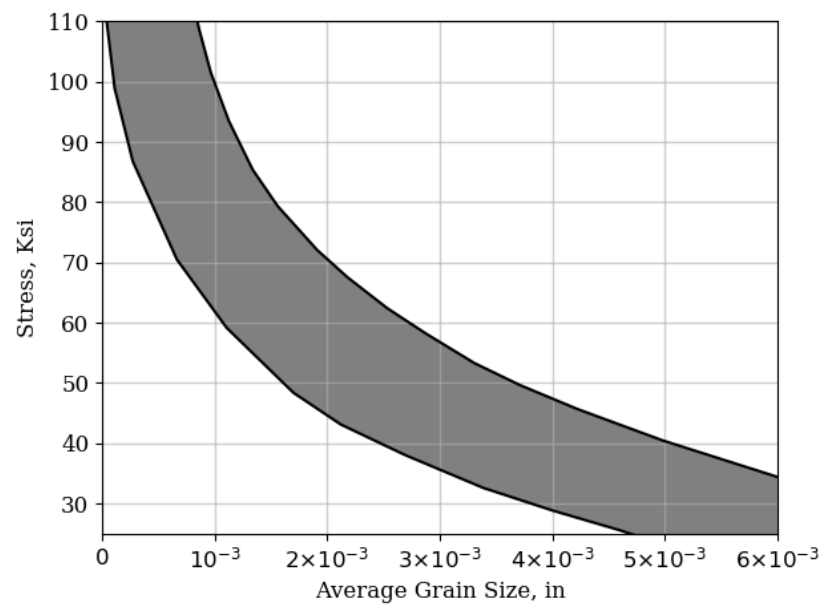

Figure 26: Effect of grain size on endurance limit of wrought IN718. Grain size variation due to differing heat treatment procedures [63].

Fatigue process can be characterized into crack initiation, crack propagation and fracture. The initiation phase includes crack nucleation and microscopic crack growth. The crack propagation phase is a macroscopic phenomenon, that leads to fracture. In case of wrought IN718, cracks are commonly originate from the surface and grow to fracture, with the cracks in a transgranular faceted mode [64]. Separate analysis is performed to understand the different fatigue stages; stress-life or strain-life approach to study crack initiation, fracture mechanics approach to study crack propagation. In the total life methods of fatigue testing, a specimen is loaded and tested till complete failure and the number of cycles is recorded. Total life methods give a good approximation of fatigue life, but this data cannot be used for performing preventive maintenance. Fatigue tests can also be performed to study crack initiation or propagation, where the specimen is considered to have failed if the specimen develops a crack of a prescribed magnitude. Most literature sources define crack initiation as crack size magnitude of $0.5 \mathrm{~mm}$ and crack propagation to describe cracks of increasing length. An alternative method would be to monitor the part compliance and stop the test when the part compliance exceeds certain threshold rather than waiting till complete fracture.

Of the various fatigue data studied (Figures 15 and 27) of traditionally manufactured wrought IN718, the most conservative estimates of fatigue life are published by Yadollahi [65] and Zhang [26]. Zhang et al. attributed fracture due to multi-source crack initiation in different planes, and macroscopic fracture that occurs when the multiple cracks coalesce. Depending on the type of fatigue test performed, fatigue crack initiation sites can be attributed to manufacturing defects, surface imperfections or subsurface defects such as pores $[26,66]$. From fractography analysis; the crack initiation behavior can be attributed to high mean stress and furthermore, initiation sites were found in $\mathrm{Nb}$ enriched carbide regions in high stress amplitude tests, whereas, in low amplitude tests transgranular crack initiation and growth took place [67]. 


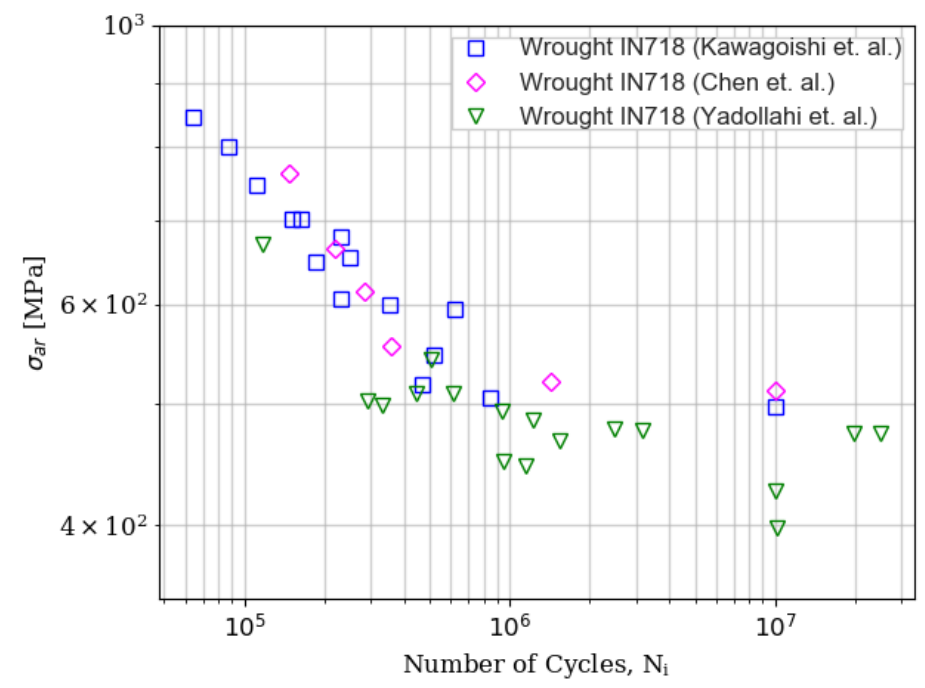

Figure 27: Compilation of rotary-bending-fatigue data for wrought IN718 [65,68,69].

\subsection{Fatigue of AM IN718}

\subsubsection{Testing techniques}

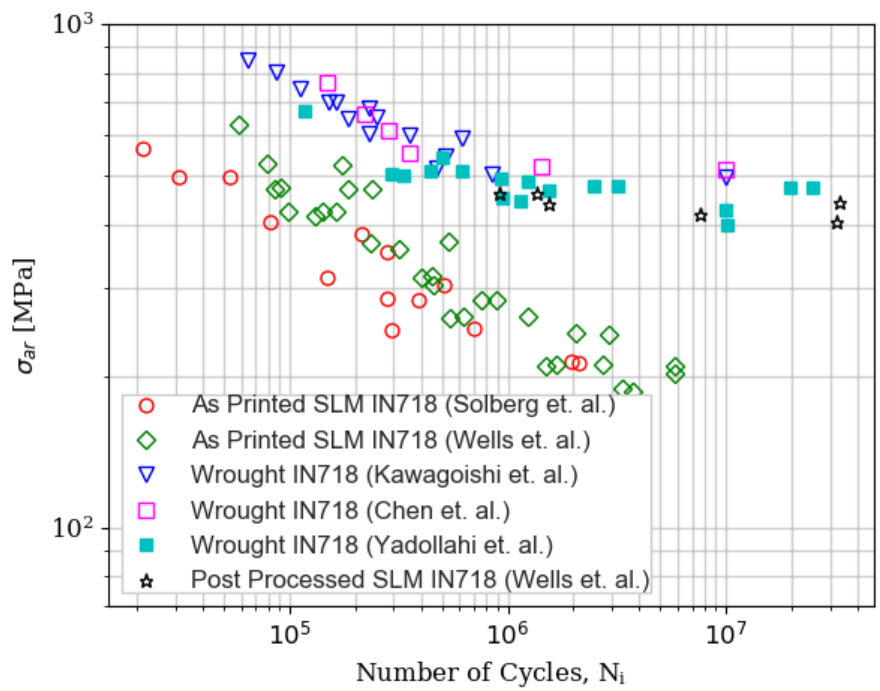

Figure 28: Comparison of fatigue properties of wrought and additively manufactured IN718 [65,68-71].

The AM metals may have inferior properties to conventional properties for static loading, ductility, strength and fatigue performance. Deteriorated performance can be attributed to internal defects such as porosity and external defects such as rough surface. In Figure 28, the S-N curves for AM IN718 and wrought IN718 are compared. Fatigue performance of AM subjected to post processing techniques such as machining and heat treatments is comparable to that of wrought parts. Heat treatment techniques such as HIP, STA etc. remove residual stress, homogenizes the microstructure and close internal pores. The porosity in AM parts are concentrated close to the surface of the component, post-process is necessary since it (i) eliminates high pore density just below an AM surface, (ii) smoothens the surface and reduces stress concentrated sites, and (iii) provides consistent dimensions to all test samples. The fatigue data for post-processed specimens are compatible with those from wrought materials.

Type of loading has a significant influence on the fatigue life of SLM IN718; this is due to the dependence of stressed volumes of a sample and different loading types. Belan [72] studied the effect of type of loading on fatigue life of wrought IN718; the author compared data generated from push-pull and three point bending tests (Figure 29). As expected, fatigue lives of samples in bending tests are significantly longer than those from push-pull tests; samples in bending test subjected to high stress at the outer surface while uniform stress is seen for the entire cross section of sample in push-pull test. 


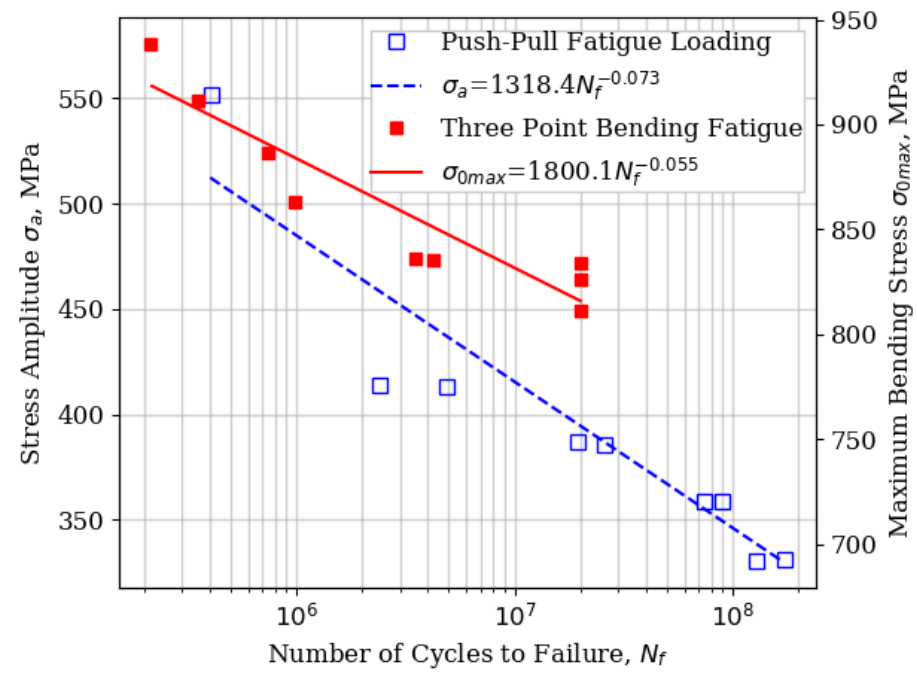

Figure 29: Comparison of effect of type of loading on wrought IN718, the S-N curves of push pull fatigue tests and three-point bending test and its comparison [72].

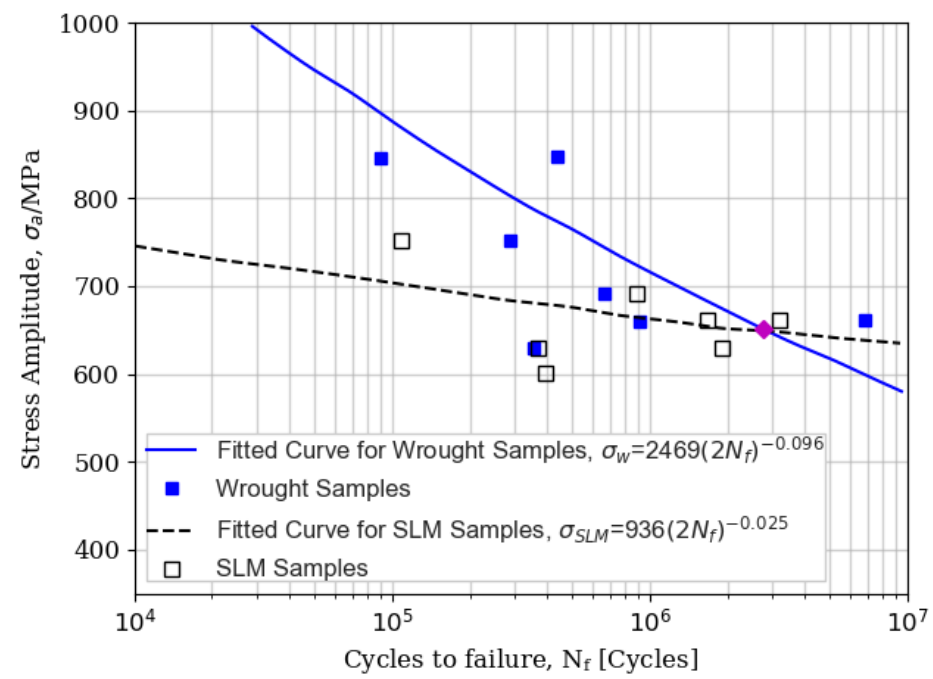

Figure 30: S-N curves wrought and SLM IN718 in push-pull mode tests [73].

\section{- Fatigue Data: Push-Pull Tests}

High-cycle fatigue studies of SLM IN718 using push-pull type machines are common. The push-pull type fatigue studies are the norm to compare fatigue lives of different materials in industry due to its conservative data, i.e., the fatigue life at the worst-case scenario.

A comparative study for high cycle fatigue of wrought IN718 and SLM IN718 $\left(650^{\circ} \mathrm{C}\right.$, testing frequency $110 \mathrm{~Hz}$, and stress ratio $R=0.1$ ) was completed [73]. The objective aimed to predict the effect of the Laves phase on the fatigue of SLM IN718 by rigorous microstructure and fractography analysis. When tested at higher stress amplitudes, the wrought IN718 exhibited superior fatigue properties than SLM IN718 (Figure 30). Observation of the fractured samples indicated that high stress-initiated fatigue cracks at multiple sites on the specimen surfaces and propagated across a grain in trans crystalline crack propagation mechanism. The S-N line for SLM samples is below that of wrought samples at low fatigue cycle, but the two lines intersects about 3 million cycles. If the trend continues then the SLM material may have longer fatigue life at very low stress.

\section{- Fatigue Data: Four-Point Bending Tests}

Two studies were conducted to characterize the fatigue properties of SLM IN718 in the as-built condition, and after post process treatments with HIP'ing, polishing and machining [74,75]. Four-point bending tests at $20 \mathrm{~Hz}$ and 
stress ratio of $R=0.1$ were conducted on both EBM and SLM IN718 samples. The heat treatment (HT) was performed on all specimen according to AMS-5664 standard (solution treatment $1066^{\circ} \mathrm{C}$ for $1 \mathrm{hr}+$ ageing $760^{\circ} \mathrm{C}$ for $10 \mathrm{hr}+$ cooling to $649^{\circ} \mathrm{C}$ at $55^{\circ} \mathrm{C} / \mathrm{hr}+$ held at $649^{\circ} \mathrm{C}$ for $8 \mathrm{hr}$ ). HIP'ing was conducted at $1200^{\circ} \mathrm{C}$ and 1200 bar for $4 \mathrm{hr}$ followed by uniform rapid quenching.

Figure 31 compares the S-N curves of wrought and SLM IN718 with and without post processing. Post process treatment by HIP'ing and HT'ing improved fatigue performance of SLM IN718 than HT'ing alone since HIP'ing would eliminate internal pores where cracks can initiate at. Machining also improve fatigue life of SLM IN718 of the as-built and HIP'ed specimen since machining would remove and minimize external defects where cracks may start from. However, machining increased the scatter of fatigue life from $10 \%$ coefficient of variation in as-built specimen to around $25 \%$ coefficient of variation in machined specimen [74].

To study the effect of different machining process on fatigue, some authors performed load-controlled constant amplitude four-point bending tests at $20 \mathrm{~Hz}$ for SLM IN718 [75]. The staircase method is used to determine the statistical properties of fatigue limit of a given material; initially, a fatigue limit is estimated, and the specimen is tested to infinite life. If the specimen fails prior to infinite life, the test is repeated with a lower load. If the specimen does not fail past infinite life, the test is repeated at a higher stress. In the staircase method, each test is dependent of the results of the previous test by increasing or decreasing the applied stress in uniform steps; following which two data reduction techniques (Dixon-Mood and Zhang-Kececioglu) can be used to analyze the statistical distribution of the staircase method test results [76]. The researchers used the staircase-method to conclude that the endurance limit for specimen fabricated by dry machining was $1040 \mathrm{MPa}$ and was $1030 \mathrm{MPa}$ for emulsion-based machining (Figure 32). The study reported that fatigue cracks initiated at the center of the specimens after dry machining, while fatigue cracks initiated $4 \mathrm{~mm}$ away from the center of specimens after flood cooling machining with an emulsion-based coolant.
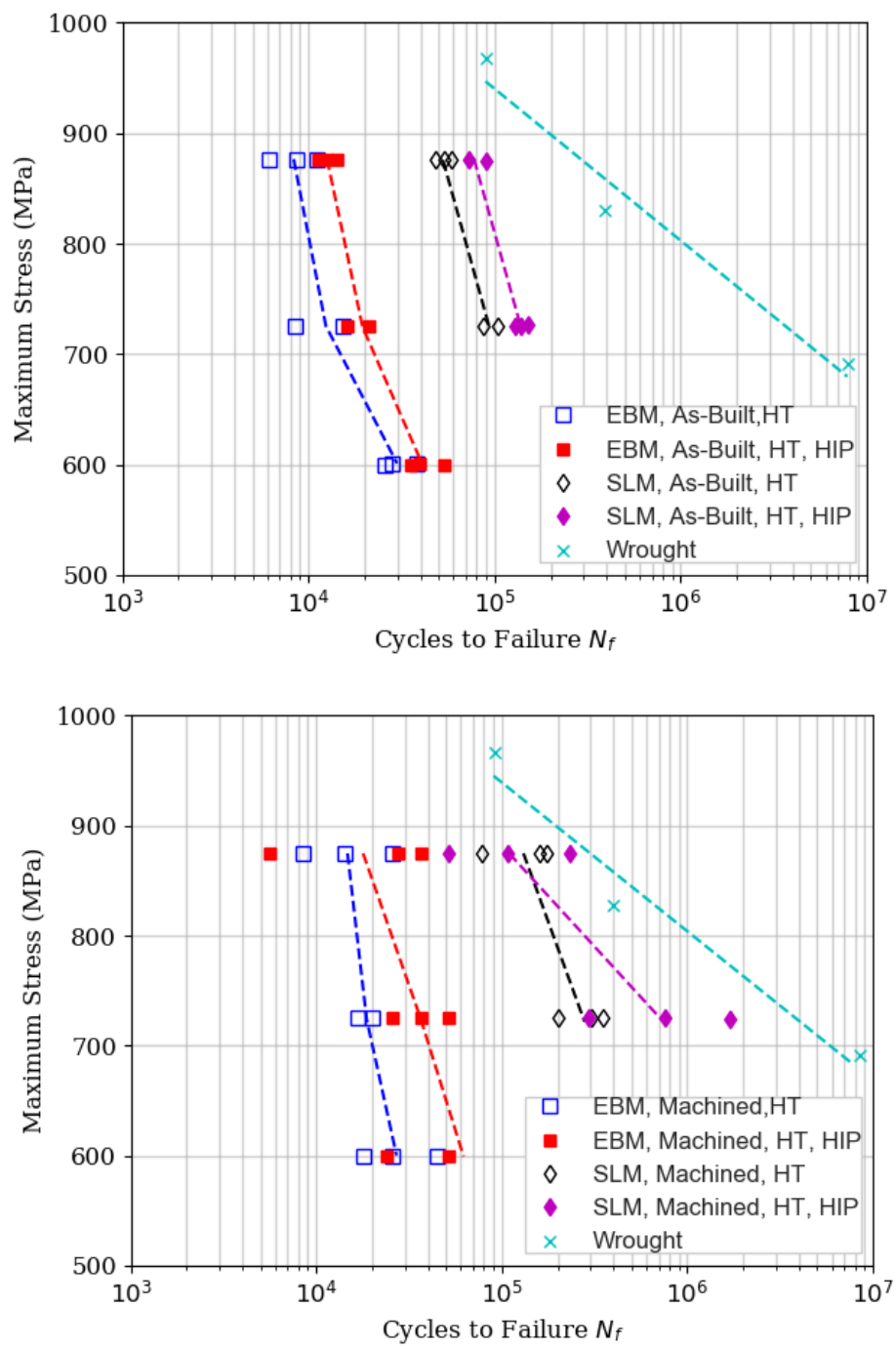

Figure 31: Comparison of S-N curves of SLM IN718 for (a) as-built specimen and (b) machined specimen [74]. 

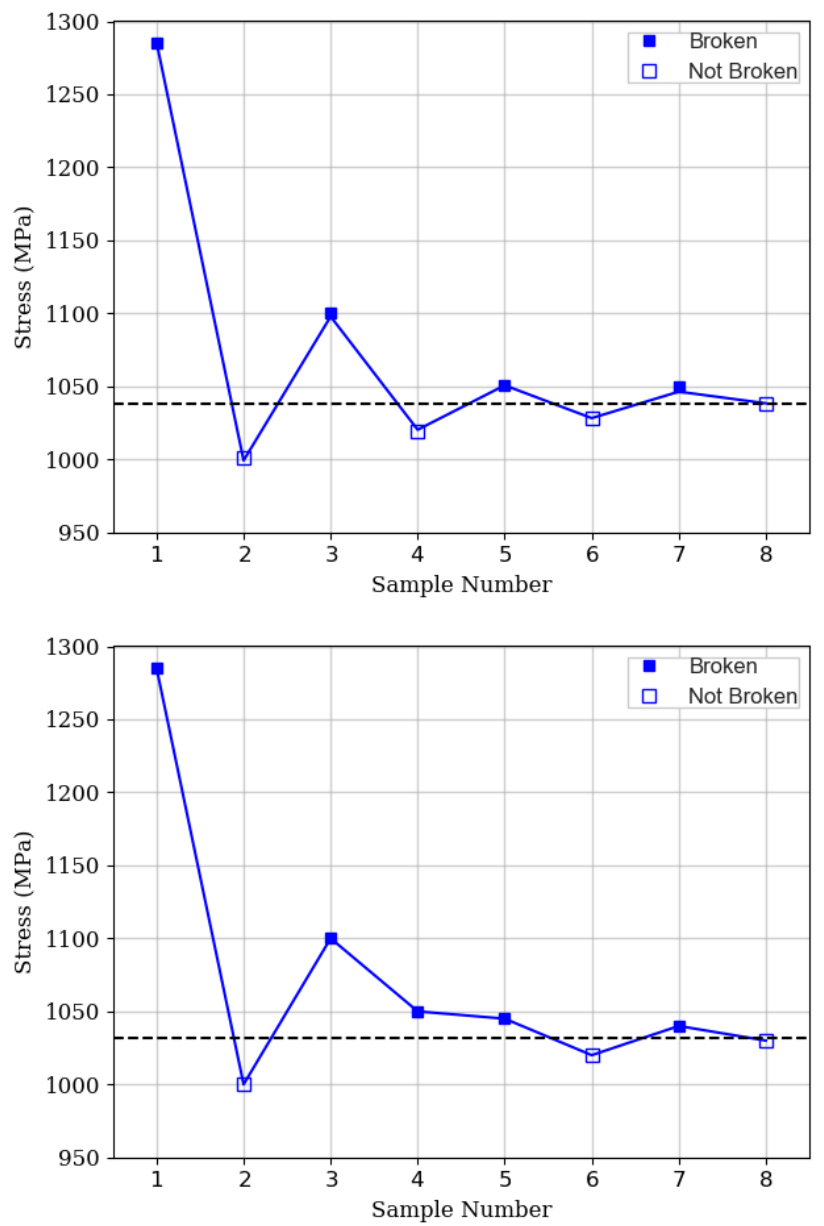

Figure 32: Endurance limit values for machined SLM IN718 for (a) dry machining and (b) flood cooling machining with emulsion-based coolant [75].

\section{- Fatigue Data: Vibration Tests}

Fatigue performance of SLM IN718 subject to vibratory bending loading was compared to the fatigue performance of cold rolled IN718 subject to rotating bending [77]. The SLM IN718 specimens printed in the same orientation were acquired from two different vendors and vibration fatigue tests conducted on an electrodynamic shaker. The specimens from vendor 1 in the study were subjected to stress relief, solution treatment and ageing, and HIP'ing. While the specimens from vendor 2 were not subjected to any post processing treatment. All the specimen showed high surface roughness values up to $12.7 \mu \mathrm{m}$ and was polished to surface roughness values less than $5.08 \mu \mathrm{m}$. Figure 33 shows reasonable agreement for fatigue data of SLM and cold rolled IN718 although they were tested in different ways (vibratory bending versus rotate bending) and different post processing conditions.

\section{- Fatigue Data: Ultrasonic Frequency Tests}

Ultrasonic frequency fatigue testing was performed on IN718 samples fabricated by Laser Enabled Net Shaping (LENS) technique. The tests were conducted with an electromagnetic resonance testing machine at $140 \mathrm{~Hz}$ and a stress ratio of $R=0.1$ [78]. The fatigue test specimens were machined from a larger component of LENS IN718 and polished to less than $0.2 \mu \mathrm{m} \mathrm{R}$, and then subjected to post process heat treatment (solution treatment at $1093^{\circ} \mathrm{C}$ for 1 hour, followed by ageing at $718^{\circ} \mathrm{C}$ for 4 hours, and cool to $620^{\circ} \mathrm{C}, 620^{\circ} \mathrm{C}$ for 16 hours and oven cooled below $371^{\circ} \mathrm{C}$ and air cooled). The authors found that fatigue fracture crack initiation occurred at the surface; and the region around the crack initiation was facetted indicative of transgranular crack propagation. The authors also reported porosity in regions surrounding the point of crack initiation. The S-N curves in Figure 34 show that the fatigue properties on LENS IN718 is similar to fatigue properties of annealed and aged IN718, in spite of the defects and porosity observed in the microstructure of LENS IN718. The data from this test were superimposed with data from reference IN718 which has been annealed and aged; the reference cites the fatigue properties of annealed and aged IN718 tested at a stress ratio $R=0.1$ which been extracted from the Aerospace Structural Metals Handbook, 1997. The "RO" data means "Run Out" when specimens did not fail at specific stress and testing cycle, the test was stopped and run at a higher load. 


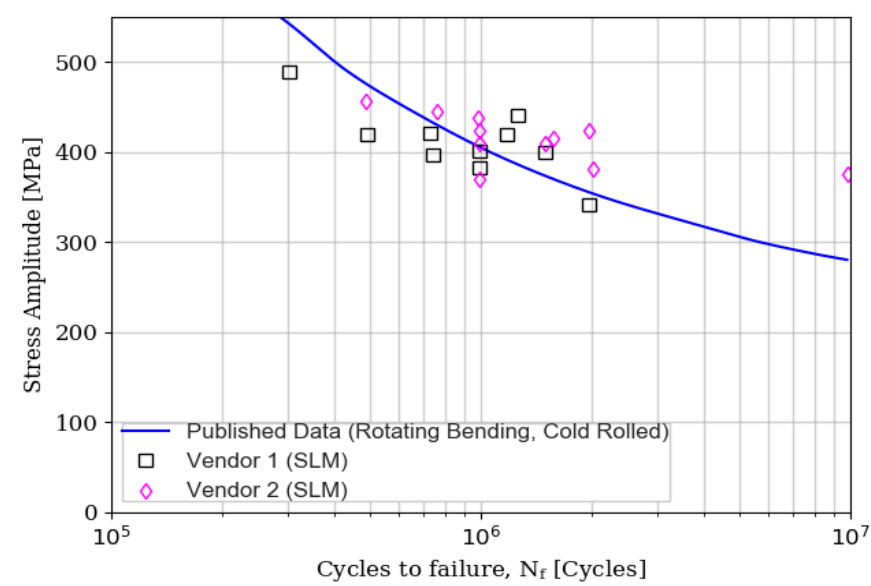

Figure 33: S-N curve showing the fatigue performance of SLM IN718 subjected to vibration bending loads and cold rolled IN718 subjected to rotating bending loads [77].

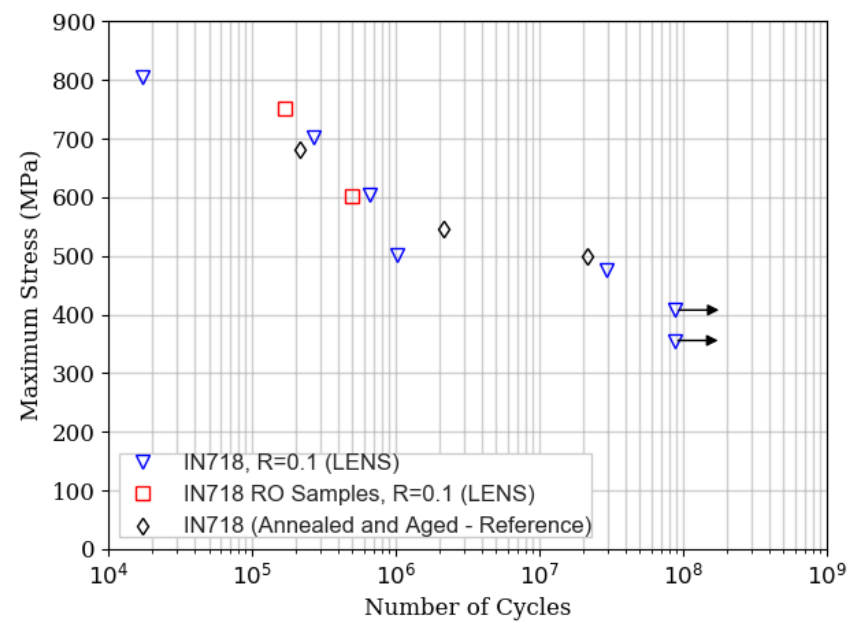

Figure 34: Fatigue data for IN718 fabricated by LENS process and tested by ultrasonic frequency fatigue testing. "RO" indicates run out [78].

\subsubsection{Factors Influencing Fatigue of SLM IN718}

Fatigue life of SLM IN718 is influenced by several factors including internal /external defects and post processing. - External Defects

Rough surface finish is the main external defects contributing to fatigue. The as-built SLM IN718 components have rough surface roughness due to the layer-by-layer manufacturing of the components which causes the 'stair case' effect. In addition, the balling effects from partially melted powder on the side walls lead to extremely poor surface finish in the order of $17-20 \mu \mathrm{m}$ Sa area surface finish [62]. The surface roughness is dependent on the AM techniques and the print parameters used to fabricate the component. Surface finish of samples fabricated by powder bed fusion (SLM, EBM...) and bidder jetting in general are smoother that those from DED or WAAM. Surface finish of SLM IN718 can be improved by optimizing the SLM parameters or applying post-printing processes.

Common methods for surface finish improvement are machining and polishing in both traditional and nontraditional methods. In process techniques such as laser re-melting can significantly decrease surface finish from 12 $\mu \mathrm{m}$ of the as- built condition to $1.5 \mu \mathrm{m}$ after re-melting the outer surface [79]. Machining SLM IN718 specimens at optimal conditions improves fatigue strength compared to the as-built specimen; however, improperly machining generates subsurface defects (e.g., fractured of brittle Laves particles, microcracks in strain hardened layer...) and deteriorates the fatigue performance. A study reported that machined specimens with fatigue strength closer to the average fatigue strength of as-built IN718, and concluded that the main problem was random distribution and excessive internal defects in SLM components [74].

Surface finish influences the fatigue properties of SLM components to a very high degree. A crack would start at the irregular spot on a surface of a sample due to high stress concentration factor. By reducing such irregular spots, we affectively lower the stress concentration factor and local stress, hence, improving the part fatigue life. A study 
reported that reducing the surface finish from $1000 \mu \mathrm{m}$ to $3 \mu \mathrm{m}$ then the fatigue life of respective samples increase from $10^{4}$ to $10^{5}$ cycles [28]; while a 50\% improvement in fatigue strength was achieved by reducing surface roughness from $14 \mu \mathrm{m}$ Ra to $0.11 \mu \mathrm{m}$ Ra through machining and polishing [80]. Figure 35 shows that low-stress grinding for smooth surface finish and negligible grinding-induced residual stress can extend the fatigue life of as-built samples at least one order of magnitude. When comparing the stress level, the low-stress ground samples can reach the same fatigue life as the as-built samples but at the $33 \%$ less stress [81].

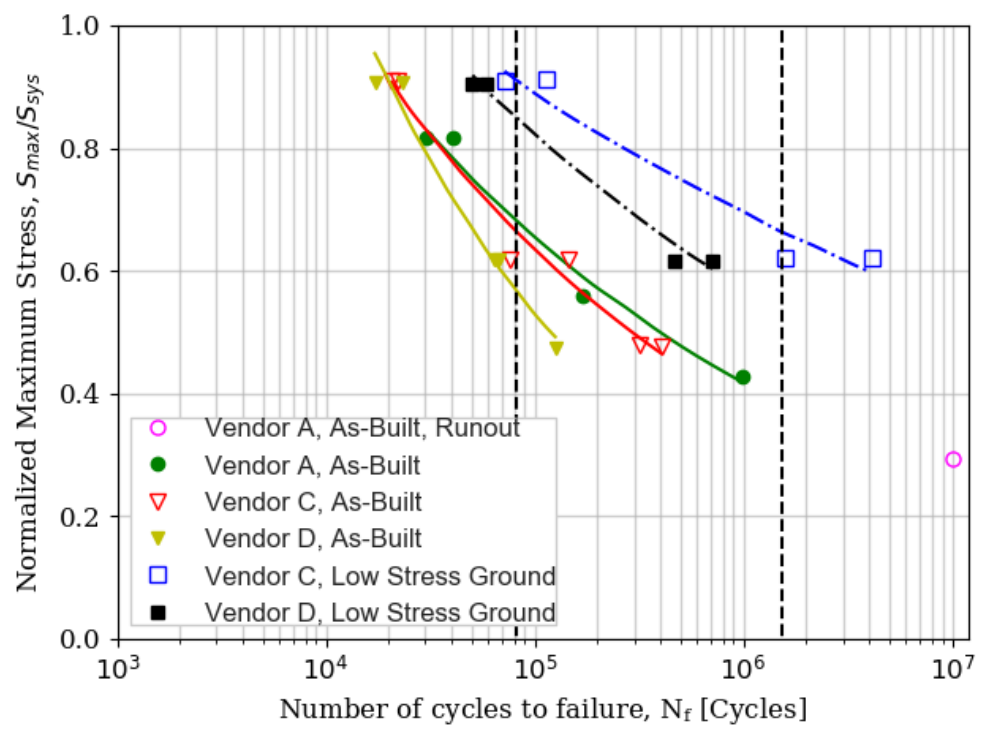

Figure 35: Fatigue results comparing low stress ground and as-built specimen of SLM IN718 [81].

\section{- Internal Defects}

Internal defects include unfavorable microstructure, crack, inclusion, and voids. The SLM IN718 has a very complex microstructure with directional columnar grains consisting of a matrix $\gamma$ phase and intermetallic precipitates $\left(\gamma^{\prime}, \gamma^{\text {" }}\right.$ and $\delta)$, Laves phase, and other intermetallic carbides as secondary phases. Such microstructural heterogeneity leads to variation in mechanical properties. The IN718 derives its high strength from $\gamma^{\prime}$ and $\gamma^{\prime \prime}$ precipitates, lattice mismatch between the interphases and high anti-phase boundary energy in the ordered $\gamma^{\prime}$ and $\gamma^{\prime \prime}$ phases. The amount and distribution of these phases can be tailored by varying both temperature and time in an aging process. The effect of microstructure and its influence on fatigue life of IN718 is significant but it has not been thoroughly investigated.

The metastable $\gamma$ " phase transforms to thermodynamically stable $\delta$ phase, large quantity of $\delta$ phase and distribution can significantly degrade fatigue and creep. Moderate amounts of $\delta$ phase at grain boundaries improves strength, but higher proportions of $\delta$ phase decrease strength and plasticity. The $\delta$ phase has no influence on high cycle fatigue because of the transgranular fatigue crack growth mode [82]. However, the $\delta$ phase improves resistance to fatigue crack growth along the grain boundary in low cycle fatigue because of the intergranular mode of fatigue crack growth [83-85]. The $\delta$ phase in IN718 causes accumulation of dislocations in its vicinity but leads to increasing fatigue crack growth rate as the volume fraction of $\delta$ phase increases in the microstructure [86].

Laves are formed at the end of solidification of melt pool in SLM process by microsegregation of high atomic number alloying elements such as niobium and molybdenum. Laves are undesirable brittle compounds that tie up strengthening elements in non-useful forms. Laves were found to impede fatigue crack growth in high cycle fatigue as the cracks had to pass around the Laves particles in the $\gamma$ phase. In low cycle fatigue usually subject to high stress amplitude, the Laves phase acts as the weakening component as they broke up and separated from the $\gamma$ phase forming microscopic holes and rupturing the interface. The fatigue cracks would propagate along the interface ruptures and accelerate the fatigue failure [73]. Figure 36a, below shows the image of a Laves particle in IN718. Chemical analysis of two points in the particle and a reference point outside of the particle reveal the significant difference in both $\mathrm{Ni}$ and $\mathrm{Nb}$ contents. Typical chemical composition of IN718 should have 50-55 wt\% Ni and 4.75-5.5 wt\% Nb, but the Laves particle in this case contains 25.3 and $72.1 \mathrm{wt} \%$ as shown in Figure 36b. The distribution of Laves phase was studied; Laves were precipitated in the sub-grain boundary region and its concentration decreased towards the top of SLM components due to decreasing cooling rates from bottom to top of a SLM part. The effect of Laves and its distribution on fatigue life o fIN718, however, is yet to be investigated [87].

Grain size also affects fatigue of SLM 718 [88]. Columnar dendritic microstructure, parallel to the building $\mathrm{z}$ axis, is caused by epitaxial grain growth due to the presence of a large temperature gradient. In the as-built SLM components columnar grains are formed in the building direction by epitaxial growth, while in the transverse section the equiaxed grains are dominant. The average width and length of grains in the transverse direction are $44 \mu \mathrm{m}$ and 
$255 \mu \mathrm{m}$, and the average size of the grains is $52 \mu \mathrm{m}$ when measured across the cross section. The rapid heating of SLM process also influences grain size significantly: coarse grained materials have higher resistance to fatigue crack growth, while fine and equiaxed grains offer higher resistance against fatigue crack initiation [89].

Common types of defects in SLM are cracks, lack of fusion (LoF) pores (Figures 17a and b). The spherical pores (Figures 17b, 21b, 25b, and 37) caused by sub optimal selection of process parameters or ineffective scanning strategies. Spherical pores are less than $100 \mu \mathrm{m}$ in size and distributed randomly throughout the part [90], caused by presence of dissolved gases in the melt pool and vaporization of low melting point constituents in the powder. In another study, the concentration of pores are found to be denser near the surface of the specimen (Figure 17b) [91]. The SLM IN718 specimen at different height sections and associated spherical porosity are shown in Figure 37, and the pore density in the outside region towards the boundary of the specimen is from 3 to 20 times greater than the interior regions. The LoF defects, also known as keyholes, are of usually varying sized caused by inadequate laser power supplied to the melt pool. Such LoF defects usually occur between scan tracks or between layers in SLM components [92], and the distance between the separating faces was less than $10 \mu \mathrm{m}$. The LoF defects in SLM IN718 can be classified as oxide filled or empty and these defects persist after HIP'ing or combination of HIP'ing and heat treating [74].The rapid heating and cooling of the melt pool by the laser introduces large temperature gradients of the order of $10^{8} \mathrm{~K} / \mathrm{s}[93]$, which gives rise to excessive residual stresses. The high thermal and residual stresses cause initiation and propagation of cracks in SLM components. Nickel based superalloys such as IN718 are more susceptible to cracking due to its low thermal conductivity and high thermal expansion coefficient; however, cracking can be mitigated by preheating the base plate and improving the ambient temperature [94,95].
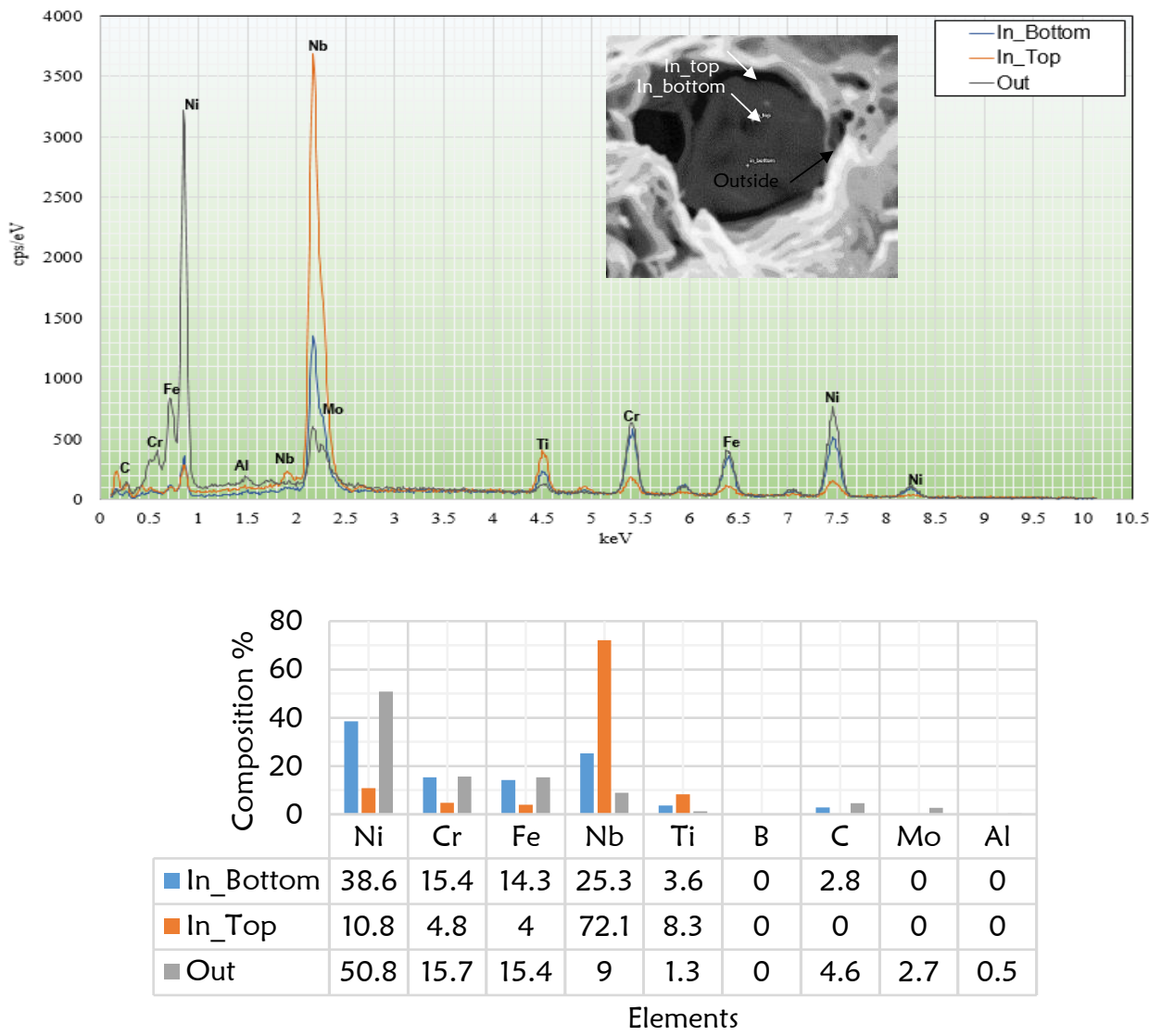

Figure 36: (a) Energy dispersive spectrums and chemical analysis of a Laves particle in SLM IN718. (b) The contrast in $\mathrm{Ni}$ and $\mathrm{Nb}$ contents of a Laves particles and its surrounded zone.

Both gas-filled and LoF pores are detrimental to the fatigue life of IN718 because they act stress risers in SLM components, and often are sites of crack initiation. The distribution of defects throughout the structure of SLM components increases the scatter of fatigue life (Figure 38), rendering predictions of fatigue life inaccurate. In Figure $38 \mathrm{a}$, the Coefficient of Variance (CoV, the ratio of standard deviation and mean) is used to compare variance of data collected at different scales. The presence of defects near the surface especially influence the scatter in fatigue life because of their random distribution; and when the loading on the outer surface is tensile in nature, defects act as crack initiation sites [74,96]. The shape, size, location and the number of defects strongly influence the fatigue life of IN718. As the number of defects increase and correspondingly the number of crack initiation sites increase, the fatigue 
life of components decrease [97]. Even though the fatigue life of machined IN718 (Figures 31a and b) is greater, there is greater scatter in the fatigue life of machined SLM IN718. As the number of defects contributing to crack initiation increases, the scatter in fatigue life increases for machined components [74], but the authors also attribute to some unknown batch wise variation affecting the scatter in fatigue life of machined SLM IN718. The effect of defect distribution is linked to fatigue life of the specimen (Figure 38b). The presence of pores and its high density near the surface decreased fatigue life. A removal of material from the surface of the SLM specimen, at least $200 \mu \mathrm{m}$ deep will eliminate the high pore density zone below the part surface [91].
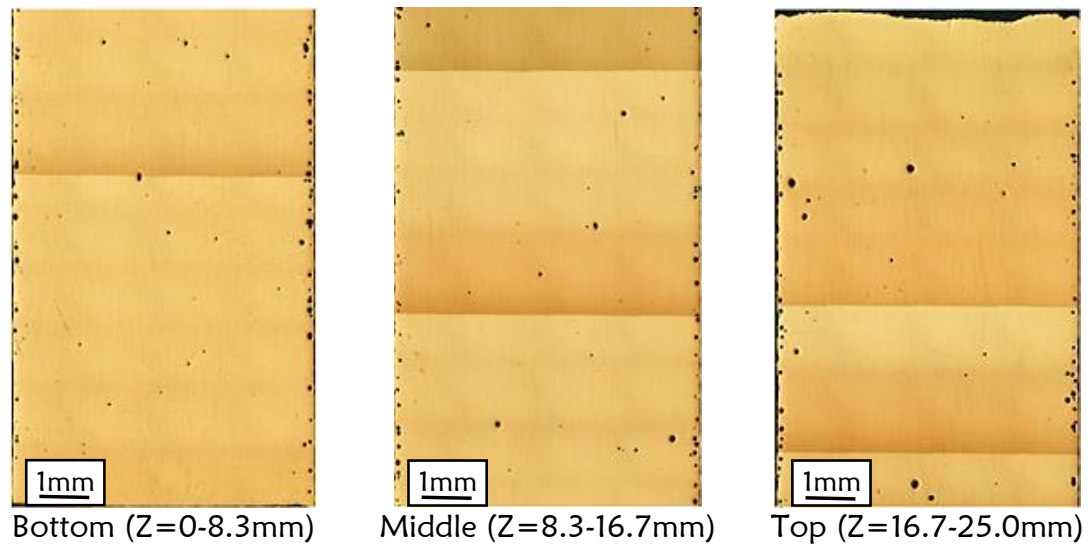

Figure 37: Composite image of SLM IN718 specimens sectioned at different heights. High pore density is seen at the part boundaries [84].
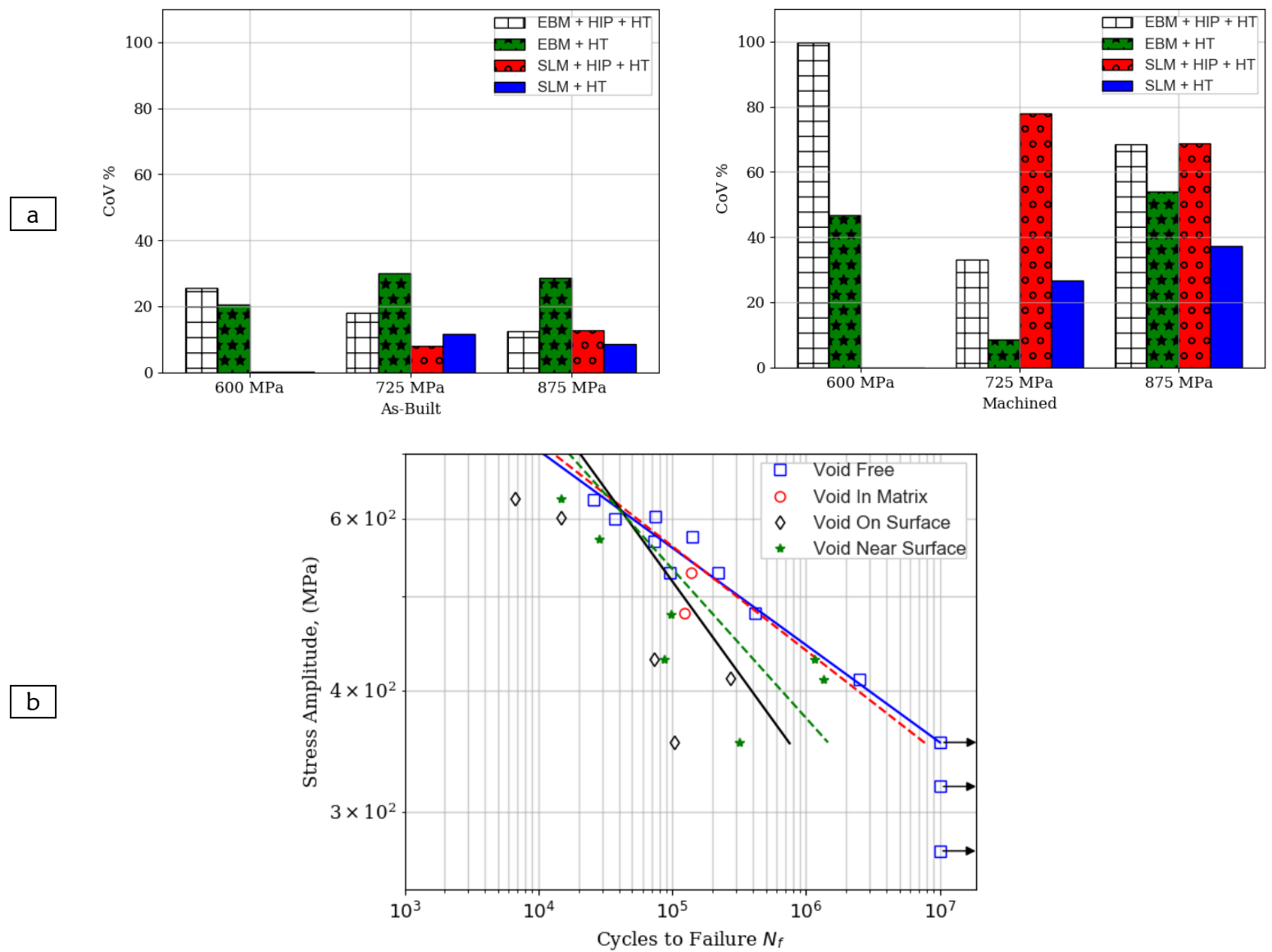

Figure 38: Scatter in fatigue life of SLM IN718 (a) Coefficient of Variance (CoV) of fatigue life for EBM and SLM IN718 at different load levels and post processing conditions [74]. (b) Effect of position of void on fatigue life of component [96]. 


\subsubsection{Effect of Process Parameters}

The internal/external defects are formed when using non-optimal AM process parameters; the issues are compounded furthermore when scanning strategies and building orientation are changed. There are several parameters in SLM process that influence the mechanical properties of components [29], however the effects of all process parameters and their effects on microstructure and properties of SLM components are not completely studied. The most commonly used scanning strategies in metal AM are stripes, island and the chessboard scanning strategies. Scanning strategies are used to control lack of fusion porosity in SLM and residual stresses; however, no direct correlations between scan strategy and the mechanical properties of SLM components were observed [98]. In addition to porosity in SLM components acting as locations of fatigue crack initiation; tensile residual stresses in the surface of SLM components create optimal conditions for initiation of cracks. Scanning strategies with shorter scan vector length has been found to reduce residual stresses in parts [99]. There appears to be some conflicting evidence on the effect of scan strategy imparting excessive residual stresses on SLM components: some authors found island scanning strategy to decrease residual stresses in components [99-101], while other authors found island scanning strategy to instill residual stresses in the part [102]. However, none of the studies reported a compressive residual stress being imparted on the component by SLM process; which can be beneficial to fatigue life of components.

A study concluded that building orientation and laser energy density affect fatigue life significantly [103]. The authors printed specimens in $0^{\circ}, 60^{\circ}$ and $90^{\circ}$ orientations. The $0^{\circ}$ orientation exhibited high surface roughness and lower fatigue life, whereas, $60^{\circ}$ orientation specimen had low surface roughness values and high fatigue life. The fracture surface from samples with high roughness displayed $60 \%$ more surface-crack initiation sites than those with low surface roughness values. In addition to part orientation and anisotropy in SLM process, energy density is observed to cause anisotropy in yield strength due to changes in microstructure texture that caused by heat flows [104].

Similar conclusions were reported by Radomila [105]. Three specimen sets were studied for the influence of microstructure and build orientation on fatigue life, The SLM specimens were printed using layer thickness of $30 \mu \mathrm{m}$ and laser power of $200 \mathrm{~W}$. The study was conducted on three sets of specimens denoted by A, B, C (Figure 39a) to study the influence of anisotropy in the lattice of specimen and their impact on fatigue properties of IN718. The fatigue tests were conducted on a miniature fatigue specimen for $\mathrm{R}=0$ at a loading frequency of $20 \mathrm{~Hz}$ at room temperature. The miniature specimen was designed to study effect of surface defects and mechanisms of crack initiation in cyclic plane bending, while inducing similar maximum stress on specimen as a traditional rotating bending beam specimen [106]. The fatigue results and effects of built orientation are shown in Figure 39b, in which the fatigue lives of specimens $A$ and $B$ are similar, while fatigue life of specimen $C$ is lower. This is due to anisotropic properties of SLM components where the building direction is the weaker direction since it is perpendicular to layer interfaces. Low scatter in fatigue data in the plot indicates uniform material microstructures; the difference in fatigue behavior between specimen group A, B and C can be attributed to anisotropy induced by differing build orientations. In specimen group $C$, applied bending stress is parallel to the build direction and perpendicular to the material deposition layers. The fracture surface indicated that specimen A with best fatigue properties had the best surface roughness in all directions (Figure 39b), whereas Specimen $C$ had the worst surface roughness and the worst fatigue performance. The study also found that cracks initiated at subsurface defects in SLM IN718 specimen.

For the best fatigue properties, the optimal energy density was found to be $60-70 \mathrm{~J} / \mathrm{mm}^{3}$ for a layer thickness of $30 \mu \mathrm{m}$, and $40-45 \mathrm{~J} / \mathrm{mm}^{3}$ for a layer thickness of $60 \mu \mathrm{m}$ [103]. Recall that energy density is defined as:

Where;

$$
E D\left(\frac{J}{m^{3}}\right)=\frac{P(W)}{H(m m) \times L(m m) \times S\left(\frac{m m}{s}\right)}
$$

$$
\begin{array}{ll}
\mathrm{ED} & \text { : Energy density } \\
\mathrm{P} & \text { : Laser power } \\
\mathrm{H} & \text { : Hatching distance } \\
\mathrm{L} & \text { : Layer thickness } \\
\mathrm{S} & \text { : Laser scanning speed }
\end{array}
$$

At extremely high and low values of laser energy density, the study showed an increase in subsurface porosity and defects that leads to a decrease in fatigue life:

- At high laser energy density, keyhole porosity was created and secondary cracking due to hot-tearing-like mechanisms.

- At low laser energy density, many LoF defects were found.

\subsubsection{Effect of Post Processing}

Hot isostatic pressing at high temperature reduces porosity defects in SLM components; therefore, increase fatigue life of components. At high temperature and pressure, HIP'ing causes plastic deformation in AM metals and closes most of the pores while changing microstructure of the material. Depending on the HIP'ing process parameters (Figure 40), a relative density of $99.985 \%$ to $99.989 \%$ can be achieved in SLM IN718 components [55]. By increasing the density of the component and closing the pores, HIP'ing process effectively reduces the number of crack initiation sites for 
fatigue fracture. Prolonging time at high temperature in HIP'ing process recrystallizes, grows the grains that consuming dendritic microstructure. Although HIP'ing can close most of the spherical gas-filled pores, it does not completely close all the voids and keyholes [55]. Fatigue studies for aluminum alloys and effects of HIP'ing are shown in Figure 41 since data for IN718 is yet to be found. Figure 41a confirms the fact that properly machining, and polishing eliminates surface defects and improves fatigue life. Stress relieving, however, may promote grain growth and reduce yield/tensile strength of the materials, therefore, lower the fatigue curve of AISi1OMg aluminum alloy. Two conclusions can be made from data in Figure 41b:

- Post processing with machining and polishing is the most effective method since it eliminates surface defects and improve fatigue life.

- Post processing with HIP'ing should be done at optimal (lower) temperature. A higher temperature promotes grain growth, lowers the material strength, and shortens fatigue life.
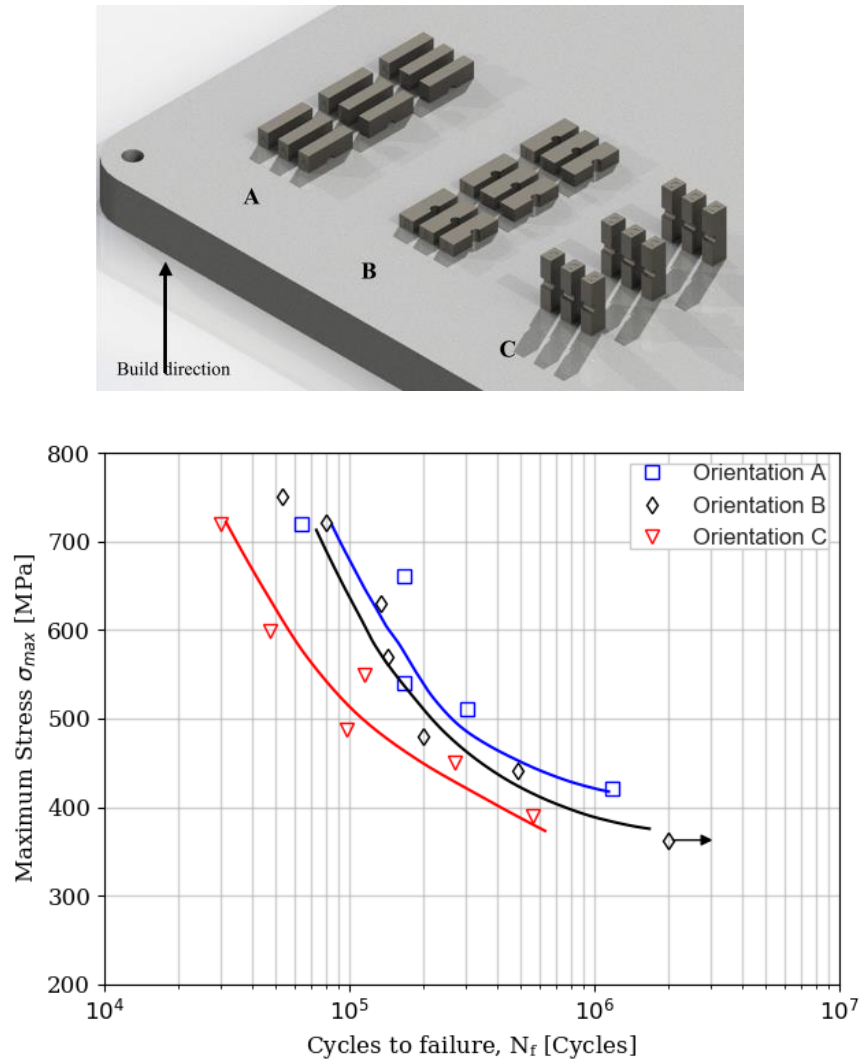

\begin{tabular}{cccc}
\hline Surface finish & Sample A & Sample B & Sample C \\
\hline $\mathrm{Ra}[\mu \mathrm{m}]$ & 6.49 & 10.67 & 15.56 \\
\hline $\mathrm{Rq}[\mu \mathrm{m}]$ & 7.58 & 12.97 & 19.63 \\
\hline $\mathrm{Rz}[\mu \mathrm{m}]$ & 29.67 & 56.96 & 84.43 \\
\hline
\end{tabular}

Figure 39: Effect of orientation on fatigue life of SLM IN718: (a) Orientation of specimen in SLM build chamber, (b) S-N curves of SLM IN718 specimens' A, B and C and the corresponding average surface roughness corresponding to specimen orientation [105]. 


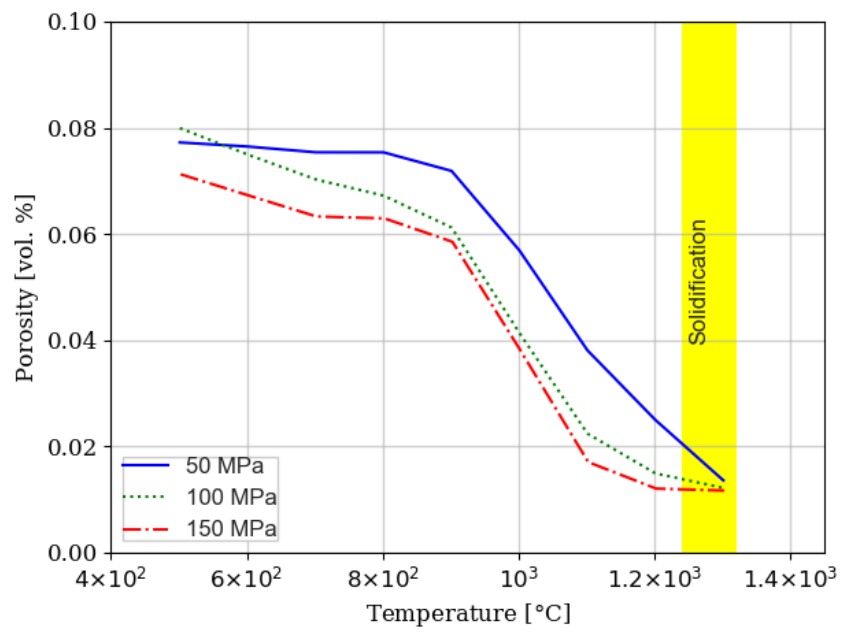

Figure 40: Porosity in SLM IN718 components after different HIP'ing pressures and temperatures [55].
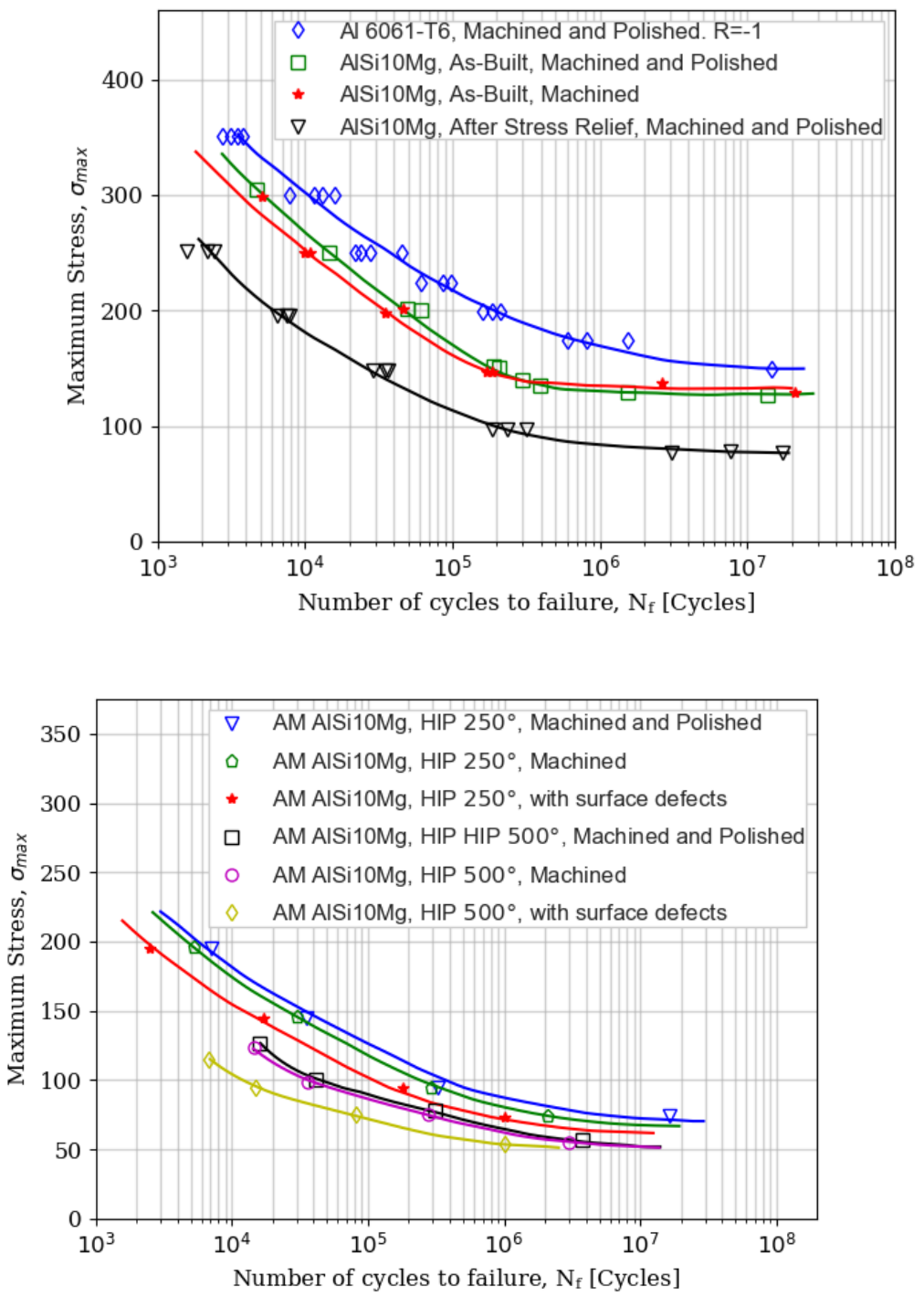

Figure 41: Fatigue of SLM AISi1OMg and 6061-T6 in (a) as built and machined condition, and (b) after stress relieving and HIP'ing [107]. 


\section{SUMMARY AND RECOMMENDATION}

The review of the common methods for fatigue testing was summarized and published data for fatigues of additively manufactured (AM) metals were presented. This paper showed:

1) The as-built AM metals exhibit few unfavourable properties compared to wrought materials: porosity, rough surface, residual stresses, brittleness, anisotropy, and inhomogeneous microstructure. Such surface and volume defects would negatively affect fatigue lives of AM components.

2) Various post processes -e.g., heat treating, machining, polishing, hot isostatic pressing...-can reduce defects, remove residual stresses, while promoting isotropy and homogeneity in AM metals. Published data showed that fatigue lives of AM metals after proper post processing could be comparable with those of wrought materials. By optimizing the AM process parameters -e.g., energy density, scanning strategy, powder quality... - then the surface and volume defects can be minimized, therefore, reducing the needs for post processing. Closed loop feedback for adaptive process parameters could be implemented to continuously adjust the process parameters for defect reduction while a part is being built.

3) An AM process and post processing could ideally be combined into a single platform. Some commercially available hybrid systems, that integrate additive and subtractive processes, can provide AM components with precise dimensions and smooth surfaces while reducing cycle time for parts with simple geometry.

4) Few fatigue research activities have emerged recently due to migrating of the superalloy Inconel 718 into additive manufacturing. Collecting high-cycle fatigue data is very time consuming when low frequency pushpull tests are used, the traditional rotate bending tests might shorten the testing time but with large scattering of data since the stressed volume on a specimen is small and non-uniform. Ultrasonic frequency fatigue tests can significantly reduce the testing time, but it is not clear how to use the resulted data from such test to predict fatigue life of actual parts in normal operating conditions. Reliability of a superalloy engineering component is also affected by combinations of creep, corrosion, and fatigue. Researchers are challenged to come up with reliable accelerating tests and collect data while mimicking actual operating conditions in a simulated environmental chamber.

5) Models are ultimately desired to convert fatigue data resulted from different testing techniques. An ideal model not only can validate a set of test data, but also can save significant testing time and cost if accelerated test data are sufficient to predict the fatigue data of engineering components in normal operating conditions.

\section{REFERENCES}

[1] Hassan, T., and Liu, Z., 2001, "On the Difference of Fatigue Strengths from Rotating Bending, Four-Point Bending, and Cantilever Bending Tests,” Int. J. Press. Vessel. Pip., 78(1), pp. 19-30.

[2] "EFatigue - Constant Amplitude Stress-Life Technical Background" [Online]. Available: https://www.efatigue.com/constantamplitude/background/stresslife.html. [Accessed: 15-Mar-2020].

[3] Budynas, R., Budynas, R. G., and Nisbett, K., 2012, Shigley's Mechanical Engineering Design, McGraw-Hill.

[4] 2015, E466-15 Standard Practice for Conducting Force Controlled Constant Amplitude Axial Fatigue Tests of Metallic Materials., ASTM International, West Conshohocken, PA.

[5] 2014, E467-08(2014) Standard Practice for Verification of Constant Amplitude Dynamic Forces in an Axial Fatigue Testing System., ASTM International, West Conshohocken, PA.

[6] 2019, E606/E606M-19e1 Standard Test Method for Strain-Controlled Fatigue Testing., ASTM International, West Conshohocken, PA.

[7] 2015, E647-15el Standard Test Method for Measurement of Fatigue Crack Growth Rates., ASTM International, West Conshohocken, PA.

[8] 2015, E739-10(2015) Standard Practice for Statistical Analysis of Linear or Linearized Stress-Life (S-N) and Strain-Life $(\varepsilon-N)$ Fatigue Data., ASTM International, West Conshohocken, PA.

[9] 2019, E1012-19 Standard Practice for Verification of Testing Frame and Specimen Alignment Under Tensile and Compressive Axial Force Application., ASTM International, West Conshohocken, PA.

[10] 2017, E1049-85(2017) Standard Practices for Cycle Counting in Fatigue Analysis., ASTM International, West Conshohocken, PA.

[11] 2020, E1823-20a Standard Terminology Relating to Fatigue and Fracture Testing., ASTM International, West Conshohocken, PA.

[12] 2015, E2207-15 Standard Practice for Strain-Controlled Axial-Torsional Fatigue Testing with Thin-Walled Tubular Specimens., ASTM International, West Conshohocken, PA.

[13] Fatemi, A., and Molaei, R., 2020, “Novel Specimen Geometries for Fatigue Testing of Additive Manufactured Metals under Axial, Torsion, and Combined Axial-Torsion Loadings," Int. J. Fatigue, 130.

[14] Cain, V., Thijs, L., Van Humbeeck, J., Van Hooreweder, B., and Knutsen, R., 2015, "Crack Propagation and Fracture Toughness of Ti6Al4V Alloy Produced by Selective Laser Melting," Addit. Manuf., 5, pp. 68-76.

[15] ASTM E647-15: Standard Test Method for Measurement of Fatigue Crack Growth Rates 1.

[16] "USF-2000A: SHIMADZU (Shimadzu Corporation)" [Online]. Available: https://www.shimadzu.com/an/test/fatigue/usf2000.html. [Accessed: 10-Mar-2020].

[17] 2018, “Ultrasonic Fatigue Testing," Mechanical Testing and Evaluation, ASM International, pp. 717-729.

[18] Peng, W., Zhang, Y., Qiu, B., and Xue, H., 2012, “A Brief Review of the Application and Problems in 
Ultrasonic Fatigue Testing," AASRI Procedia, 2, pp. 127-133.

[19] George, T. J., Seidt, J., Herman Shen, M. H., Nicholas, T., and Cross, C. J., 2004, "Development of a Novel Vibration-Based Fatigue Testing Methodology," Int. J. Fatigue, 26(5), pp. 477-486.

[20] Ishihara, S., McEvily, A. J., Sato, M., Taniguchi, K., and Goshima, T., 2009, "The Effect of Load Ratio on Fatigue Life and Crack Propagation Behavior of an Extruded Magnesium Alloy," Int. J. Fatigue, 31(11-12), pp. 1788-1794.

[21] Dowling, N. E., 2004, Mean Stress Effects in Stress-Life and Strain-Life Fatigue.

[22] Morrissey, R. J., McDowell, D. L., and Nicholas, T., 1999, "Frequency and Stress Ratio Effects in High Cycle Fatigue of Ti-6Al-4V," Int. J. Fatigue, 21(7), pp. 679-685.

[23] Esin, A., 1980, A Method for Correlating Different Types of Fatigue Curve.

[24] Strzelecki, P., and Tomaszewski, T., 2018, "Analysis of Axial Load and Bending Load Effects on the Fatigue Life,” AIP Conference Proceedings, American Institute of Physics Inc.

[25] Manson, S. S., and Muralidharan, U., 1987, "Fatigue Life Prediction in Bending From Axial Fatigue Information,” Fatigue Fract. Eng. Mater. Struct., 9(5), pp. 357-372.

[26] Zhang, Y., Duan, Z., and Shi, H., 2013, "Comparison of the Very High Cycle Fatigue Behaviors of INCONEL 718 with Different Loading Frequencies," Sci. China Physics, Mech. Astron., 56(3), pp. 617-623.

[27] Mayer, H., Papakyriacou, M., Pippan, R., and Stanzl-Tschegg, S., 2001, "Influence of Loading Frequency on the High Cycle Fatigue Properties of AlZnMgCu1.5 Aluminium Alloy," Mater. Sci. Eng. A, 314(1-2), pp. 4854.

[28] Frazier, W. E., "Metal Additive Manufacturing: A Review."

[29] DebRoy, T., Wei, H. L., Zuback, J. S., Mukherjee, T., Elmer, J. W., Milewski, J. O., Beese, A. M., WilsonHeid, A., De, A., and Zhang, W., 2018, "Additive Manufacturing of Metallic Components - Process, Structure and Properties," Prog. Mater. Sci., 92, pp. 112-224.

[30] Olakanmi, E. O., Cochrane, R. F., and Dalgarno, K. W., 2015, “A Review on Selective Laser Sintering/Melting (SLS/SLM) of Aluminium Alloy Powders: Processing, Microstructure, and Properties,” Prog. Mater. Sci., 74, pp. 401-477.

[31] Körner, C., Helmer, H., Bauereiß, A., and Singer, R. F., 2014, “Tailoring the Grain Structure of IN718 during Selective Electron Beam Melting," MATEC Web Conf., 14, p. 8001.

[32] Ziaee, M., and Crane, N. B., 2019, "Binder Jetting: A Review of Process, Materials, and Methods," Addit. Manuf., 28, pp. 781-801.

[33] Herzog, D., Seyda, V., Wycisk, E., and Emmelmann, C., 2016, “Additive Manufacturing of Metals," Acta Mater., 117, pp. 371-392.

[34] Wu, B., Pan, Z., Ding, D., Cuiuri, D., Li, H., Xu, J., and Norrish, J., 2018, “A Review of the Wire Arc Additive Manufacturing of Metals: Properties, Defects and Quality Improvement,” J. Manuf. Process., 35, pp. 127139.

[35] Gong, X., Anderson, T., and Chou, K., 2012, REVIEW ON POWDER-BASED ELECTRON BEAM ADDITIVE MANUFACTURING TECHNOLOGY.

[36] Thijs, L., Verhaeghe, F., Craeghs, T., Humbeeck, J. Van, and Kruth, J. P., 2010, “A Study of the Microstructural Evolution during Selective Laser Melting of Ti-6Al-4V,” Acta Mater., 58(9), pp. 3303-3312.

[37] Maskery, I., Aboulkhair, N. T., Corfield, M. R., Tuck, C., Clare, A. T., Leach, R. K., Wildman, R. D., Ashcroft, I. A., and Hague, R. J. M., 2016, "Quantification and Characterisation of Porosity in Selectively Laser Melted Al-Si10-Mg Using X-Ray Computed Tomography,” Mater. Charact., 111, pp. 193-204.

[38] Amato, K. N., Gaytan, S. M., Murr, L. E., Martinez, E., Shindo, P. W., Hernandez, J., Collins, S., and Medina, F., 2012, "Microstructures and Mechanical Behavior of Inconel 718 Fabricated by Selective Laser Melting," Acta Mater., 60(5), pp. 2229-2239.

[39] Sadiq, M. A., Hoang, N. M., Valencia, N., Obeidat, S., and Hung, W. N. P., 2018, "Experimental Study of Micromilling Selective Laser Melted Inconel 718 Superalloy,” Procedia Manufacturing, Elsevier B.V., pp. 983992.

[40] Hung, W., 2020, "Post-Processing of Additively Manufactured Metal Parts," Additive Manufacturing Processes, ASM International, pp. 298-315.

[41] Committee, A. M. S. F. C. H. R. A., and others, 2016, “AMS 5662,” SAE Int. SAE Int. Warrendale, PA, USA.

[42] Aerospace, S. A. E., 2012, “Aerospace Material Specification: AMS 5383," SAE Int. Warrendale, PA, USA.

[43] Wang, X., Gong, X., and Chou, K., 2017, Review on Powder-Bed Laser Additive Manufacturing of Inconel 718 Parts, SAGE Publications Ltd.

[44] "SpaceX Launches 3D-Printed Part to Space, Creates Printed Engine Chamber | SpaceX” [Online]. Available: https://www.spacex.com/news/2014/07/31/spacex-launches-3d-printed-part-space-creates-printed-enginechamber-crewed. [Accessed: 18-Mar-2020].

[45] INCONEL \& Alloy 718.

[46] Aghajani, A., Tewes, J., Parsa, A. B., Hoffmann, T., Kostka, A., and Kloewer, J., 2016, "Identification of MoRich M23C6 Carbides in Alloy 718,” Metall. Mater. Trans. A Phys. Metall. Mater. Sci., 47(9), pp. 4382-4392.

[47] Trosch, T., Strößner, J., Völkl, R., and Glatzel, U., 2016, "Microstructure and Mechanical Properties of Selective Laser Melted Inconel 718 Compared to Forging and Casting," Mater. Lett., 164, pp. 428-431. 
[48] Huang, W., Yang, J., Yang, H., Jing, G., Wang, Z., and Zeng, X., 2019, "Heat Treatment of Inconel 718 Produced by Selective Laser Melting: Microstructure and Mechanical Properties," Mater. Sci. Eng. A, 750, pp. 98-107.

[49] Tucho, W. M., Cuvillier, P., Sjolyst-Kverneland, A., and Hansen, V., 2017, "Microstructure and Hardness Studies of Inconel 718 Manufactured by Selective Laser Melting before and after Solution Heat Treatment," Mater. Sci. Eng. A, 689, pp. 220-232.

[50] Kirka, M. M., Medina, F., Dehoff, R., and Okello, A., 2017, "Mechanical Behavior of Post-Processed Inconel 718 Manufactured through the Electron Beam Melting Process,” Mater. Sci. Eng. A, 680, pp. 338-346.

[51] Li, C., Liu, Z. Y., Fang, X. Y., and Guo, Y. B., 2018, "Residual Stress in Metal Additive Manufacturing," Procedia CIRP, Elsevier B.V., pp. 348-353.

[52] "ASTM F3055 - 14a, 'Standard Specification for Additive Manufacturing Nickel Alloy ( UNS N07718) with Powder Bed Fusion,' F3055 - 14a, Pp. 1-8, 2014.”

[53] Tien, J. K., 2012, Superalloys, Supercomposites and Superceramics (Google EBook), San Diego, CA (US); Academic Press, Inc., United States.

[54] Barros, R., Silva, F. J. G., Gouveia, R. M., Saboori, A., Marchese, G., Biamino, S., Salmi, A., and Atzeni, E., 2019, "Laser Powder Bed Fusion of Inconel 718: Residual Stress Analysis before and after Heat Treatment," Metals (Basel)., 9(12).

[55] Tillmann, W., Schaak, C., Nellesen, J., Schaper, M., Aydinöz, M. E., and Hoyer, K. P., 2017, "Hot Isostatic Pressing of IN718 Components Manufactured by Selective Laser Melting," Addit. Manuf., 13, pp. 93-102.

[56] Blackwell, P. L., 2005, "The Mechanical and Microstructural Characteristics of Laser-Deposited IN718," J. Mater. Process. Technol., 170(1-2), pp. 240-246.

[57] Jia, Q., and Gu, D., 2014, "Selective Laser Melting Additive Manufacturing of Inconel 718 Superalloy Parts: Densification, Microstructure and Properties," J. Alloys Compd., 585, pp. 713-721.

[58] ZHANG, H., DONG, D., SU, S., and CHEN, A., 2019, "Experimental Study of Effect of Post Processing on Fracture Toughness and Fatigue Crack Growth Performance of Selective Laser Melting Ti-6Al-4V," Chinese J. Aeronaut., 32(10), pp. 2383-2393.

[59] Popovich, V. A., Borisov, E. V., Popovich, A. A., Sufiiarov, V. S., Masaylo, D. V., and Alzina, L., 2017, “Impact of Heat Treatment on Mechanical Behaviour of Inconel 718 Processed with Tailored Microstructure by Selective Laser Melting," Mater. Des., 131, pp. 12-22.

[60] Kaynak, Y., and Tascioglu, E., 2018, "Finish Machining-Induced Surface Roughness, Microhardness and XRD Analysis of Selective Laser Melted Inconel 718 Alloy," Procedia CIRP, Elsevier B.V., pp. 500-504.

[61] Han, J., Wu, M., and Ge, Y., 2019, "A Study on the Dimension Accuracy on the Inner Structure of the 3D Printed Parts Caused by the Scanning Strategy," Materials (Basel)., 12(8).

[62] Jain, S., Corliss, M., Tai, B., and Hung, W. N., 2019, "Electrochemical Polishing of Selective Laser Melted Inconel 718," Procedia Manufacturing, Elsevier B.V., pp. 239-246.

[63] INCONEL \& Alloy 718.

[64] Ma, X.-F., Duan, Z., Shi, H.-J., Murai, R., and Yanagisawa, E., 2010, "Fatigue and Fracture Behavior of NickelBased Superalloy Inconel 718 up to the Very High Cycle Regime *," J Zhejiang Univ-Sci A (Appl Phys Eng), 11(10), pp. 727-737.

[65] Yadollahi, A., and Shamsaei, N., 2017, “Additive Manufacturing of Fatigue Resistant Materials: Challenges and Opportunities," Int. J. Fatigue, 98, pp. 14-31.

[66] Li, P., Warner, D. H. H., Fatemi, A., and Phan, N., 2016, "Critical Assessment of the Fatigue Performance of Additively Manufactured Ti-6Al-4V and Perspective for Future Research,” Int. J. Fatigue, 85, pp. 130-143.

[67] Ono, Y., Yuri, T., Sumiyoshi, H., Takeuchi, E., Matsuoka, S., and Ogata, T., 2004, "High-Cycle Fatigue Properties at Cryogenic Temperatures in Inconel 718 Nickel-Based Superalloy,” Mater. Trans., 45(2), pp. 342345.

[68] Chen, Q., Kawagoishi, N., and Nisitani, H., 1999, Evaluation of Notched Fatigue Strength at Elevated Temperature by Linear Notch Mechanics.

[69] Kawagoishi, Chen, and Nisitani, 2000, "Fatigue Strength of Inconel 718 at Elevated Temperatures," Fatigue Fract. Eng. Mater. Struct., 23(3), pp. 209-216.

[70] Solberg, K., and Berto, F., 2019, “Notch-Defect Interaction in Additively Manufactured Inconel 718," Int. J. Fatigue, 122, pp. 35-45.

[71] Morgan, K., and Wells, D., 2016, Overview of Fatigue and Damage Tolerance Performance of SLM Alloy 718.

[72] Belan, J., Kuchariková, L., Tillová, E., Závodská, D., and Chalupová, M., 2019, “Effect of Fatigue Loading Mode on 718 Alloy Fatigue Properties,” Period. Polytech. Transp. Eng., 47(4), pp. 335-341.

[73] Sui, S., Chen, J., Fan, E., Yang, H., Lin, X., and Huang, W., 2017, "The Influence of Laves Phases on the HighCycle Fatigue Behavior of Laser Additive Manufactured Inconel 718," Mater. Sci. Eng. A, 695, pp. 6-13.

[74] Balachandramurthi, A. R., Moverare, J., Dixit, N., and Pederson, R., 2018, "Influence of Defects and As-Built Surface Roughness on Fatigue Properties of Additively Manufactured Alloy 718,” Mater. Sci. Eng. A, 735, pp. 463-474.

[75] Periane, S., Duchosal, A., Vaudreuil, S., Chibane, H., Morandeau, A., Cormier, J., and Leroy, R., 2019, 
"Machining Influence on the Fatigue Resistance of Inconel 718 Fabricated by Selective Laser Melting (SLM)," Procedia Struct. Integr., 19, pp. 415-422.

[76] Lin, S.-K., Lee, Y.-L., and Lu, M.-W., 2001, "Evaluation of the Staircase and the Accelerated Test Methods for Fatigue Limit Distributions," Int. J. Fatigue, 23(1), pp. 75-83.

[77] Scott-Emuakpor, O., Schwartz, J., George, T., Holycross, C., Cross, C., and Slater, J., 2015, "Bending Fatigue Life Characterisation of Direct Metal Laser Sintering Nickel Alloy 718," Fatigue Fract. Eng. Mater. Struct., 38(9), pp. 1105-1117.

[78] Amsterdam, E., and Kool, G. A., 2009, "High Cycle Fatigue of Laser Beam Deposited Ti-6Al-4V and Inconel 718," ICAF 2009, Bridging the Gap Between Theory and Operational Practice - Proceedings of the 25th Symposium of the International Committee on Aeronautical Fatigue, Springer, Dordrecht, pp. 1261-1274.

[79] Kruth, J.-P., Badrossamay, M., Yasa, E., Deckers, J., Thijs, L., and Humbeeck, J., 2010, "Part and Material Properties in Selective Laser Melting of Metals," 16th Int. Symp. Electromachining, ISEM 2010.

[80] Wan, H. Y., Luo, Y. W., Zhang, B., Song, Z. M., Wang, L. Y., Zhou, Z. J., Li, C. P., Chen, G. F., and Zhang, G. P., 2020, "Effects of Surface Roughness and Build Thickness on Fatigue Properties of Selective Laser Melted Inconel 718 at $650{ }^{\circ} \mathrm{C}$," Int. J. Fatigue, 137, p. 105654.

[81] Lambert, D., and Raytheon, P., EVALUATION OF THE EFFECT OF SURFACE FINISH ON HIGH-CYCLE FATIGUE OF SLM-IN718.

[82] Gopikrishna, D., Jha, S. N., and Dash, L. N., 1997, Influence of Microstructure on Fatigue Properties of Alloy 718.

[83] Deng, D., 2018, Additively Manufactured Inconel 718 : Microstructures and Mechanical Properties.

[84] Deng, G. J., Tu, S. T., Zhang, X. C., Wang, J., Zhang, C. C., Qian, X. Y., and Wang, Y. N., 2016, "Small Fatigue Crack Initiation and Growth Mechanisms of Nickel-Based Superalloy GH4169 at $650{ }^{\circ} \mathrm{C}$ in Air," Eng. Fract. Mech., 153, pp. 35-49.

[85] Wan, H. Y., Zhou, Z. J., Li, C. P., Chen, G. F., and Zhang, G. P., 2018, "Enhancing Fatigue Strength of Selective Laser Melting-Fabricated Inconel 718 by Tailoring Heat Treatment Route,” Adv. Eng. Mater., 20(10).

[86] An, J., Wang, L., Liu, Y., Cai, W., and Song, X., 2017, "The Role of $\delta$ Phase for Fatigue Crack Propagation Behavior in a Ni Base Superalloy at Room Temperature," Mater. Sci. Eng. A, 684, pp. 312-317.

[87] Zhang, B., Wang, P., Chew, Y., Wen, Y., Zhang, M., Wang, P., Bi, G., and Wei, J., 2020, "Mechanical Properties and Microstructure Evolution of Selective Laser Melting Inconel 718 along Building Direction and Sectional Dimension," Mater. Sci. Eng. A, 794, p. 139941.

[88] Zhang, D., Niu, W., Cao, X., and Liu, Z., 2015, "Effect of Standard Heat Treatment on the Microstructure and Mechanical Properties of Selective Laser Melting Manufactured Inconel 718 Superalloy," Mater. Sci. Eng. A, 644, pp. 32-40.

[89] Korth, G. E., Effects of Various Parameters on the Fatigue Life of Alloy 718.

[90] Zhang, B., Li, Y., and Bai, Q., "Defect Formation Mechanisms in Selective Laser Melting: A Review."

[91] Wang, F., Bosque, H. Del, Hyder, J., Corliss, M., and Hung, W. N., 2020, "Experimental Investigation of Porosity Distribution in Selective Laser Melted Inconel 718,” Procedia Manuf., 48, pp. 807-813.

[92] Gong, H., Rafi, K., Gu, H., Starr, T., and Stucker, B., 2014, "Analysis of Defect Generation in Ti-6Al-4V Parts Made Using Powder Bed Fusion Additive Manufacturing Processes,” Addit. Manuf., 1, pp. 87-98.

[93] Gu, D., Hagedorn, Y.-C., Meiners, W., Meng, G., Rui, , Santos Batista, J., Wissenbach, K., and Poprawe, R., 2012, "Densification Behavior, Microstructure Evolution, and Wear Performance of Selective Laser Melting Processed Commercially Pure Titanium,” Acta Mater., 60, pp. 3849-3860.

[94] Kempen, K., Vrancken, B., Buls, S., Thijs, L., Humbeeck, J. Van, and Kruth, J.-P., 2014, "Selective Laser Melting of Crack-Free High Density M2 High Speed Steel Parts by Baseplate Preheating."

[95] Carter, L. N., Essa, K., and Attallah, M. M., "Optimisation of Selective Laser Melting for a High Temperature Ni-Superalloy."

[96] Luo, Y. W., Zhang, B., Li, C. P., Chen, G. F., and Zhang, G. P., 2019, "Detecting Void-Induced Scatter of Fatigue Life of Selective Laser Melting-Fabricated Inconel 718 Using Miniature Specimens."

[97] Belan, J., Hurtalová, L., Vaško, A., Tillová, E., and Chalupová, M., 2017, "Fatigue Test of the Inconel Alloy 718 under Three Point Bending Load at Low Frequency," Advanced Structured Materials, Springer Verlag, pp. 75-84.

[98] Ali, H., Ghadbeigi, H., and Mumtaz, K., "Effect of Scanning Strategies on Residual Stress and Mechanical Properties of Selective Laser Melted Ti6Al4V," Mater. Sci. Eng. A, 712, pp. 175-187.

[99] Zaeh, M. F., and Branner, G., 2010, "Investigations on Residual Stresses and Deformations in Selective Laser Melting," Prod. Eng., 4(1), pp. 35-45.

[100] Kruth, J.-P., Deckers, J., Yasa, E., and Wauthlé, R., 2012, "Assessing and Comparing Influencing Factors of Residual Stresses in Selective Laser Melting Using a Novel Analysis Method,” Proc. Inst. Mech. Eng. Part B J. Eng. Manuf., 226(6), pp. 980-991.

[101] Mercelis, P., and Kruth, J. P., 2006, "Residual Stresses in Selective Laser Sintering and Selective Laser Melting," Rapid Prototyp. J., 12(5), pp. 254-265.

[102] Lu, Y., Wu, S., Gan, Y., Huang, T., Yang, C., Junjie, L., and Lin, J., 2015, "Study on the Microstructure, Mechanical Property and Residual Stress of SLM Inconel-718 Alloy Manufactured by Differing Island Scanning 
Strategy," Opt. Laser Technol., 75, pp. 197-206.

[103] Watring, D. S., Carter, K. C., Crouse, D., Raeymaekers, B., and Spear, A. D., 2019, “Mechanisms Driving HighCycle Fatigue Life of as-Built Inconel 718 Processed by Laser Powder Bed Fusion," Mater. Sci. Eng. A, 761.

[104] Liu, S. Y., Li, H. Q., Qin, C. X., Zong, R., and Fang, X. Y., 2020, “The Effect of Energy Density on Texture and Mechanical Anisotropy in Selective Laser Melted Inconel 718," Mater. Des., 191, p. 108642.

[105] Konečná, R., Nicoletto, G., Kunz, L., and Bača, A., 2016, "Microstructure and Directional Fatigue Behavior of Inconel 718 Produced by Selective Laser Melting," Procedia Structural Integrity, Elsevier B.V., pp. 23812388.

[106] Nicoletto, G., 2017, “Anisotropic High Cycle Fatigue Behavior of Ti-6Al-4V Obtained by Powder Bed Laser Fusion,” Int. J. Fatigue, 94, pp. 255-262.

[107] Uzan, N. E., Shneck, R., Yeheskel, O., and Frage, N., 2017, "Fatigue of AlSi10Mg Specimens Fabricated by Additive Manufacturing Selective Laser Melting (AM-SLM)," Mater. Sci. Eng. A, 704, pp. 229-237. 